\title{
APPLICATION OF A HEURISTIC METHOD TO A WATER DISTRIBUTION SYSTEM FOR DETERMINING OPTMIMAL WATER QUALITY MONITORING LOCATIONS
}

\author{
A Thesis \\ presented to \\ the Faculty of California Polytechnic State University, \\ San Luis Obispo
}

In Partial Fulfillment
of the Requirements for the Degree
Master of Science in Civil and Environmental Engineering

by

Lawrence David Johnson

June 2012 
(C) 2012

Lawrence David Johnson

ALL RIGHTS RESERVED 


\section{COMMITTEE MEMBERSHIP}

TITLE:

AUTHOR:

DATE SUBMITTED:

COMMITTEE CHAIR:

COMMITTEE MEMBER:

COMMITTEE MEMBER:
Application of a Heuristic Method to a Water Distribution System for Determining Optimal Water Quality Monitoring Locations

Lawrence David Johnson

June, 2012
Shikha Rahman, PhD., Associate Professor

Misgana Muleta, PhD., Assistant Professor

Tryg Lundquist PhD., P.E. Associate Professor 


\begin{abstract}
Application of a Heuristic Method to a Water Distribution System for Determining Optimal Water Quality Monitoring Locations
\end{abstract}

\title{
Lawrence David Johnson
}

Although regulations and requirements for water quality source monitoring have increased, drinking water distribution systems can still be considered vulnerable to purposeful or accidental contamination.

This study analyzes the transport of the hypothetical contaminant Cryptosporidium through the distribution system of a city with a population of 30,000 to 50,000 in an attempt to locate the optimal monitoring locations in the distribution system. Cryptosporidium was selected due to its resistance to chlorine and it's conservative properties for vulnerability assessments. The method for selecting the optimal monitoring locations was taken from Chastain (2004) which developed and examined the method for a virtual city. However, Chastain did not apply the method to an actual city. This study looks to use Chastain's method conjunctively with WaterCAD ${ }^{\circledR}$ and Excel in an attempt to accommodate to the small scale systems which are more vulnerable relatively speaking.

The results of the analysis, shown in Appendices A and B, are grouped into zones of significance which contain a cluster of optimal points for placing water quality sensors. These zones of significance are to be taken as a guide for mitigating potential terrorist initiated events on the water distribution system. 


\section{ACKNOWLEDGEMENTS}

I would first like to thank all of my committee members for their time and dedication, each of whom were always available to speak with me, even during the trying times of the end of a school year. I would especially like to thank my thesis advisor Dr. Shikha Rahman who fundamentally guided me through the project process. Dr. Rahman always made time to see me for encouragement and for the discussion of any questions and concerns. I would also like to thank Dr. Tryg Lundquist, who broadened my view of hydraulic models and was always available to talk through my project concerns. I would also like thank Dr. Misgana Muleta who always greeted me with a smile and was eager to guide me to the right solutions for any questions I had. Dr. Muleta has definitely left a lasting impression on me in regards to the need for calibration of data which I have taken to heart.

I would also like to thank my fellow Civil and Environmental colleagues at Cal Poly, all of whom provided me with a constant source of energy and drive to do my absolute best on not only my project but in all facets of my academic career.

Last, but certainly not least, I would like to express my eternal thanks to my friends and family, especially, my mother, father and sister, all have provided me with their unrelenting support in everything I do. They have become the models for which I strive to become in my future and am forever grateful for their support. 


\section{TABLE OF CONTENTS}

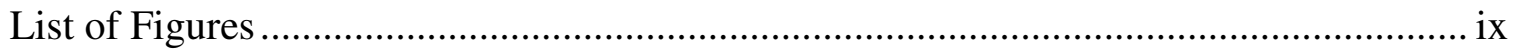

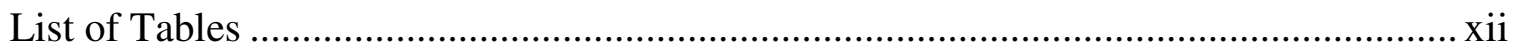

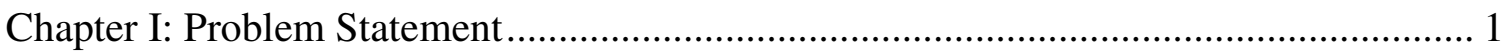

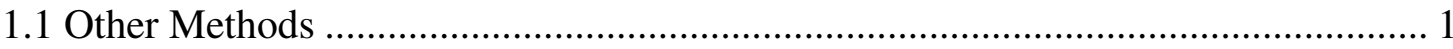

Chapter II: Water System Vulnerability ……………………................................. 5

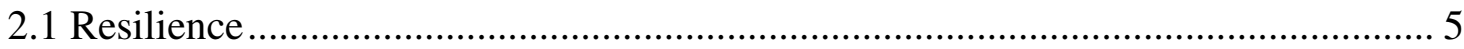

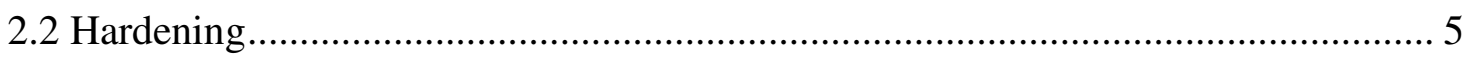

2.3 Water Distribution System Components .......................................................... 6

2.3.1 Water Supply ……………………………………..................................... 7

2.3.1.1 Groundwater ……................................................................................ 7

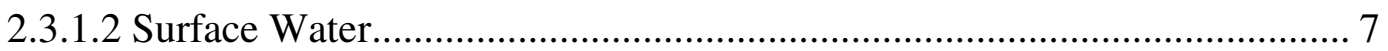

2.3.1.3 Groundwater under Direct Influence of Surface Water ............................. 8

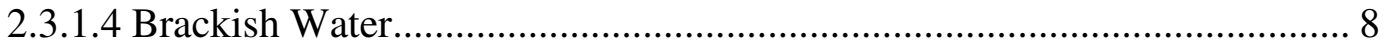

2.3.2 Treatment Plant .................................................................................. 9

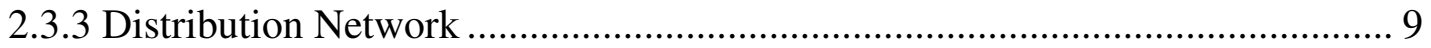

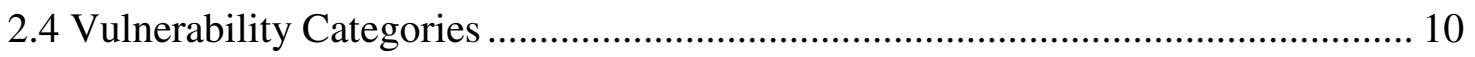

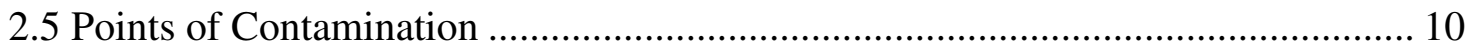

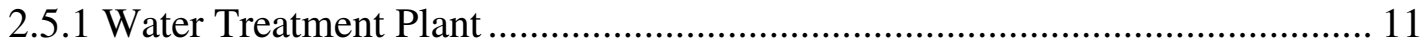

2.5.2 Pump Stations and Valves .......................................................................... 11 


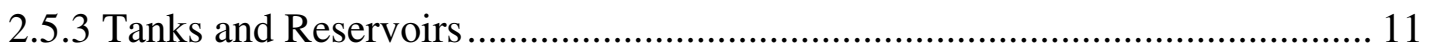

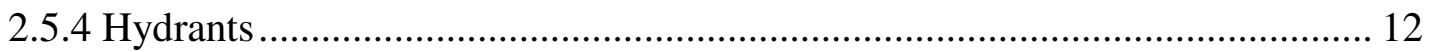

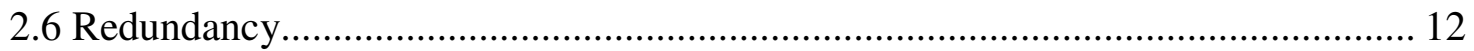

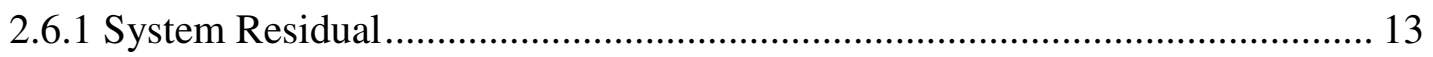

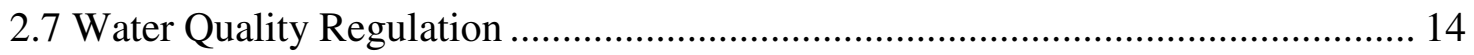

2.7.1 Surface Water Treatment Rule................................................................. 14

2.7.2 Interim Enhanced Surface Water Treatment Rule ......................................... 15

2.7.3 Long Term 1 Enhanced Surface Water Treatment Rule.................................. 15

2.7.4 Long Term 2 Enhanced Surface Water Treatment Rule................................. 16

Chapter III: Contaminants and Monitoring Capabilities ............................................... 17

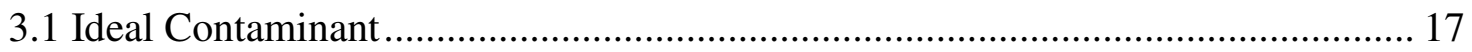

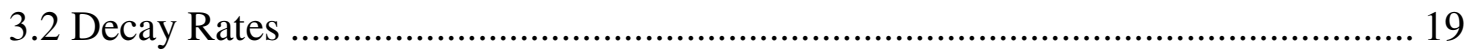

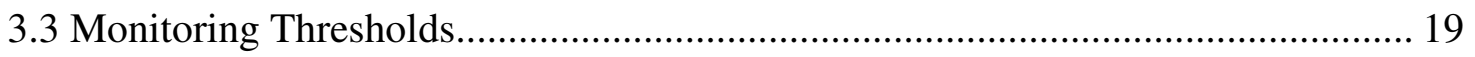

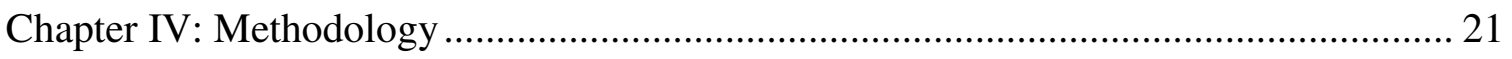

4.1 Contaminant/Agent Selection ............................................................................ 21

4.2 Constituent Properties ...................................................................................... 21

4.3 Release Type

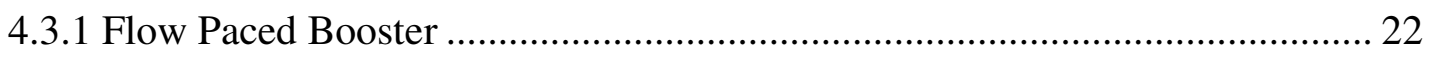

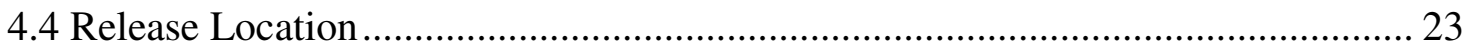

4.5 Pipe Mixing Theory ………………………………...................................... 24 


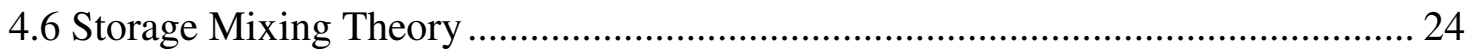

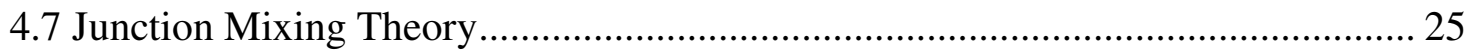

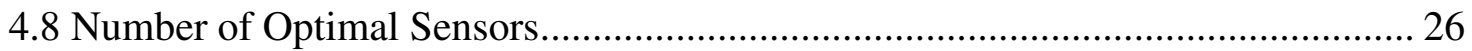

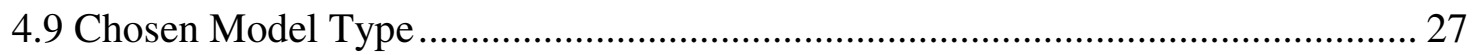

4.10 Summarization of Optimal Sensor Location Method .......................................... 27

Chapter V: Calibration of Water Distribution Model .................................................... 30

5.1 Adding Pump Controls to Model...................................................................... 32

5.2 Adjusting Fixed Grade Elevations ..................................................................... 32

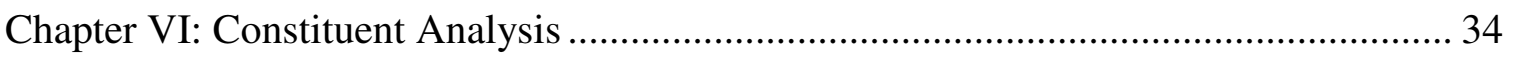

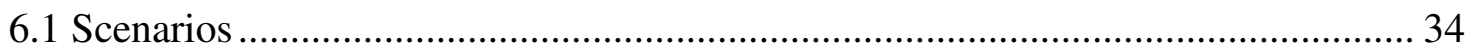

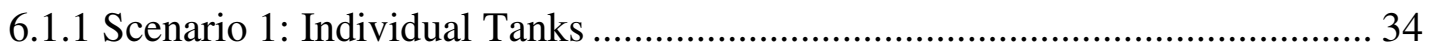

6.1.2 Scenario 2: Individual Tanks, Half of the Initial Contaminant Concentration 34

6.1.3 Scenario 3: Tank Combinations based on boost schedules .............................. 35

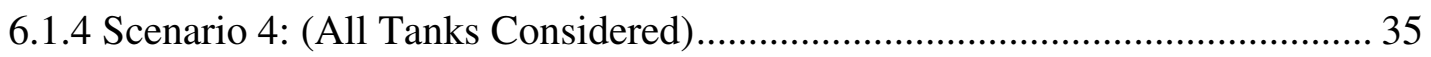

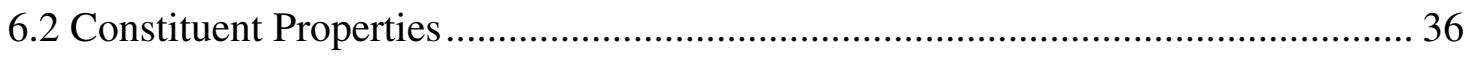

6.2.1 Chosen Contaminant .................................................................................... 36

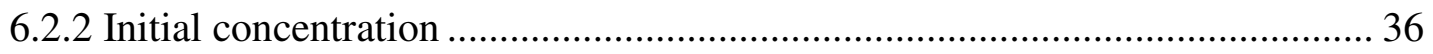

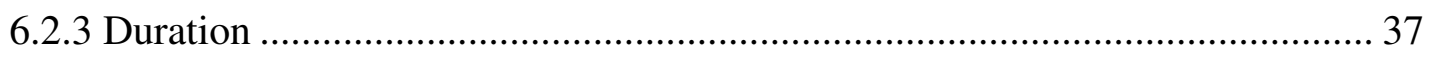

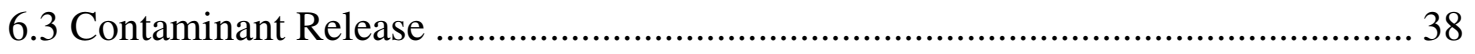

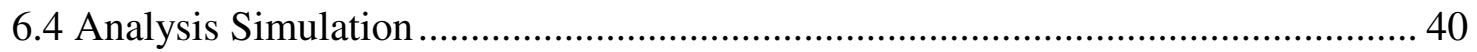


Chapter VII: Results and Discussion

7.1 Exporting WaterCAD ${ }^{\circledR}$ Results to Excel .......................................................... 42

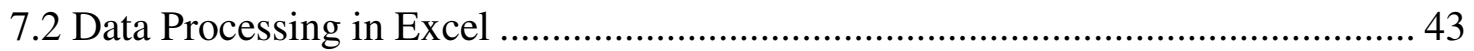

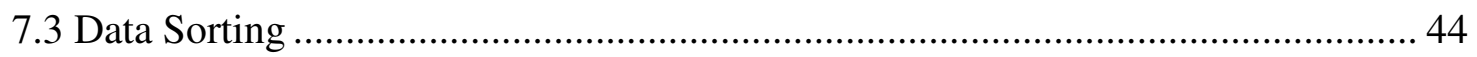

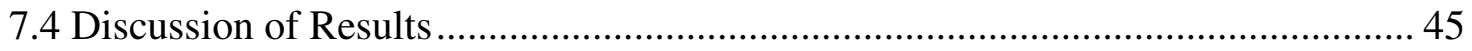

7.4.1 All Tanks Active Scenario (Scenario 4) .................................................... 46

7.4.2 Tank Combinations Based on Boost Schedule (Scenario 3) ......................... 47

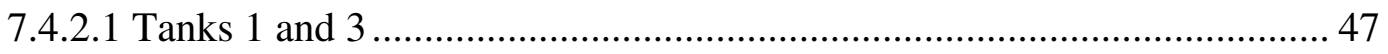

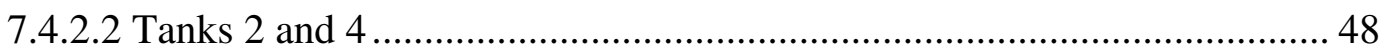

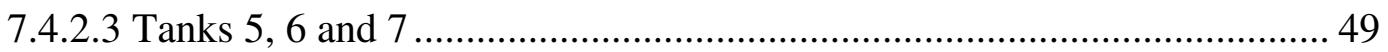

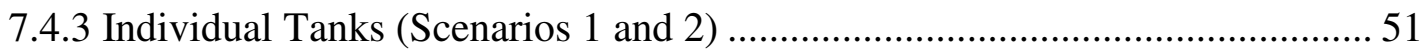

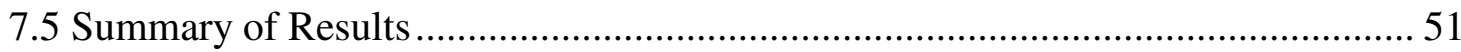

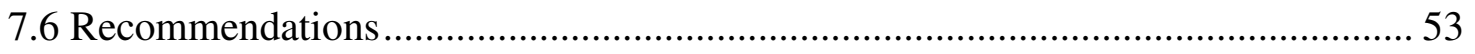

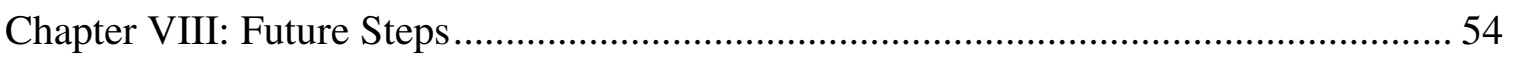

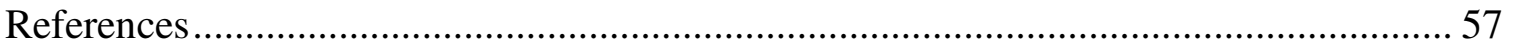

Appendix A: Visual Results for Each Scenario ............................................................ 61

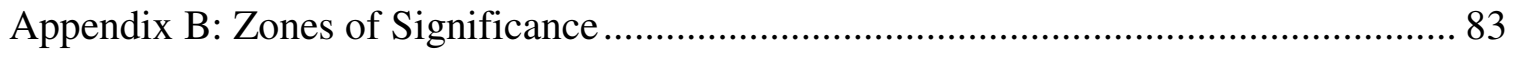




\section{LIST OF FIGURES}

Figure 1: Basic components of a water utility infrastructure (Cullinane 1989) 6

Figure 2: Hierarchical relationship of system, components, subcomponents, sub-

subcomponents for a water distribution system (Cullinane 1989) ............................... 9

Figure 3: Looped and branched systems after failure. (Walski et al. (2007)................... 13

Figure 4: Fixed Grade Elevation Calibration Process.............................................. 33

Figure 5: Alternatives Menu for Applying Constituent ................................................. 38

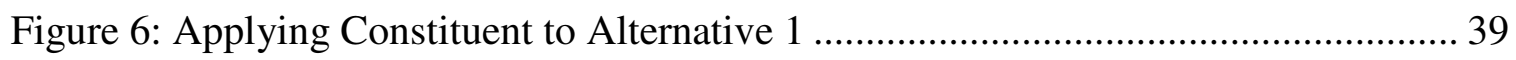

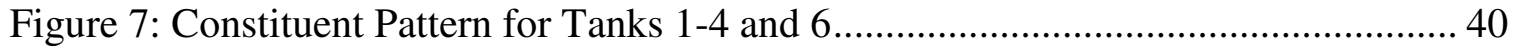

Figure 8: Movement of a contaminant through a distribution system .......................... 41

Figure 9: Frequency of detected contaminations above the minimum threshold at a

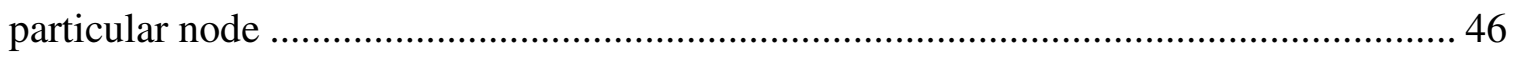

Figure 10: High Priority Zones for the CITY to implement Monitoring Stations............ 46

Figure 11: Optimal Sensor Points for Tanks 1 and 3 combined (Full Concentration) ..... 47

Figure 12: Optimal Sensor Points for Tanks 1 and 3 combined (Half Concentration)..... 48

Figure 13: Optimal Sensor Points for Tanks 2 and 4 combined (Full Concentration) ..... 49

Figure 14: Optimal Sensor Points for Tanks 2 and 4 combined (Half Concentration)..... 49

Figure 15: Optimal Sensor Points for Tanks 5, 6 and 7 combined (Full Concentration) . 50

Figure 16: Optimal Sensor Points for Tanks 5, 6 and 7 combined (Half Concentration). 51

Figure 17: Optimal Sensor Points for All Tanks (Full Concentration)............................ 61

Figure 18: Optimal Sensor Points for All Tanks (Half Concentration) .......................... 62

Figure 19: Optimal Sensor Points for Tanks 1 and 3 (Full Concentration) ..................... 63

Figure 20: Optimal Sensor Points for Tanks 1 and 3 (Half Concentration) ..................... 64 
Figure 21: Optimal Sensor Points for Tanks 2 and 4 (Full Concentration) ..................... 65

Figure 22: Optimal Sensor Points for Tanks 2 and 4 (Half Concentration) .................... 66

Figure 23: Optimal Sensor Points for Tanks 5, 6, and7 (Full Concentration) ................... 67

Figure 24: Optimal Sensor Points for Tanks 5, 6, and 7 (Half Concentration) ................ 68

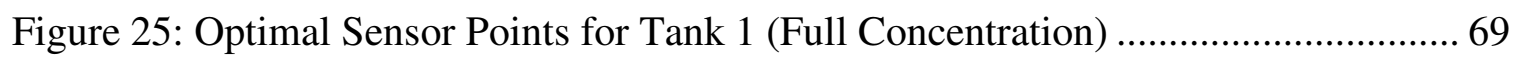

Figure 26: Optimal Sensor Points for Tank 1 (Half Concentration)............................. 70

Figure 27: Optimal Sensor Points for Tank 2 (Full Concentration) ….......................... 71

Figure 28: Optimal Sensor Points for Tank 2 (Half Concentration) ............................ 72

Figure 29: Optimal Sensor Points for Tank 3 (Full Concentration) .............................. 73

Figure 30: Optimal Sensor Points for Tank 3 (Half Concentration)............................. 74

Figure 31: Optimal Sensor Points for Tank 4 (Full Concentration) ............................... 75

Figure 32: Optimal Sensor Points for Tank 4 (Half Concentration)............................. 76

Figure 33: Optimal Sensor Points for Tank 5 (Full Concentration) ............................. 77

Figure 34: Optimal Sensor Points for Tank 5 (Half Concentration)............................. 78

Figure 35: Optimal Sensor Points for Tank 6 (Full Concentration) ............................. 79

Figure 36: Optimal Sensor Points for Tank 6 (Half Concentration) .............................. 80

Figure 37: Optimal Sensor Points for Tank 7 (Full Concentration) .............................. 81

Figure 38: Optimal Sensor Points for Tank 7 (Half Concentration).............................. 82

Figure 39: Zones of Significance for Tank 1 (Full Concentration) .............................. 83

Figure 40: Zones of Significance for Tank 1 (Half Concentration) .............................. 83

Figure 41: Zones of Significance for Tank 2 (Full Concentration) ............................... 84

Figure 42: Zones of Significance for Tank 2 (Half Concentration) .............................. 84

Figure 43: Zones of Significance for Tank 3 (Full Concentration) …........................... 85 
Figure 44: Zones of Significance for Tank 3 (Half Concentration).............................. 85

Figure 45: Zones of Significance for Tank 4 (Full Concentration) .............................. 86

Figure 46: Zones of Significance for Tank 4 (Half Concentration).............................. 86

Figure 47: Zones of Significance for Tank 5 (Full Concentration) …......................... 87

Figure 48: Zones of Significance for Tank 5 (Half Concentration).............................. 87

Figure 49: Zones of Significance for Tank 6 (Full Concentration) ............................. 88

Figure 50: Zones of Significance for Tank 6 (Half Concentration) .............................. 88

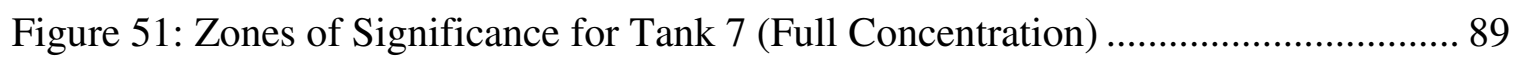

Figure 52: Zones of Significance for Tank 7 (Half Concentration).............................. 89 


\section{LIST OF TABLES}

Table 1: Log removal values as expressed in contaminant removal percentages (USEPA

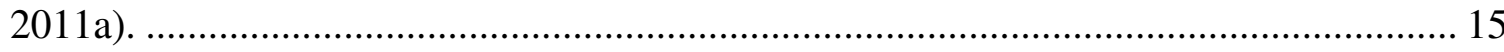

Table 2: Comparative Toxicity of Natural Poisons (Deininger 2000)........................... 18

Table 3: Booster Pump Schedule for Tanks 1-7 ..................................................... 31

Table 4: Sample WaterCAD ${ }^{\circledR}$ Control Inputs for Tank 1 ............................................ 32

Table 5: New Fixed Grade Elevations after Calibration................................................. 33

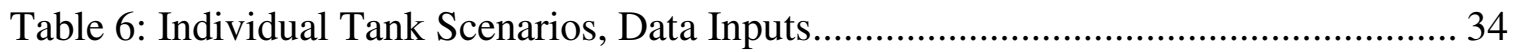

Table 7: Individual Tanks, Half Concentration, Data inputs ....................................... 35

Table 8: Constituent Inputs for Cryptosporidium ................................................... 37

Table 9: Desired Format after converting WaterCAD ${ }^{\circledR}$ output via Excel Macro ............. 43

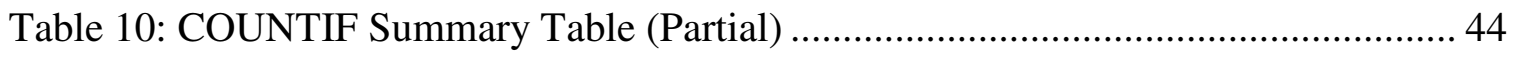




\section{CHAPTER I: PROBLEM STATEMENT}

The September 11, 2001 terrorist attacks in the US, have led to a heightened security awareness regarding our nation's vital resources, including water infrastructure. In particular, the Homeland Security Presidential Directive 7 of 2003 and the Bioterrorism Preparedness Act of 2002 fostered expanding awareness of the vulnerability of water infrastructure. Although water quality monitoring in the US is intensive at the influent and effluent points of drinking water treatment plants, the water distribution systems often lack water quality monitoring. This lack of information from the distribution systems is compounded by the inherent vulnerability of distribution systems, which range over wide areas and are difficult to harden against mischief. To improve water quality monitoring and monitoring efficiency, optimal locations for monitoring stations within water distribution systems need to be identified.

\subsection{Other Methods}

Chastain (2004) discusses methodologies to identify the optimal monitoring locations in a water distribution system. These methods are sparse and often rely on the assumption that the contamination event is steady and continuous which would not reflect a possible terrorist activated contamination correctly. Kessler, Ostfeld \& Sinai (1998) propose a method focused on contaminant advection. Their method, however, assumes a steady release of contaminant and selects contaminants which are not conservative. Chastain (2004) argues these methods have seen little application due to the complexity of their algorithms and the varying assumptions required to carry out these detailed processes. These methods also do not use the extended period simulation models that are 
now available, which provide a better depiction of system hydraulics and water movement to real world data (Chastain 2004).

Commercially available software has been developed that attempts to identify the optimal water quality monitoring locations. The Threat Ensemble Vulnerability Assessment and Sensor Placement Optimization Tool (TEVA-SPOT) is a free program which was recently developed by the USEPA. It uses a graphical user interface that will also integrate with the EPANET software in terms of the hydraulic analysis portion of the optimal sensor placement algorithms. But this software also uses the assumption of a continuous injection of a contaminant, which is not likely to be indicative of a terrorist contamination. The processing time also increases with the increasing size of the water distribution system, and can make it rather expensive and time dependent to apply the generic optimization algorithms. It can however, serve as a good starting point for distribution systems managers given that both the hydraulic software and the optimization software are both available free from the USEPA.

One reason that optimization research has been minimal is the sensitivity of information on distribution systems, post 9/11, make it difficult for academic researchers to obtain real distribution systems maps and models. As experienced in the present thesis research, many water utility operators are hesitant to release data on the geophysical properties of their water delivery systems as precaution against inadvertently aiding system attackers. One solution to this concern is the creation and use of virtual cities (Brumbelow et al. 2007) which provides a practical, publicly-available model that can be used for various research analyses. 
For the research conducted in this paper, a real system was used from a California city which serves a community of 30,000 to 50,000 residents. For simplicity, the California city will be referred to as "the CITY" in this thesis. The geophysical properties and name of this system will remain anonymous as requested by the CITY.

The process by which the optimal operating points will be identified will begin with first assessing the model given by the CITY and calibrating it, if required, to more accurately represent the hydraulics of the city's water distribution system (WDS). A constituent analysis will then be performed under various scenarios which are outlined in the later sections of this thesis. The results of this constituent analysis will then be imported into an Excel spreadsheet in order to determine which nodes detected the highest number of contaminations over a selected duration of time. The node with the highest number of detections would be considered the most efficient node for a particular scenario. Summary tables and figures will be provided, outlining and explaining the resulting trends from the analysis. One of the overall objectives of this research is to maintain simplicity in order to make the process and method more accessible for small to mid-sized water distribution systems operators. The method proposed also would be applicable to a larger distribution system.

The following chapters begin with first identifying the typical components of a water distribution system and the vulnerability of their components to attack, whether from natural phenomenon or terrorist activity. The contaminants of interest are explored next in order to determine types of contaminants better suited for vulnerability assessments. These sections are followed by the selected assumptions, calibration of the model, and outline of the various scenarios that are used in the analysis. Next, the 
constituent analyses are described in detail, followed by the data processing procedures performed in excel. The results are displayed graphically in order to qualitatively identify the zones of significance where optimal nodes are frequently identified. The final chapter then explores various recommendations for future work based on this study. 


\section{CHAPTER II: WATER SYSTEM VULNERABILITY}

Mitigating all vulnerabilities in a system is impractical. However, systems might be hardened to a point that is both effective and affordable. The degree of hardening will depend on the current system conditions as well as the inherent resilience of the system.

\subsection{Resilience}

Resilience is, “...the capacity of a system to absorb disturbance and still retain its basic function and structure" (Walker \& Salt 2006), and this important concept applies to water distribution systems, as it is a good indicator of the overall vulnerability of the system.

\subsection{Hardening}

Finding optimal water quality locations is one way operators of a WDS can harden the water distribution system overall. Water system hardening has increased in the past twenty years likely from technological advancements, increased understanding of systems and through legislative requirements, among other factors. In addition, the wastewater and drinking water infrastructures are in extremely poor condition overall (ASCE 2009). Many of these piping systems have been in the ground for over 50 years, are highly degraded, and are in need of replacement. ASCE estimated that it would cost approximately $\$ 255$ billion to repair the degraded water infrastructure over the next five years. US investment is projected to fall short of this number by approximately $\$ 110$ billion. Since funding is an issue for most major cities and districts, many are fixing the sewer and drinking water lines piecemeal when failure occurs. This means that most cities are operating within the factor of safety for which the pipelines were designed. This 
could pose major adverse health and environmental concerns in the future if wastewater is allowed to leach on a consistent basis. This shows how the distribution system is already in a vulnerable state and any hardening associated projects will propel the system to be safer from a variety of threats.

\subsection{Water Distribution System Components}

In order to assess the vulnerable aspects of a water system, we must first identify the components of the WDS. A public water system is defined as a system with at least 15 connections or serving at least 25 people for a period of at least 60 days (Deininger 2000). A typical WDS consists of a water source, a treatment system for that water source, and a transmission and distribution system that transports the treated water to the users of the system.

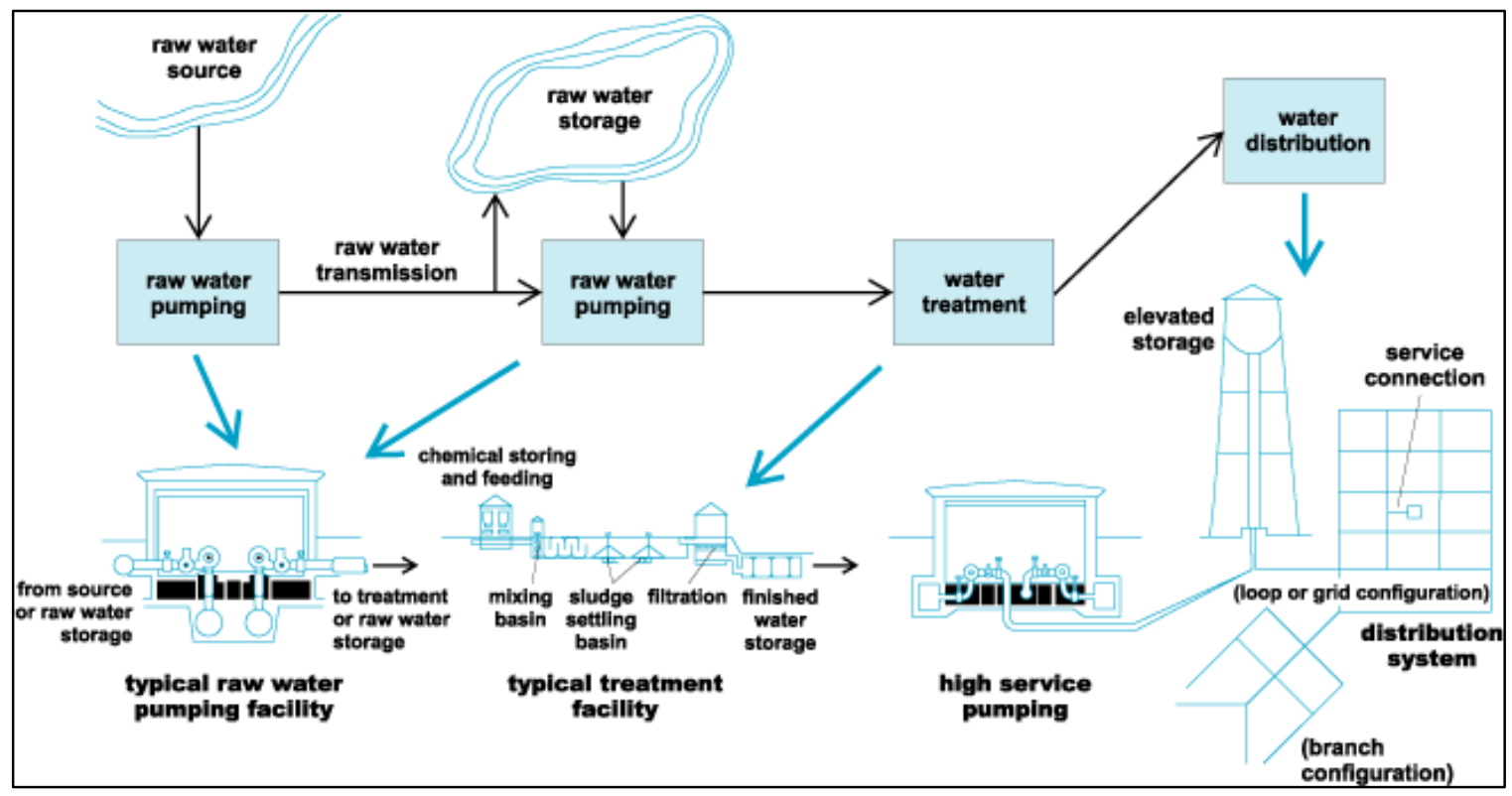

Figure 1: Basic components of a water utility infrastructure (Cullinane 1989) 


\subsubsection{Water Supply}

Water supplies can be generalized in one of four categories: groundwater, surface water, groundwater under the direct influence of surface water, and brackish water. Each source water type would present different advantages and disadvantages in regards to contamination entry points into a water distribution system. The following sections describe each source water type.

\subsubsection{Groundwater}

Groundwater sources can be unconfined aquifers, confined aquifers, perched aquifers as well as combinations of these. Unconfined aquifers allow for natural groundwater recharge as the aquifer is directly connected with the surface soil strata. Confined aquifers would allow little natural recharge, thus requiring an artificial recharge such as pumping directly into the confined aquifer.

Groundwater is usually preferable to surface water for a number of factors. Groundwater provides a natural water filter through the process of infiltration for groundwater recharge. Hence, groundwater can be used with little or no treatment. It also serves as a natural storage mechanism with more consistent volumetric yield levels (Chastain 2004).

\subsubsection{Surface Water}

Surface water can include rivers, lakes and reservoirs which collect and transport storm and snow runoff. Due to the nature of the collection of surface water, the water quality can often fluctuate depending on various factors as the runoff travels over the watershed. The Surface Water Treatment Rule from the USEPA sets the regulations and 
requirements for monitoring and the removal of contaminants through disinfection as discussed in 2.6.1.

\subsubsection{Groundwater under Direct Influence of Surface Water}

The USEPA has recently issued the Long Term 2 Enhanced Surface Water Treatment Rule that requires the communities using groundwater under the direct influence of surface water to disinfect for the parasitic protozoan Cryptosporidium. This type of source water generally includes a system by which surface water is diverted into ponds where the water can then percolate through the soil into the groundwater for recharge. The water is then pumped from the groundwater, treated and distributed to the community for use.

\subsubsection{Brackish Water}

This water source may refer to the mixing of seawater and freshwater, as in estuaries. This is much less common than the other water sources as it requires a close proximity to the ocean and is significantly more expensive. As the technology improves, a shift may occur to the use of more desalination plants in order to remove the salt from the supply. However, this lack in advancement has been the limiting factor for most coastal communities. Coastal communities must also be aware of salt water intrusion into the underground aquifers. This could compromise the water source and require additional means to either treat for the intrusion or to prevent brackish water from intruding using various preventive methods. 


\subsubsection{Treatment Plant}

Treatment of source water is now required for all water distribution systems based on the progression of the regulations by the USEPA. Each treatment system varies based on the source water conditions and the system needs. If the source water, or other conjunctive water sources, contains high quality water, then the simplest form of water treatment would consist of chlorine disinfection. Other added layers of treatment could include a $\mathrm{pH}$ adjustment, filtration systems, chlorine dioxide disinfection, ozone disinfection, ultraviolet disinfection etc.

\subsubsection{Distribution Network}

The distribution system consists of the pipes, pumps, tanks and other appurtenances that distribute the treated water to the users of the system. The distribution network is generally comprised of looped piping systems in order to provide redundancy to the system. A minimum system pressure is also an indication of redundancy and reliability.

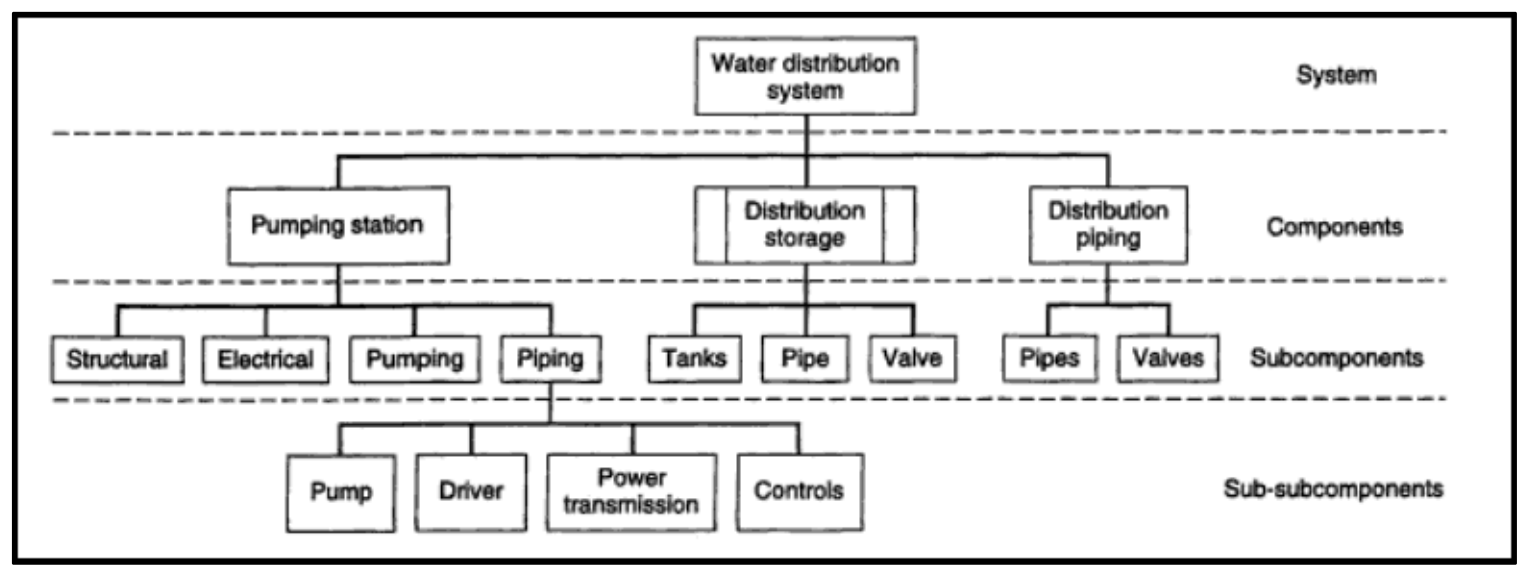

Figure 2: Hierarchical relationship of system, components, subcomponents, subsubcomponents for a water distribution system (Cullinane 1989) 


\subsection{Vulnerability Categories}

With the basic water system components identified we can begin to look at the various vulnerabilities and threats associated with them. Haimes et al. (1998) describes the various vulnerability categories in regards to WDS. They are summarized as follows:

Physical Threats: Includes any physical damage to the infrastructure of a water system, i.e. dams, tanks, pipes, valves, treatment facilities, canals, aqueducts, etc., due to natural calamities or intentional attacks.

Chemical and Biological Threats: Includes any contamination of the system water, whether intentional or unintentional. This can include source water contamination, reservoir contamination, groundwater contamination or contamination directly into the distribution or transmission system.

Cyber Threats: Includes any attacks on the Supervisory Control and Data Acquisition (SCADA) systems, which control the various operations and monitoring of the system.

For this study, we will focus on the biological threat aspect as it pertains to directly contaminating the distribution system through intentional means.

\subsection{Points of Contamination}

Chemical or biological agents must have an entry point into the water distribution system in order for contamination to occur. Possible entry points are outlined next and briefly discussed. 


\subsubsection{Water Treatment Plant}

Almost $19 \%$ of community water systems are fed by surface water sources (Deininger et. al. 2000). The other $81 \%$ are fed by groundwater sources, which in most cases for sustained groundwater use is directly influenced by surface water infiltration in order to recharge the groundwater levels during periods of low water use. Therefore, a majority of the source water hinges on surface water protection. Since surface water is open to the environment, it is an easily accessible point of contamination for those looking to intentionally compromise a community's water supply. Even through source water contamination, it will not necessarily follow that a community's water system will be compromised. This is due to the treatment and monitoring that are required by the USEPA regulations. Due to these water quality requirements, outlined in section 2.6, source water contamination would likely be identified, treated for, and initiate shutdown of service if it cannot be readily eradicated from the system.

\subsubsection{Pump Stations and Valves}

Most pump stations are protected from intrusion by the pump housings as well as locked buildings which contain them. Valves should also have similar means of protection. If accessed however, an improper shutdown of a pump or valve could potentially cause severe water hammer or cavitation effects in other areas of the system.

\subsubsection{Tanks and Reservoirs}

Tanks and reservoirs are the main focus for this research due to their easier accessibility. These hydraulic structures are a target of concern as they are usually secluded with limited security. Most importantly, these structures have a direct influence 
on the system hydraulics and provide a quick means of contaminating a large portion of a system in a short amount of time.

\subsubsection{Hydrants}

A possible scenario for contamination could include pumping into the distribution system through a hydrant. This would require a portable tank as well as a pump and motor assembly with enough total dynamic head to counter the outgoing pressure of the distribution lines. This scenario would pose a risk for anyone attempting to contaminate due to the high exposure probability. Hydrants are generally located in highly populated areas in order to efficiently provide fire safety to the buildings nearby. This is compounded by the fact that the pump and motor assembly would cause a significant amount of noise, which would likely be heard by the nearby residents.

\subsection{Redundancy}

All water systems should have planned redundancies to improve the likelihood of continued performance during unforeseen periods of disturbance. These disturbances can be anything from an electrical failure, power outage, pump replacement, motor failure, maintenance, etc. Redundancy is often achieved by providing multiples of the vital components in the system, i.e. a second pumping system parallel to the normally operating pumping system, or backup generators in case of power outages. This insures that the system will still function, possibly with a decreased level of service, when a disturbance occurs.

Another means of redundancy is provided through the pipe network design of the water distribution system. Looped networks are more favorable than non-looped 
networks due to the added level of reliability. In the case of a pipe break, a looped system would be able to redirect flow to a greater number of customers than branched system would. This is illustrated in figure 3 where a pipe break scenario is shown.

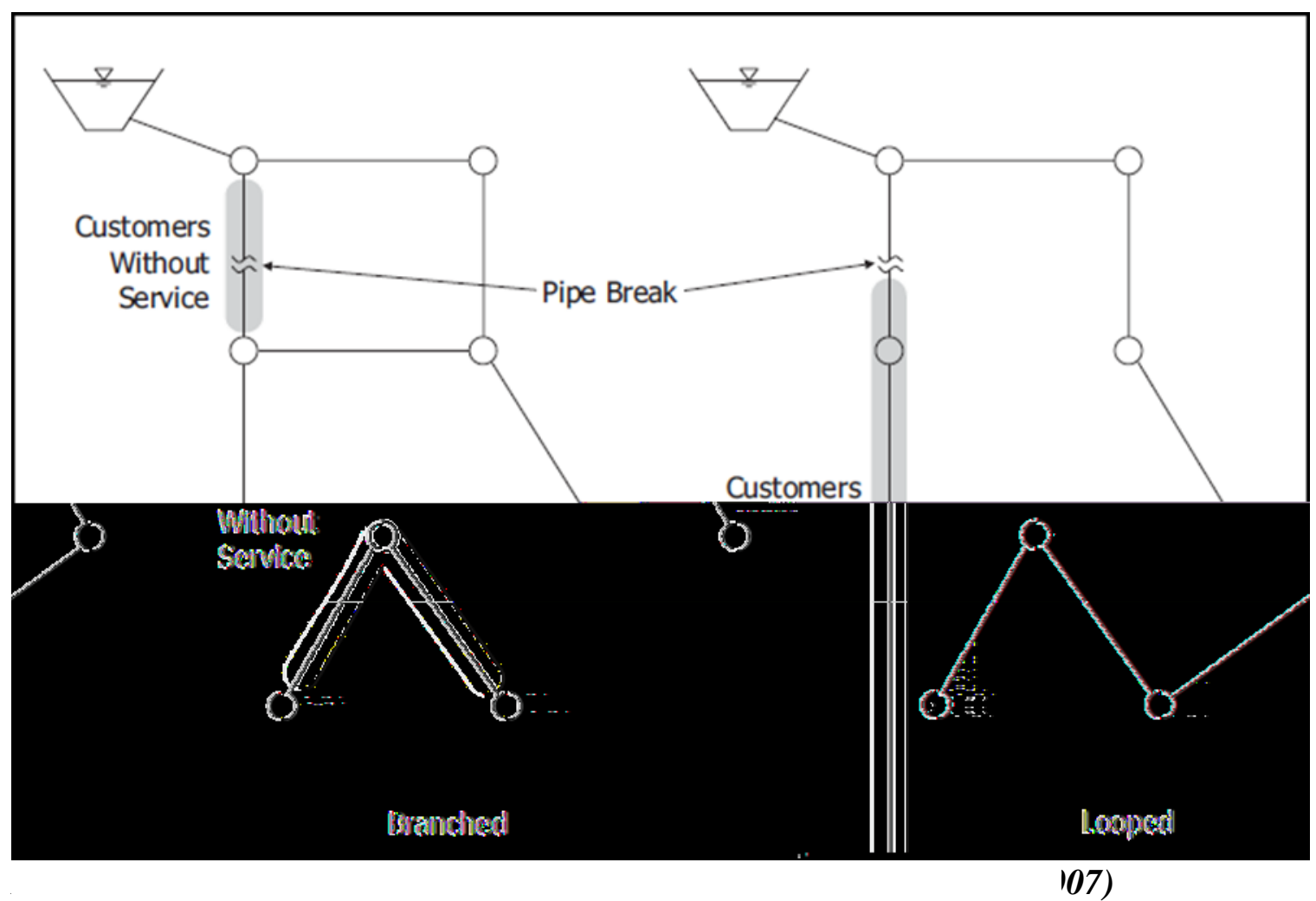

As can be observed in the schematic, the lower portion of the branched network is without service during the pipe break scenario whereas the looped network design still provides service to the majority of the users during the same event.

\subsubsection{System Residual}

One means that most systems use to gauge the safety and the quality of the water in the distribution phase is through the concept of a system residual. A system residual is measured through water quality testing and shows that a minimum concentration of disinfectant, in most cases this is a chlorine concentration, is maintained in the system from the source to the end point. This provides confirmation to the USEPA that the 
system is meeting disinfection requirements and regulations throughout the system.

However, microbial contaminants such as Cryptosporidium and Giardia have shown a resistance to the chlorine residual, making it possible for a system to have the USEPA required chlorine residual but still not meet water quality requirements. In recent years this has become a main concern, especially after the case study of the Cryptosporidium outbreak in Milwaukee, Wisconsin in 1993 where approximately 400,000 people became ill because of the contamination (Corso et al. 2003).

\subsection{Water Quality Regulation}

This section outlines the implemented regulations by the USEPA and illustrates the progression of drinking water safety in regards to water distribution rules and regulations. These regulations require various degrees of disinfection which can be met by a variety of methods. Common disinfection methods include chlorine, ozone, chlorine dioxide, ultraviolet, filtration, etc. The type and scale of the method of disinfection depends on the system needs and the source water quality which are unique for each case.

\subsubsection{Surface Water Treatment Rule}

Brought on by the passage of the Safe Drinking Water Act of 1979 that provided the authorization to the USEPA for regulating drinking water quality, the Surface Water Treatment Rule (SWTR) of 1989 requires water systems to remove contaminants from source water through some means of filtration or disinfection. This rule also provides the maximum contaminant levels (MCL) and maximum contaminant level goals (MCLG) of various critical contaminants. The contaminants include various microbial contaminants and viruses which pose the most threat to serious illness of the user if exposure were to occur (USEPA, 2011a). 
The SWTR also stipulated contaminant removal requirements specified by a log removal value. These values are summarized below in tabular format.

Table 1: Log removal values as expressed in contaminant removal percentages (USEPA 2011a).

\begin{tabular}{cc}
\hline Log Removal Number & $\begin{array}{c}\text { Percentage of Contaminant Required } \\
\text { to be Removed }\end{array}$ \\
\hline 2-Log & $99 \%$ \\
3- $\log$ & $99.9 \%$ \\
4- $\log$ & $99.99 \%$ \\
\hline
\end{tabular}

Contaminants were issued various log removal requirements based on the MCL specified by the USEPA. Water systems must achieve a 3-log removal of giardia, and a 4-log removal of viruses. These values depend on the nature of the contaminant and its associated risk to human health. In order to ensure these regulations were being followed, the USEPA requires these contaminant levels to be measured via turbidity and by maintaining a system residual of disinfection throughout distribution. Cryptosporidium has posed a particular problem for operators due to its resistance toward chlorine disinfection, which is the most common form of residual disinfection for water distribution.

\subsubsection{Interim Enhanced Surface Water Treatment Rule}

Following the SWTR, the Interim Enhanced Surface Water Treatment Rule (IESWTR) was passed in 1998. This requires water systems which provide water for at least 10,000 users to improve filtration and lower turbidity at the end point.

\subsubsection{Long Term 1 Enhanced Surface Water Treatment Rule}

The Long Term 1 Enhanced Surface Water Treatment Rule (LT2ESWTR) expanded 
upon the IESWTR by including systems that serve fewer than 10,000 people to the requirements of the IESWTR. Enforcement of this rule began in 2002.

\subsubsection{Long Term 2 Enhanced Surface Water Treatment Rule}

On August 11, 2003 the USEPA proposed the Long Term 2 Enhanced Surface Water Treatment Rule (LT2ESWTR). This rule affects any water distribution systems that serve to a community with source water stemming from either surface water or groundwater under the direct influence (GWUDI) of surface water. The rule directly relates to the contamination of water systems with Cryptosporidium. This has become a concern for water providers due to the resistance of Cryptosporidium to chlorine residuals and other disinfectants. If consumed, Cryptosporidium can cause gastrointestinal illness and in the cases of individuals with weakened immune systems, can be fatal. 


\section{CHAPTER III: CONTAMINANTS AND MONITORING CAPABILITIES}

\subsection{Ideal Contaminant}

One of the key questions to be answered for any vulnerability assessment, in regards to contamination analysis, is which contaminant to model. Franke (1977) lists factors that should be considered in the evaluation of an "ideal" biological or chemical contaminant from a terrorist perspective:

- High Toxicity

- No Taste or odor

- Chemical and physical stability

- Delayed action to protect the sabotage agent

- Difficult recognition of poisoning, no specific pathologic changes in the organism

- Difficulties with the detection of the poison with normal analytical methods

- Unusual effect of poisons, no known antidotes

The availability of a particular agent is important to consider in terms of selecting the "ideal" contaminant. Ease of access and transportation of the contaminant may correlate with the amount of risk associated with a particular agent. In addition, the mechanism by which a particular contaminant is to be introduced into the distribution system should be considered. These factors will change depending on the point of injection, level of security at that point and the effect using that point will have on the system. Thus, quantifying risk in regards to contaminant selection is rather difficult as a number of factors must be considered simultaneously. One way to quantify risk is through the $\mathrm{LD}_{50}$ value associated with a particular contaminant. $\mathrm{LD}_{50}$ (or Lethal Dose 
50 ) is the amount of contaminant needed to cause fatalities in $50 \%$ of the sample population. Table 2 illustrates $\mathrm{LD}_{50}$ values for various substances. The lower the $\mathrm{LD}_{50}$ value, the more toxic the substance.

Table 2: Comparative Toxicity of Natural Poisons (Deininger 2000).

\begin{tabular}{cc}
\hline Substance & $\mathbf{L D}_{\mathbf{5 0}}$ in $\mathbf{~ u g} / \mathbf{k g}$ (mouse) \\
\hline Botulinus & 0.00003 \\
Tetanus & 0.001 \\
Tetrodotoxin & 9 \\
Saxitoxin & 9 \\
Batrachotoxin & 2.7 \\
Palytoxin & 0.15 \\
\hline
\end{tabular}

Terrorist would likely choose contaminants with low $\mathrm{LD}_{50}$ values in an attempt to harm as many people as possible. In addition to low $\mathrm{LD}_{50}$ values, terrorists would need to consider the possibility of inactivation of the pathogen due to the chlorine residual in the distribution network.

The present system residual is a reason why the tolerance to chlorine is another important factor to consider due to a vast majority of water distribution systems using chlorine residuals to disinfect. This eliminates many contaminants with far more risk associated with them, such as Botulinus Toxin A, because of the ability of the chlorine residual to disinfect most toxins (Deininger 2000).

A comprehensive list of all of the contaminants of concern which can be found on the USEPA's website (USEPA, 2009b). This list breaks down that contaminants into several categories based on pathogen type (i.e. biological, by-product, microorganism, 
organic chemical, etc.) The list also contains information on the MCL's, MCLG's, potential health effects, and common sources for each contaminant.

\subsection{Decay Rates}

The rate of decay of a contaminant is an important property which must be considered conservatively in contaminant vulnerability assessments. If a contaminant does degrade or decay at a significant rate, it should be modeled accordingly in the vulnerability analysis. However, it is recommended that conservative, non-decaying contaminants be chosen for modeling due to the desired conservative nature of the assessment (Haested Methods, 2007). In this case, the system would have an analysis for which no decay is observed. A second analysis could then be performed to identify the sensitivity, if any, of a change in concentration.

\subsection{Monitoring Thresholds}

The USEPA provides research into sensor technologies that detect anomalous changes in the baseline water quality (USEPA, 2009a). This is due to the need for water quality monitoring to be both economically viable for mass implementation in a water system and to sense many different types of contaminants. These sensors therefore do not focus on identifying the type of contaminant, concentration amount, accuracy or precision of the contaminant in question. Instead, the sensor detects the deviation from baseline water quality and then alerts the water utility. Following this alert, further sampling and analysis would then be required to determine the exact extent of the contamination event in both quantity and quality. This continuous monitoring of the baseline water quality will also provide secondary benefits in a water distribution system. 
A minimum threshold change was also needed for the USEPA study, in order to verify that a change in the baseline water quality could be detected even at the small MCL levels that are required by the USEPA regulation. It was found that contaminant concentrations of $1.0 \mathrm{mg} / \mathrm{L}$ were typical for both injection method tests. This concentration was detectable by at least one of the monitoring sensors in the test. This 1.0 $\mathrm{mg} / \mathrm{L}$ value is far below most Immediately Dangerous to Life or Health (IDLH) values as specified by the USEPA for most contaminants. It was also tested and confirmed that the act of injecting the contaminant during testing did not alter the results or affect baseline water quality values. 


\section{CHAPTER IV: METHODOLOGY}

\subsection{Contaminant/Agent Selection}

The contaminant that was selected for application to the CITY was Cryptosporidium. Cryptosporidium is a single celled parasite that is commonly found in rivers and lakes, especially when raw sewage or animal fecal material is being discharged into the water source. Cryptosporidium oocysts are highly resistant to chlorine residuals, and they are notoriously difficult to disinfect. This resistance is due to the outer shell that accompanies the oocyst, allowing it to survive for long periods of time outside of a host body. Cryptosporidium is one of the most common waterborne diseases among humans in the United States (CDC 2011). This may make Cryptosporidium a contaminant of choice for terrorists as the vast majority of distribution systems would be vulnerable to its introduction. The use of Cryptosporidium as a weapon can seem counterintuitive due to the fact that many other contaminants, such as Botulinus Toxin A, are considered to be of a much higher risk and therefore have much lower Lethal Dose $\left(\mathrm{LD}_{50}\right)$ values. However, these types of contaminants are eliminated with a properly maintained chlorine residual in the distribution system.

\subsection{Constituent Properties}

With the selection of Cryptosporidium as the contaminant of concern for this research came a need to select a decay rate for the constituent properties section of the WaterCAD ${ }^{\circledR}$ analysis. A bulk reaction rate of zero, indicating no decay occurs, was selected for the decay rate due to literature indicating that the decay rate for a 1-log removal of the pathogen would take approximately 39 days (Toze et al. 2010). Since the extended period simulation (EPS) for this study was only 24 hours, this would constitute 
less than a 3\% decay of the pathogen. Considering this decay negligible also made the analysis more conservative, as it assumes that the contaminant moves primarily by advection through the system and does not degrade. Any additional decay would simply lessen the spread extent that was found in this analysis. Use of conservative constituent analysis is usually recommended for vulnerability assessments based on Haested Methods (2007). The contaminant therefore will only change concentration due to either dilution or with the contaminant being removed from the system via daily demand patterns. When the contaminant is removed from the system by the user it is assumed that the primary means of acquiring the contaminant will be through ingestion of the contaminated water.

\subsection{Release Type}

The release was assumed to be a quantity of $300,000 \mathrm{mg} / \mathrm{L}$ at a rate of $50 \mathrm{gpm}$ for one hour. An assumption is being made for the concentration units where 1 oocyst/L is equivalent to $1 \mathrm{mg} / \mathrm{L}$ for modeling purposes. These values were chosen based on the assumptions of Chastain (2004). These properties were then applied to each tank in the contamination analysis in WaterCAD ${ }^{\circledR}$ through the use of a flow paced booster in the contamination alternatives manager.

\subsubsection{Flow Paced Booster}

The flow paced booster involves raising the concentration of the fluid by a fixed quantity even through flow changes. This is used to model flow driven constituent movement throughout the system. It is given by the following equation:

$$
C_{o}=\frac{\sum Q_{i} C_{i}}{\sum Q_{i}}+C_{f}
$$




$\begin{array}{lll}C_{0} & = & \text { Concentration at and out of node }\left(\mathrm{M} / \mathrm{L}^{3}\right) \\ C_{f} & = & \text { Increase in concentration at node }\left(\mathrm{M} / \mathrm{L}^{3}\right) \\ C_{i} & = & \begin{array}{l}\text { Concentration of the } i \text {-th inflow node into } \\ \text { the node }\left(\mathrm{M} / \mathrm{L}^{3}\right)\end{array} \\ Q_{i} & = & \text { Flow from } i \text {-th inflow into node }\left(\mathrm{L}^{3} / \mathrm{T}\right)\end{array}$

Using the above equation, WaterCAD ${ }^{\circledR}$ adds a set concentration of a constituent after mixing of all inflow to the node from other points in the network.

\subsection{Release Location}

An intentional contamination release could occur at any potential opening in the system as outlined in section 2.4. It was assumed for the purpose of this analysis that the most likely point of contamination would be through the tanks of the system. This is due to the ease of accessibility of most water distribution tanks compared to that of pumping system connections. The release location inherently needed to be downstream of the source water and treatment plant in order to examine the effects on the distribution system alone. Hydrants are considered a low priority of interest due to the possibility of using portable tanks and pump and motor assemblies to pump the contaminant into a hydrant against the pressure of the system. This was determined to be too risky for those looking to intentionally compromise a system due to the highly exposed nature of hydrant locations. This high potential for exposure would be due to the noise of the pump and motor assembly, which would be required to run for at least an hour for this analysis. 


\subsection{Pipe Mixing Theory}

The main transport mechanism of the constituent through the system is assumed to be through advection. With this assumption the contaminant will travel through a pipe at the same average velocity as the fluid within the pipe while simultaneously reacting at a given rate if the contaminant decays or grows. Longitudinal dispersion is assumed to not be a significant means of contaminant transport through the pipe under most operating conditions. Advection in the pipe is given in WaterCAD ${ }^{\circledR}$ by the following equation:

$$
\begin{aligned}
\frac{\partial C_{i}}{\partial t} & =-u_{i} \frac{\partial C_{i}}{\partial x}+r\left(C_{i}\right) \\
\text { Where: } \quad & =\text { Concentration (mass/volume) in pipe } \mathrm{i} \\
C_{i} & =\text { Flow Velocity (length/time) in pipe i } \\
& =\text { Rate of reaction (mass/volume/time) as a function } \\
& \text { of concentration } \\
t & =\text { Time } \\
x & =\text { Longitudinal distance in pipe }
\end{aligned}
$$

\subsection{Storage Mixing Theory}

The storage facilities (i.e. tanks and reservoirs) are assumed to have completely mixed contents. Given that a minimum momentum flux is imparted to the inflow and that the conditions of the tank correspond with fill and draw techniques, then this is a reasonable assumption (Rossman and Grayman, 1999). Concentrations could change however, due to various reactions within the tank. The following equation expresses the storage mixing in WaterCAD ${ }^{\circledR}$ : 


$$
\frac{V_{s} C_{S}}{\partial t}=\sum i \varepsilon I_{s} Q_{i} C_{i \mid x=L_{i}}-\sum j \varepsilon O_{s} Q_{j} C_{s}+r C_{s}
$$

$\begin{array}{lll}V_{s} & = & \text { Volume in storage at time } \mathrm{t} \\ C_{s} & = & \text { Concentration within the storage facility } \\ I_{s} & = & \text { Set of links providing flow into the facility } \\ O_{s} & = & \begin{array}{l}\text { Set of links withdrawing flow from the } \\ \text { facility }\end{array} \\ Q_{j} & = & \text { Flow (Volume/Time) in link j } \\ Q_{i} & = & \text { Flow (Volume/Time) in link i }\end{array}$

\subsection{Junction Mixing Theory}

Mixing of inflow from two or more pipes is assumed to be completely instantaneous. Therefore the flow concentration is a weighted average of the inflow pipe flow concentrations. For any node k, the concentration can be found by the following equation:

$$
C_{i \mid x=0}=\frac{\sum j \varepsilon I_{k} Q_{j} C_{j \mid x=L_{j}}+Q_{k, \text { ext }} C_{k, \text { ext }}}{\sum j \varepsilon I_{k} Q_{j}+Q_{k, e x t}}
$$

$\begin{array}{lll}I & = & \text { Link with flow leaving node } k \\ I_{k} & = & \text { Set of links with flow into } k \\ L_{j} & = & \text { Length of link } j \\ Q_{j} & = & \text { Flow (volume/time) in link } j \\ Q_{k, \text { ext }} & = & \begin{array}{l}\text { External source flow entering the } \\ \text { network at node } k\end{array} \\ C_{k, \text { ext }} & =\begin{array}{l}\text { Concentration of the external flow } \\ \text { entering at node } k\end{array}\end{array}$




$$
\begin{array}{lll}
C_{i \mid x=0} & =\quad \text { The concentration at the start of link } i \\
C_{i \mid x=L} & =\quad \text { The concentration at the end of link } i \\
\varepsilon & =\quad \text { Roughness Height }(\mathrm{m}, \mathrm{ft} .)
\end{array}
$$

Equations $\{2-4\}$ are subject to the following assumptions made by $\mathrm{WaterCAD}^{\circledR}$ in order to solve for the concentration in each pipe as well as the concentration in each storage structure:

- Initial conditions that specify $C_{i}$ for all $x$ in each pipe $i$ and $C_{s}$ in each storage facility $s$ at time 0.

- Boundary conditions that specify values for $C_{k, \text { ext }}$ and $Q_{k, \text { ext }}$ for all time $t$ at each node $k$ which has external mass inputs.

- Hydraulic conditions which specify the volume $V_{s}$ in each storage facility $s$ and the flow $Q_{i}$ in each link $i$ at all times $t$.

WaterCAD ${ }^{\circledR}$ uses a Lagranian Transport Algorithm to track each discrete parcel of water. The algorithm uses relatively short time steps to accommodate for the short times of travel within the pipes.

\subsection{Number of Optimal Sensors}

The number of optimal sensor is assumed to be less than the number of tanks (i.e. less than seven). This is assumed due to the fact that if seven sensors were economically viable, than the optimal locations for those seven sensors would be at the closest nodes to the respective tanks in order to immediately detect a contamination event as it left the tanks and dispersed into the system. However, this assumes that the tanks are the source 
of the constituents in the system. If the system was compromised through another point of access, then these would cease to be the optimal locations for sensor placement. This leads back to the idea that vulnerability is a moving target. Once one aspect of the system is hardened, it leaves other aspects vulnerable. The decision of how many optimal sensors to use and their ultimate locations should be dependent on the economic viability of those sensors as well as the inherent differences associated with each individual water distribution system.

\subsection{Chosen Model Type}

Two models were provided by the CITY. Both an average day system and a maximum day system were provided for analysis. The maximum day system was selected to be the primary system for analysis for the purpose of remaining conservative. The main aim for this type of vulnerability assessment is to mitigate the worst attack that a terrorist may have on a water distribution system, which may include targeting a water system on a summer day during peak water use hours.

\subsection{Summarization of Optimal Sensor Location Method}

The following summarizes the method set forth by Chastain (2004). The method is outlined sequentially.

1. Apply the developed Design Basis Threat (DBT) at each injection point and generate a matrix which includes the concentrations that each junction in the system detects over the complete duration of analysis.

2. Compare all time step data from all analyses with the chosen minimum concentration values in order to assign each concentration a " 1 " if the 
value is greater than the minimum concentration or a " 0 " if the value is below.

3. Sum the number of times a particular node detects a contamination above the minimum threshold.

4. Sort the data to find the node that had the highest number of detections throughout the duration.

5. It is recommended to perform sensitivity analyses in regards to the effect of the initial concentration and the minimum concentration threshold.

As Chastain describes, there is no one optimal node for any given WDS. There is however, a cluster of points that can be considered optimal and would serve to detect a wide variety of events. These clusters will be identified as the zones of significance and will be outlined for each scenario in the analysis. An important assumption that is made for this analysis is that contamination only occurs at the junction nodes and that all nodes have equal importance. Therefore, it is through the junction flex tables that the concentration matrix is developed. It is also assumed that the possible monitoring point locations will be at a junction node in the system.

The method proposed by Chastain differs from other algorithms in the following ways:

- The method uses a separate extended period simulation for each injection scenario. After which, all of the results are used to locate the optimal nodes. This is contrary to most other algorithms which use a single hydraulic analysis and then attempt to optimize based on that sole hydraulics analysis. 
- This method uses the principle of superposition by combing the results from all analyses and for all time steps in order to rank the individual nodes of the system. This approach has become increasingly less burdensome due to the advancements in data processing, computing power, and hydraulics software. 


\section{CHAPTER V: CALIBRATION OF WATER DISTRIBUTION MODEL}

Once a model was obtained from the CITY an overall assessment of the model was then required. The CITY was using $\mathrm{H}_{2} \mathrm{ONET}^{\circledR}$ software which has an export feature to save the water distribution model as an EPANET input file. This file could then be imported into either EPANET or another modeling software program capable of reading the input file. In this case, Bentley's WaterCAD ${ }^{\circledR}$ was used to import the EPANET input file. WaterCAD ${ }^{\circledR}$ was chosen due to its local availability at California Polytechnic State University in San Luis Obispo as well as the increased amount of modeling capabilities and functions.

The tanks in the system are modeled as reservoirs within the model. Upon a detailed discussion with the modeler and the operations department of the CITY, the reason for this modeling decision was determined as based on the operation of the tanks. Each tank operates with an isolation valve that is opened during periods of boosting. The tank then releases water into the system via a pump which pressurizes the pipe connecting the tank to the system to the current operating pressure. In this sense, the tanks do not contribute to the hydraulics of the system when they are not pumping. In other words, during boosting hours the isolation valves are opened and the pumps are turned on allowing for flow to be contributed to the system from the tanks. When boosting hours terminate, the isolation valve closes which effectively removes the tanks from the rest of the WDS. Also, the tank levels do not vary much during the operation periods and therefore do not cause a high amount of pressure difference between when the tanks are filling or boosting. Thus, the tanks are modeled as reservoirs with fixed energy grade lines in order to mimic the flow rates and pressures that are actually 
observed. When the tanks are not in operation, the valve is then closed in the connecting pipe, effectively isolating it from the system.

Once imported into WaterCAD ${ }^{\circledR}$ the system was assessed by running a hydraulics analysis to verify that the distribution system was successfully imported with no errors to be corrected. The hydraulics analysis did yield a preliminary issue concerning tanks 1-7, which are of a primary concern in regards to the contamination scenarios. Upon further inspection it was found that the pipes connecting the tanks to the rest of the system were closed in the initial settings. This effectively isolated the tanks from the rest of the system rendering them unused in the hydraulics analysis. The operations department of the CITY was contacted in order to adjust the controls and the physical properties of tanks 1-7 in order to better mimic flow rates that were being seen in the system currently. The controls were set according to the data in the chart below, provided by the CITY operations department.

Table 3: Booster Pump Schedule for Tanks 1-7

\begin{tabular}{ccc}
\hline Tank \# & Boost Days & Boost Times \\
\hline 1 & Thursday, Sunday & $5 \mathrm{am}-8 \mathrm{am}$ \\
3 & Tuesday, Saturday & $5 \mathrm{am}-9 \mathrm{am}$ \\
4 & Thursday, Sunday & $5 \mathrm{am}-9 \mathrm{am}$ \\
5 & Tuesday, Saturday & $5 \mathrm{am}-9 \mathrm{am}$ \\
6 & Monday, Wednesday, Friday & $4 \mathrm{am}-9 \mathrm{am}$ \\
7 & Monday, Wednesday, Friday & $5 \mathrm{am}-4 \mathrm{pm}$ \\
\hline
\end{tabular}




\subsection{Adding Pump Controls to Model}

With the acquisition of the pumping schedules from the operations department of the CITY, the controls could now be set to mimic the boost and fill schemes as seen in actual operation. In the controls section of WaterCAD ${ }^{\circledR}$ under the components tab, logical statements can be created to let the program know when the tanks should open and close. An example logical statement for Tank 1 is shown in Table 4:

\section{Table 4: Sample WaterCAD ${ }^{\circledR}$ Control Inputs for Tank 1}

\begin{tabular}{cccc}
\hline ID & Type & Priority & Description \\
\hline LC 1848 & Simple & $<$ default $>$ & If Clock Time $=5: 00$ AM THEN P2576 Pipe Status = \\
Open & If Clock Time $=8: 00$ AM THEN P2576 Pipe Status \\
LC 1851 & Simple & $<$ default $>$ & Iosed \\
\hline
\end{tabular}

Table 4, shown above, illustrates the logical operators within the controls. According to the description, at 5:00AM the pipe status of pipe P2576 will change from closed to open. This will allow water to exit Tank 1 for the duration in which P2576 is open. Then, as the second logical control states, the pipe status of P2576 will close at 8:00AM, effectively isolating the tank from the rest of the system. These controls assume that the initial conditions of the pipes are set to closed. These logical controls are set for each tank and vary depending on the boost and fill times respectively.

\subsection{Adjusting Fixed Grade Elevations}

In order to adjust the flow rates of the tanks to mimic real world pumping data, the fixed grade elevations were adjusted until the correct outgoing flow rate was obtained. 


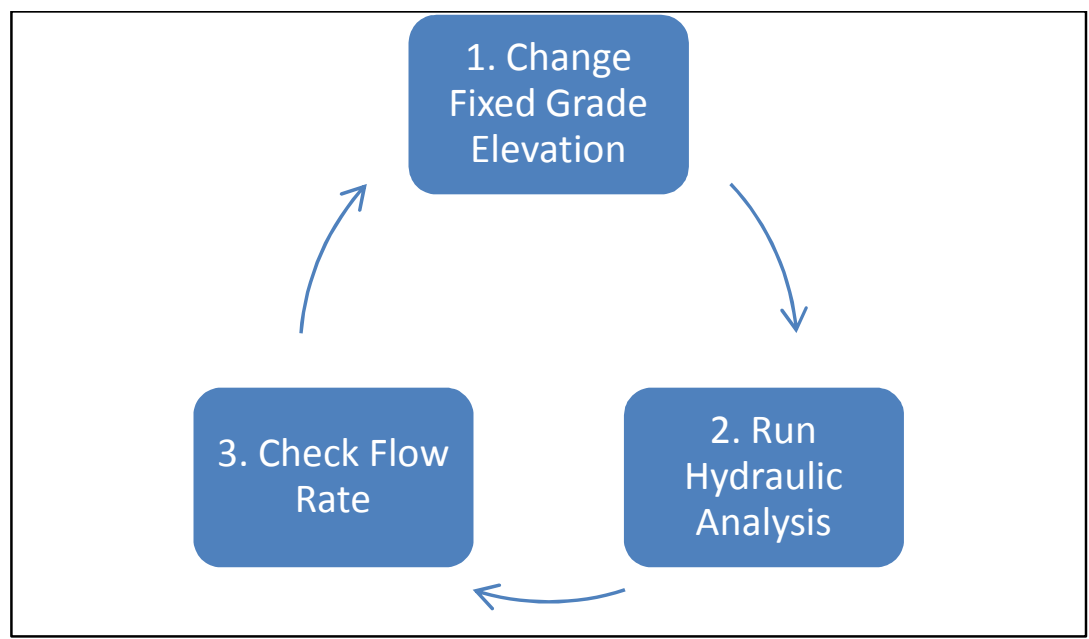

Figure 4: Fixed Grade Elevation Calibration Process

This was performed in a trial and error fashion, illustrated in figure 4 , due to the hydraulic interconnectedness of the fixed grade elevations. When one fixed grade value is changed, multiple pumping rates also change. In order to see the changes, a hydraulic analysis was performed after each change in the elevation. After multiple iterations, the fixed grade elevations were fine tuned to reflect nearly identical flow rates from Tanks 1-7 as observed in real life (Table 5).

Table 5: New Fixed Grade Elevations after Calibration

\begin{tabular}{ccc}
\hline Tank \# & $\begin{array}{c}\text { Fixed Grade Elevation } \\
\text { (Before Calibration) }\end{array}$ & $\begin{array}{c}\text { Fixed Grade Elevation } \\
\text { (After Calibration) }\end{array}$ \\
\hline 1 & $141.00 \mathrm{ft}$ & $245.47 \mathrm{ft}$ \\
2 & $139.00 \mathrm{ft}$ & $242.96 \mathrm{ft}$ \\
3 & $142.00 \mathrm{ft}$ & $272.72 \mathrm{ft}$ \\
4 & $145.00 \mathrm{ft}$ & $276.35 \mathrm{ft}$ \\
6 & $127.25 \mathrm{ft}$ & $271.82 \mathrm{ft}$ \\
7 & $137.20 \mathrm{ft}$ & $273.29 \mathrm{ft}$ \\
\hline
\end{tabular}




\section{CHAPTER VI: CONSTITUENT ANALYSIS}

\subsection{Scenarios}

\subsubsection{Scenario 1: Individual Tanks}

For the individual tank analysis the following data scenarios were input into WaterCAD ${ }^{\circledR}$ via the alternative and scenario managers. The analysis duration was 24 hours.

Table 6: Individual Tank Scenarios, Data Inputs

\begin{tabular}{|c|c|c|c|c|}
\hline Tank & $\begin{array}{c}\text { Initial } \\
\text { Concentration } \\
(\mathrm{mg} / \mathrm{L})\end{array}$ & $\begin{array}{l}\text { Injection } \\
\text { Method }\end{array}$ & $\begin{array}{l}\text { Mass Flow } \\
\text { Rate }(\mathrm{mg} / \mathrm{s})\end{array}$ & $\begin{array}{l}\text { Simulation } \\
\text { Start Time }\end{array}$ \\
\hline 1 & 300,000 & $\begin{array}{c}\text { Flow Paced } \\
\text { Booster }\end{array}$ & 50 & 5:00AM \\
\hline 2 & 300,000 & $\begin{array}{c}\text { Flow Paced } \\
\text { Booster }\end{array}$ & 50 & 5:00AM \\
\hline 3 & 300,000 & $\begin{array}{c}\text { Flow Paced } \\
\text { Booster }\end{array}$ & 50 & 5:00AM \\
\hline 4 & 300,000 & $\begin{array}{c}\text { Flow Paced } \\
\text { Booster }\end{array}$ & 50 & 5:00AM \\
\hline 5 & 300,000 & $\begin{array}{c}\text { Flow Paced } \\
\text { Booster }\end{array}$ & 50 & 4:00AM \\
\hline 6 & 300,000 & $\begin{array}{c}\text { Flow Paced } \\
\text { Booster }\end{array}$ & 50 & 5:00AM \\
\hline 7 & 300,000 & $\begin{array}{c}\text { Flow Paced } \\
\text { Booster }\end{array}$ & 50 & 4:00PM \\
\hline
\end{tabular}

6.1.2 Scenario 2: Individual Tanks, Half of the Initial Contaminant Concentration

This scenario was to test the sensitivity of how changing the initial concentration of the contaminant would affect the results for optimal sensor locations. All other inputs were kept the same as the previous scenario with the full concentration. The alternative and scenario inputs are outlined in Table 7. 


\begin{tabular}{ccccc}
\hline Tank & $\begin{array}{c}\text { Initial } \\
\text { Concentration } \\
(\mathbf{m g} / \mathbf{L})\end{array}$ & $\begin{array}{c}\text { Injection } \\
\text { Method }\end{array}$ & $\begin{array}{c}\text { Mass Flow } \\
\text { Rate }(\mathbf{m g} / \mathbf{s})\end{array}$ & $\begin{array}{c}\text { Simulation } \\
\text { Start Time }\end{array}$ \\
\hline 1 & 150,000 & $\begin{array}{c}\text { Flow Paced } \\
\text { Booster }\end{array}$ & 50 & $5: 00 \mathrm{AM}$ \\
2 & 150,000 & $\begin{array}{c}\text { Flow Paced } \\
\text { Booster }\end{array}$ & 50 & $5: 00 \mathrm{AM}$ \\
3 & 150,000 & $\begin{array}{c}\text { Flow Paced } \\
\text { Booster } \\
\text { Flow Paced } \\
\text { Booster }\end{array}$ & 50 & $5: 00 \mathrm{AM}$ \\
4 & 150,000 & 50 & $5: 00 \mathrm{AM}$ \\
5 & 150,000 & $\begin{array}{c}\text { Flow Paced } \\
\text { Booster } \\
6\end{array}$ & 50 & $4: 00 \mathrm{AM}$ \\
7 & 150,000 & $\begin{array}{c}\text { Flow Paced } \\
\text { Booster }\end{array}$ & 50 & $5: 00 \mathrm{AM}$ \\
\hline
\end{tabular}

6.1.3 Scenario 3: Tank Combinations based on boost schedules

This scenario looks at multiple tank contamination spreads based on the tank operation schedule. By combining the tanks which operate on the same schedule, a clearer depiction of real world contamination spreads should be observed in the results. Based on the tank boosting schedules outlined in Chapter 5, the following tank combinations will be analyzed:

- Tanks 1 and 3

- Tanks 2 and 4

- $\quad$ Tanks 5,6 and 7

\subsubsection{Scenario 4: (All Tanks Considered)}

The last scenario looks at the absolute worst case where all tanks are contaminated and all are operating on the same day. This is less likely to occur in reality, 
given that the pumping schedules are not likely to change dramatically. However, the results should indicate the most efficient points in the system were the pumping schemes to be compromised, causing a full scale contamination of each tank.

\subsection{Constituent Properties}

\subsubsection{Chosen Contaminant}

As outline in Chapter IV, the chosen contaminant for analysis in the WaterCAD ${ }^{\circledR}$ constituent model was Cryptosporidium. This biological contaminant was chosen due to its resistance to chlorine disinfection. This resistance allows the Cryptosporidium oocysts to survive for long periods of time in chlorine disinfected systems, making them a prime target of choice for those attempting to intentionally contaminate a distribution system. A Bulk coefficient of zero was used for the constituent property. This was chosen to be conservative in the analysis of the constituent movement. With a bulk coefficient of zero, the contaminant is assumed to not decay as it moves through the system. Therefore, if the contaminant does decay, it will spread to a lesser extent than the analysis to be performed in this research.

\subsubsection{Initial concentration}

The chosen initial concentration to be released in the various scenarios considered is $300,000 \mathrm{mg} / \mathrm{L}$. This was determined to mimic the initial conditions that were used by Chastain (2004). Chastain identified that it would be possible to bring a 3,000 gallon tanker to a concentration of 300,000 mg/L based on Teunis et al. (2002). This study indicated that a culture of Cryptosporidium could be created to bring a 3,000 gallon tanker to a concentration of $300,000 \mathrm{mg} / \mathrm{L}$. The concentration was then halved for all 
scenarios to determine its effect, if any, on the optimal monitoring point rankings and locations.

This pumping rate is set at 50 gallons per minute, emptying the contents of the tank in 1 hour. This could yield a scenario where contamination could occur at any time during the night. Once the contaminant was fully discharged into the tank, it would be released into the system when the tank's pumping system activated based on its pumping schedule which was described previously.

\subsubsection{Duration}

A 24 hour duration was selected due to the requirements set forth by the USEPA. The USEPA stipulates that a water utility has 24 hours to notify the users of a system when a contaminant is first detected. This was also the same duration that was selected by Chastain (2004). The chosen duration also seemed reasonable based on the preliminary testing of the constituent modeling processes with the various scenarios. The constituent properties were set to the values provided in Table 8 .

Table 8: Constituent Inputs for Cryptosporidium

\begin{tabular}{cc}
\hline Diffusivity & $1.300 * 10^{-008} \mathrm{ft}^{2} / \mathrm{s}$ \\
\hline Unlimited Concentration? & Unchecked \\
\hline Concentration Limit & $300,000 \mathrm{mg} / \mathrm{L}$ \\
\hline Bulk Reaction Order & 1.0 \\
\hline Bulk Reaction Rate & $0.000(\mathrm{mg} / \mathrm{L})^{\wedge}(1-\mathrm{n}) /$ day \\
\hline Wall Reaction Order & Zero Order \\
\hline First Order Wall Reaction Rate & $0.000 \mathrm{ft} / \mathrm{day}$ \\
\hline Is Roughness Correlated & Unchecked
\end{tabular}


Note in table 8 that the diffusivity constant was the default value given by WaterCAD ${ }^{\circledR}$. Diffusion is not the main contaminant transport mechanism due to the advection dominated nature of the system. Therefore, this default value will have a minimal effect on the results.

\subsection{Contaminant Release}

Release was only considered at the tanks of the system as they are the most likely target for intentional contamination. The release locations therefore depend on which tanks are considered operational. Once the scenarios are created, the release location can be set in $\mathrm{WaterCAD}^{\circledR}$ through the alternatives menu (Figure 5).

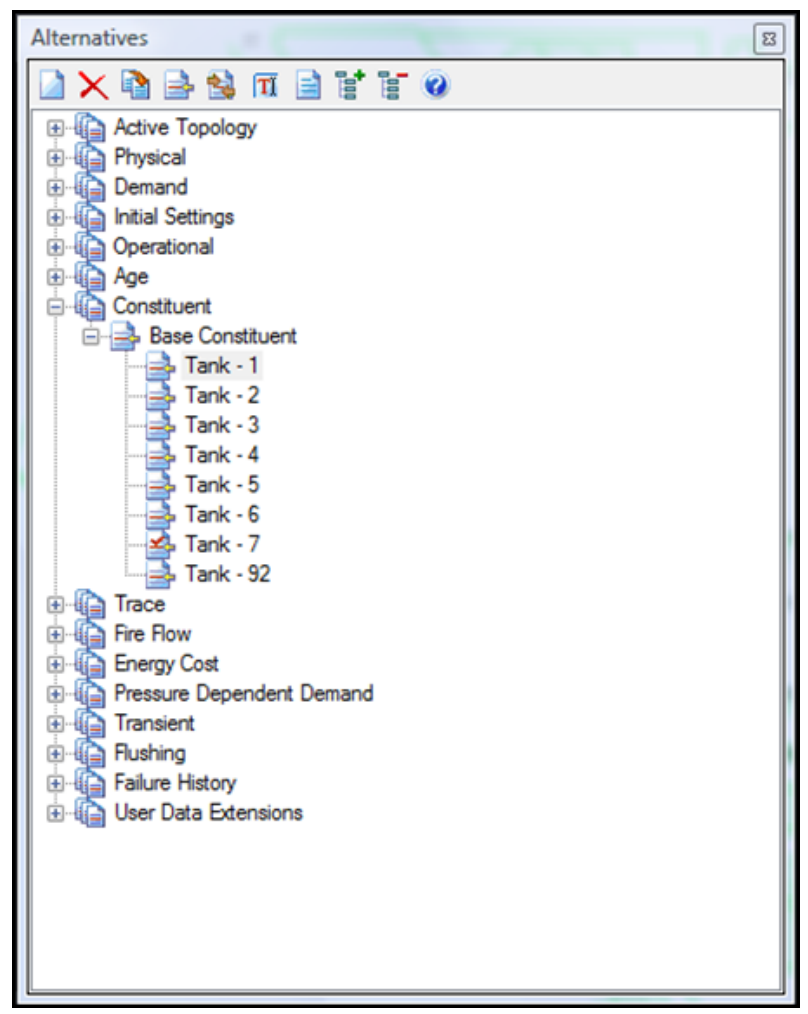

Ienu for Applying Constituent

Under the constituent category several child alternatives can be created to correlate with however many scenarios are to be performed for analysis. Double clicking on one of the 
created constituent child alternatives will open the alternative properties flex tables shown in figure 6.

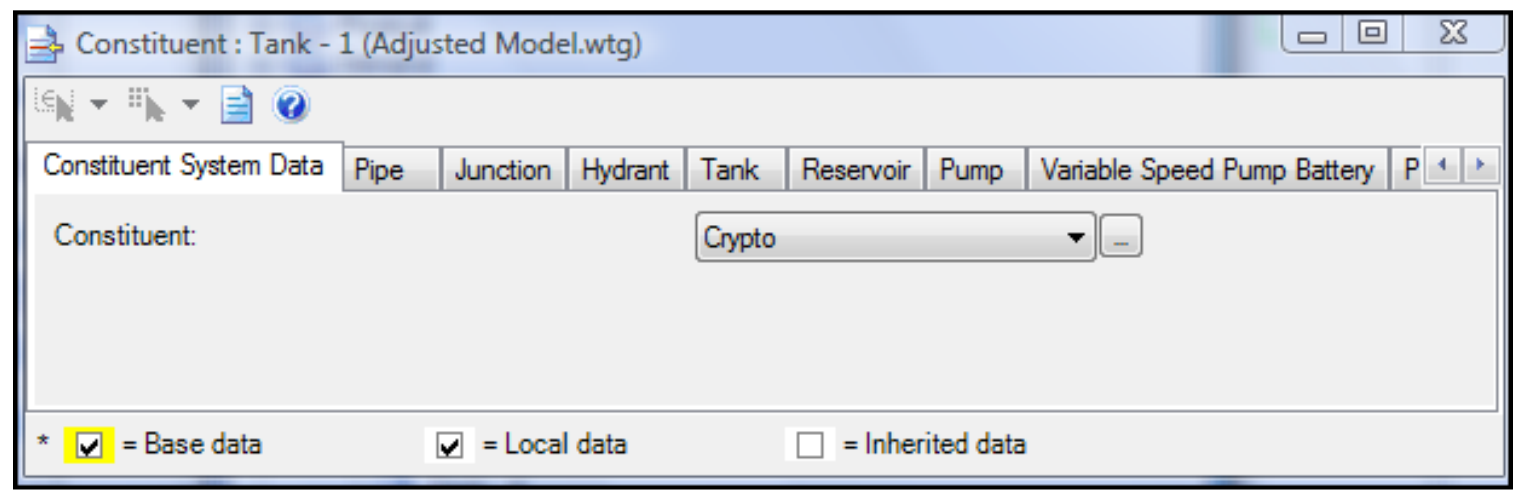

Figure 6: Applying Constituent to Alternative 1

Here the constituent can be selected via a drop down menu. If the constituent has not been created, one can be input by clicking on the ellipsis button to the right of the drop down menu. Now that $\mathrm{WaterCAD}^{\circledR}$ has a constituent selected, it can be applied to a location in the system for release. Using the tabs shown in Figure 6, the component of the system where the contaminant is to be released can be selected. For the purpose of this study, the contaminant was released in the tanks. However, because the tanks were modeled as reservoirs, the input for the contaminant release is in the reservoir tab. Within the reservoir tabs are the various options for contaminant release types. A flow paced booster was selected, along with inputting the concentration amount, initial concentration and mass flow rate values.

A constituent pattern was also created to model the release time for each scenario. This was done using an hourly pattern which coincided with the tank boosting schedules for each scenario. Since release only requires a duration of one hour to completely release the contaminant concentration, a pattern was created to release the contaminant for one hour starting at the time at which the tank is active. An example is shown in figure 7. 


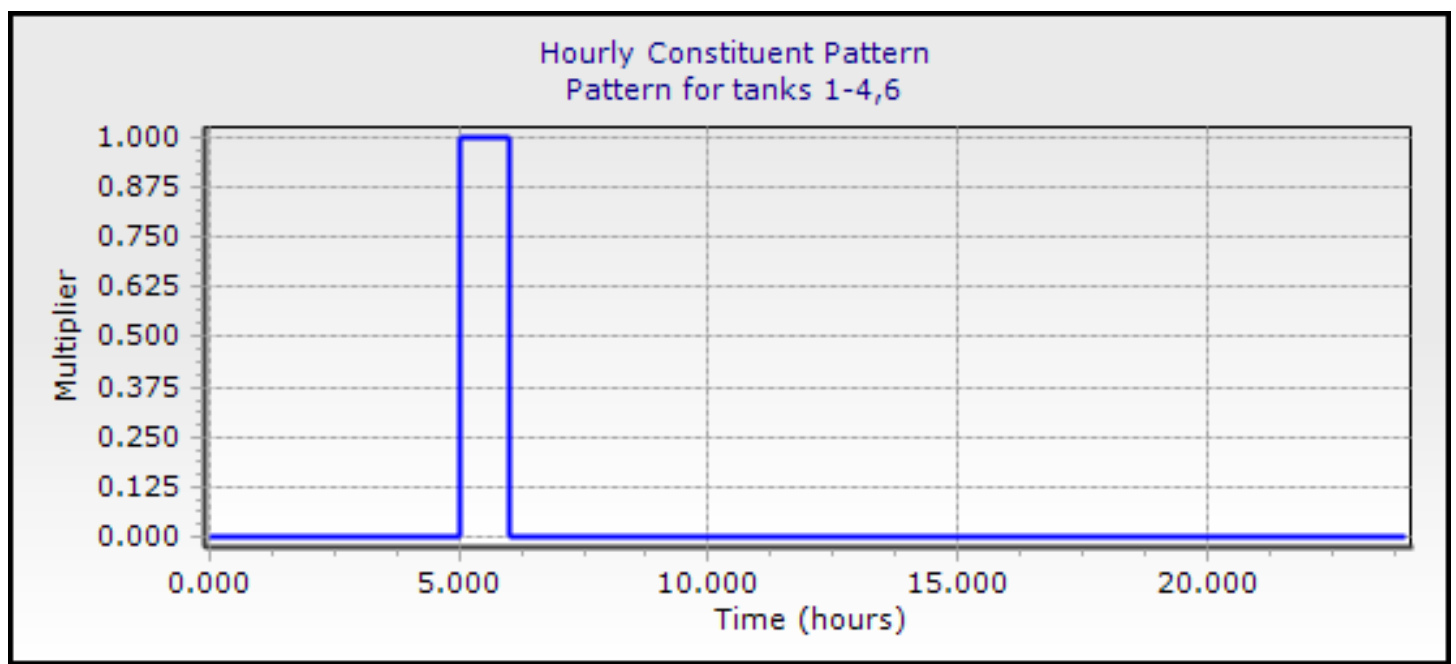

Figure 7: Constituent Pattern for Tanks 1-4 and 6

This pattern will allow the constituent to release for one hour duration at the specified mass flow rate and location.

\subsection{Analysis Simulation}

Once the scenarios, constituent properties and release locations have been input into WaterCAD ${ }^{\circledR}$, the constituent simulation is ready to be performed. The simulation is set up to an extended period simulation (EPS), with the correct duration and desired time steps within the calculation options menu. The analysis type must also be switched from a hydraulics analysis to a constituent analysis in order for the concentrations to be recorded. Then, the scenarios can be run through the batch feature in the scenarios editor. The resulting concentration values of the contaminant spread can then be viewed in the flex tables. This may require the user to add a "concentration (calculated)" data column in the flex tables using the edit table feature in order to view the results.

A better way to view the results in a holistic manner is through the incorporation of color coding within WaterCAD ${ }^{\circledR}$. The "Concentration (Calculated)" field can be 
selected as well as various color thresholds for varying concentration values. A before and after screen shot of the color coding effects is shown in Figure 8 below. Figure 8 shows the spread of the contaminant in the system after one hour of contamination. Green pipelines indicate that there is no contaminant within the pipeline. Red pipelines indicate a concentration greater than $250,000 \mathrm{mg} / \mathrm{L}$ within the pipeline. This provides a qualitative view of the overall spread of the contamination event and its severity for each hour of simulation. The simulation hour can be changed using the time browser in WaterCAD ${ }^{\circledR}$, yielding an updated contamination spread with color coding as well.

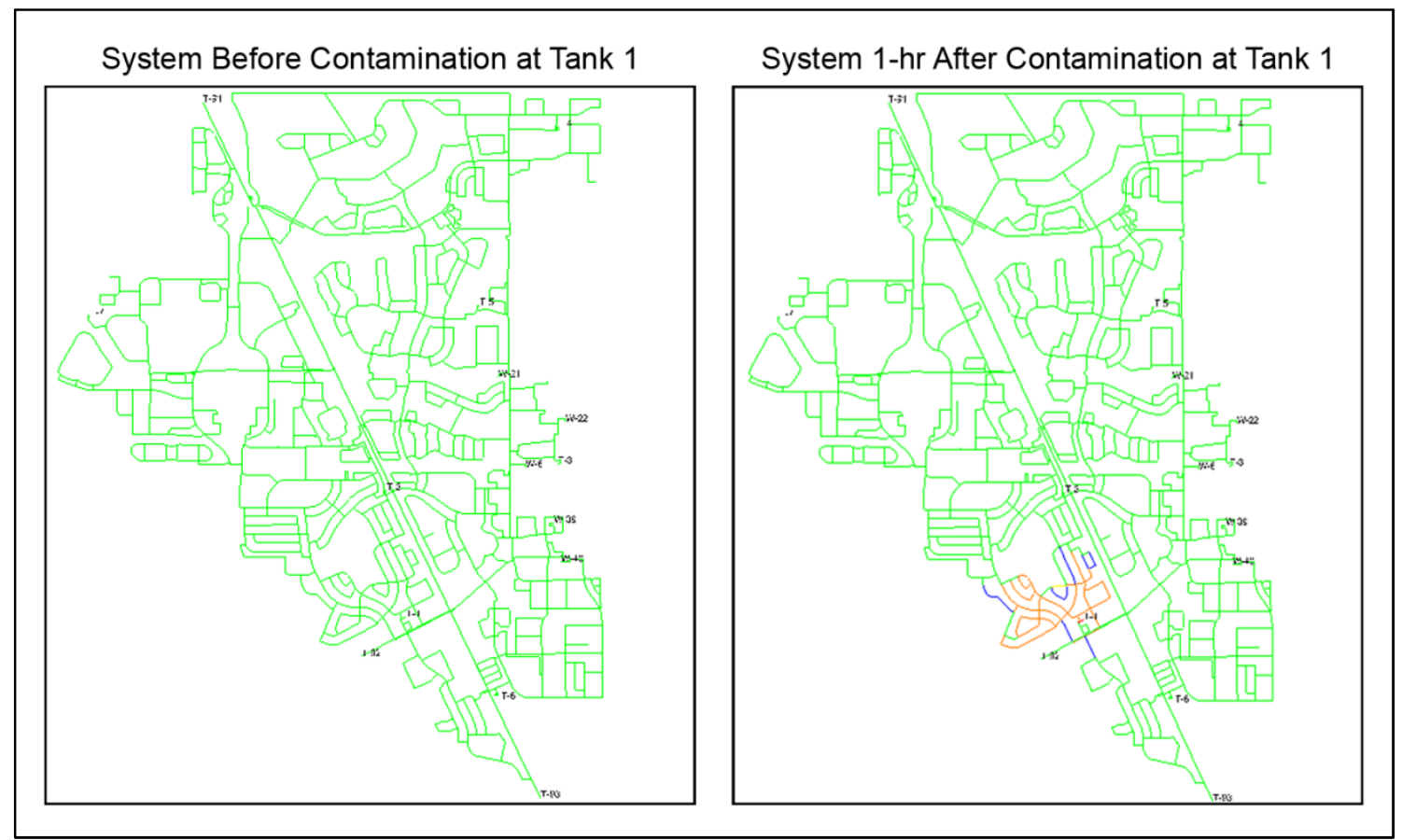

Figure 8: Movement of a contaminant through a distribution system 


\section{CHAPTER VII: RESULTS AND DISCUSSION}

\subsection{Exporting WaterCAD ${ }^{\circledR}$ Results to Excel}

WaterCAD ${ }^{\circledR}$ has a feature to export a flex table's data set into various formats including a compatible excel format. First the results of the flex tables were modified to include only concentration data for the Junctions. The junction flex table was selected and filtered using the edit button at the top of the table. All categories from the right hand table except for the label and concentration (calculated) categories were removed in order to limit the data, and file size, that the export would include. The file was exported by using the report drop-down arrow at the top of the flex table and selecting the option to report all time steps. After creating the report, the file was converted into an excel format through the export feature of the report. The newly created excel file was named appropriately for ease of tracking data for each scenario and the process was repeated for each scenario that has been created in $\mathrm{WaterCAD}^{\circledR}$.

With the current V8i version of WaterCAD ${ }^{\circledR}$, the export feature, although functional, does not yield a data set that is clean and easily configurable to application in Excel. To counteract the formatting that $\mathrm{WaterCAD}^{\circledR}$ exports, a macro was developed in excel in order to open the raw $\mathrm{WaterCAD}^{\circledR}$ file to convert and relocate the contamination data into a more useful form. The macro was developed by first reorganizing and reformatting the data of one $\mathrm{WaterCAD}^{\circledR}$ export file by hand, while recording the keystrokes and commands via the macro record feature in Excel. The partial chart in Table 9 illustrates the format that is desired where the various nodes are in the first column with their corresponding concentration readings at the various time steps. 
Table 9: Desired Format after converting WaterCAD ${ }^{\circledR}$ output via Excel Macro

\begin{tabular}{ccccccc}
\hline \multirow{2}{*}{ NODE } & \multicolumn{7}{c}{ Time Step (hours) } \\
\cline { 2 - 7 } & $\mathbf{0}$ & $\mathbf{1}$ & $\mathbf{2}$ & $\mathbf{3}$ & $\mathbf{4}$ & $\mathbf{5}$ \\
\hline BP-90_ND & 0 & 0 & 0 & 0 & 0 & 0 \\
BP-90_NU & 0 & 0 & 0 & 0 & 0 & 0 \\
J3000 & 0 & 0 & 0 & 0 & 0 & 0 \\
$\mathbf{J 3 0 0 5}$ & 0 & 0 & 0 & 0 & 0 & 0 \\
$\mathbf{J 3 0 1 0}$ & 0 & 0 & 0 & 0 & 0 & 0 \\
$\mathbf{J 3 0 1 5}$ & 0 & 0 & 0 & 0 & 0 & 0 \\
$\mathbf{J 3 0 2 0}$ & 0 & 0 & 0 & 0 & 0 & 0 \\
$\mathbf{J 3 0 2 5}$ & 0 & 0 & 0 & 0 & 0 & 0 \\
$\mathbf{J 3 0 3 0}$ & 0 & 0 & 0 & 0 & 0 & 0 \\
$\mathbf{J 3 0 3 5}$ & 0 & 0 & 0 & 0 & 0 & 0 \\
$\mathbf{J 3 0 4 0}$ & 0 & 0 & 0 & 0 & 0 & 0 \\
\hline
\end{tabular}

The macro was applied to a button, which can be found in the developer tab in Excel, for quick use when the other WaterCAD ${ }^{\circledR}$ files were imported for adjustment. Another issue that was encountered from the WaterCAD ${ }^{\circledR}$ formatting was that the data was formatted as text instead of as a number. This will pose problems if any of the data is used in formulas which require numerical values, and can potentially give invalid results. These were reformatted as numerical values within excel to mitigate the potential formulaic errors due to numbers stored as text.

\subsection{Data Processing in Excel}

Now that the data is organized by the macro that was outlined above, it can be processed using the COUNTIF function in excel. COUNTIF will count a specified cell based on the criteria specified. The specified criteria will depend on the minimum thresholds that a sensor can read. The minimum concentration threshold can be taken as $1.0 \mathrm{mg} / \mathrm{L}$ (USEPA 2009a). Therefore, the COUNTIF should be set as follows: COUNTIF (CELLRANGE, “>1”) 
The cell range is the row of concentration values for a particular node. The quotation marks surrounding the specified requirement should be noted. If these quotations are omitted, then the equation will result in an error. A partial example of the COUNTIF summary tables is given in Table 10. This should be done for each injection point. Since the injection points for this research were the tanks, each tank has a COUNTIF summary table like the one below (Table 10).

\section{Table 10: COUNTIF Summary Table (Partial)}

\begin{tabular}{cc}
\hline \multicolumn{2}{c}{ Tank 1 } \\
\hline NODE & Count \\
\hline J3780 & 17 \\
$\mathrm{~J} 3810$ & 16 \\
$\mathrm{~J} 3745$ & 14 \\
$\mathrm{~J} 5740$ & 14 \\
$\mathrm{~J} 5735$ & 13 \\
$\mathrm{~J} 3535$ & 12 \\
$\mathrm{~J} 3670$ & 12 \\
$\mathrm{~J} 3735$ & 12 \\
$\mathrm{~J} 3740$ & 12 \\
$\mathrm{~J} 3765$ & 12 \\
\hline
\end{tabular}

\subsection{Data Sorting}

Once the COUNTIF summary tables have been completed for each of the injection nodes, they can then be sorted to display the node with the highest frequency of contamination counts. This is accomplished by first highlighting both the NODE column and the COUNT column. Then under the DATA tab in the excel ribbon there is a button labeled SORT. A message in excel will then require the user to select how to sort the data. Depending on the organization of the data, the selection may differ than in this study. In the COLUMN input, the COUNTIF values were selected as the primary column to sort. In the SORT ON input, the default selection of VALUES was left as the chosen 
input. Finally for the ORDER input, the LARGEST TO SMALLEST option was chosen. The data is now sorted with the node having the highest number of contamination counts at the top of the summary table. The various tables can now be combined based on the desired scenarios in order to obtain the nodes with the highest efficiency for each scenario. The results of the analysis are shown visually through pipe and node network maps in Appendix A. These maps are provided for each scenario and the nodes are highlighted that detected the highest number of contaminant concentrations over a twenty four hour period. This time period fluctuates based on which tank is used to distribute the contaminant. This fluctuation is due to the varied tank pumping schedules previously referred to in Chapter 5.

\subsection{Discussion of Results}

All of the following graphics are color coded depicting the nodes with the highest number of contamination detections in the analysis. Therefore, all graphics in chapter 7 will follow the general legend shown in figure 9. This indicates that nodes color coded red detected a contaminant more times than any other node in the system during the 24 hour duration. Nodes with colors other than red identified in figure 9 , had fewer of contamination detections over the same duration, but were still significant as compared to the vast majority of nodes in the system. Nodes which do not have color coding either did not detect a contamination during the analysis or were deemed to be below the threshold for significant contamination counts. The number of color coded nodes depended on the scenario. Enough nodes were color coded to show the significant zones in the system where optimal nodes could be located. Larger views of all scenarios are located in Appendix A. 


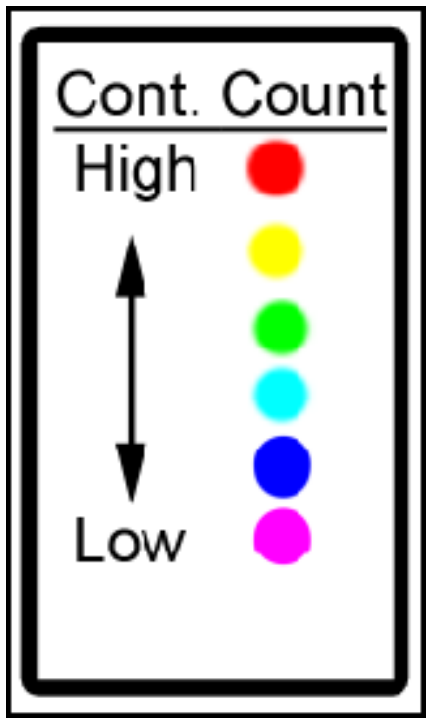

Figure 9: Frequency of detected contaminations above the minimum threshold at a particular node

\subsubsection{All Tanks Active Scenario (Scenario 4)}

What became apparent from the results is that there seemed to be three zones in the system where nodes were frequently seen as having a high amount of detections. This includes a series of pipe loops near the center of the model and a longer stretch of pipeline on the northeastern portion of the model and shown in Figure 10.

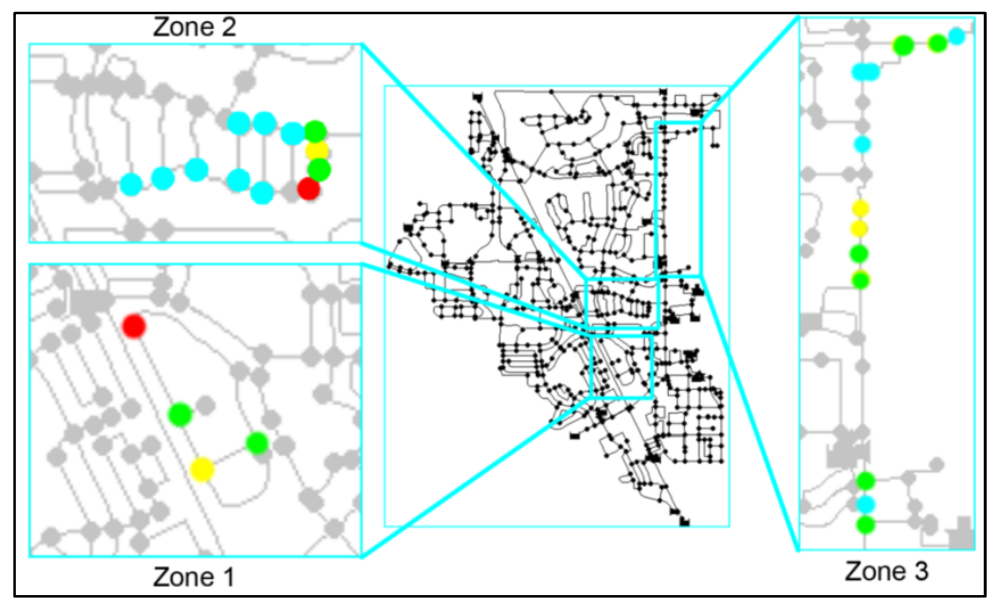

Figure 10: High Priority Zones for the CITY to implement Monitoring 


\subsubsection{Tank Combinations Based on Boost Schedule (Scenario 3)}

The scenarios outlined in this section are most indicative of a contamination event because the scenarios combine the tanks which operate on the same schedules based on the pumping schedules. This would assume that each tank in the pairing is contaminated with the constituent and would be indicative of a case where terrorist compromise all tanks in the system. In this case, when the various tank pairings became active, it would be expected to see the results shown here.

\subsubsection{Tanks 1 and 3}

According to the pumping schedule used to calibrate the model, tanks 1 and 3 operate on the same schedule. They are active on Thursdays and Sundays starting at 5:00AM. Figure 11 illustrates the results were clustered around two sections of the system.

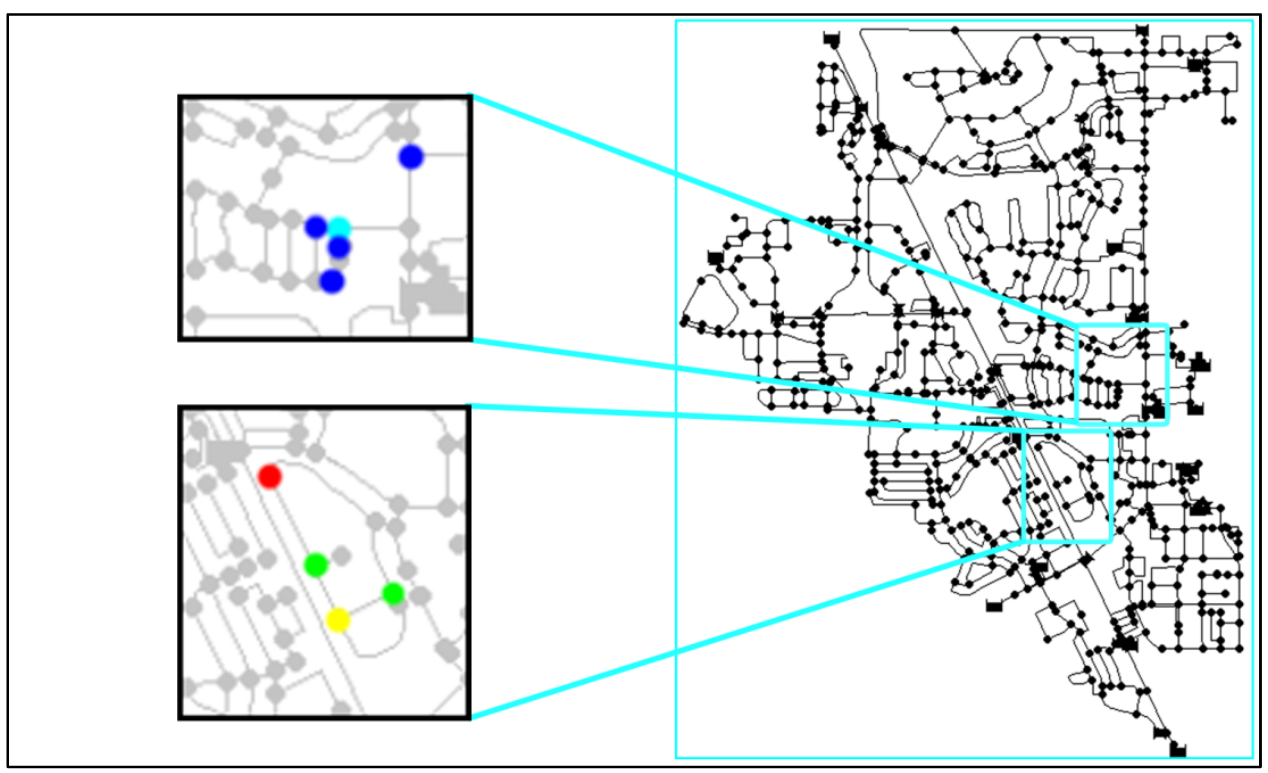

Figure 11: Optimal Sensor Points for Tanks 1 and 3 combined (Full Concentration) 
Comparing figure 11 to figure 12 , we can see that the change in concentration of the contaminant did not have a significant impact on the optimal node locations. In both scenarios, the two zones of high detection counts were the same, with only a slight variability in the particular nodes color coding assignments.

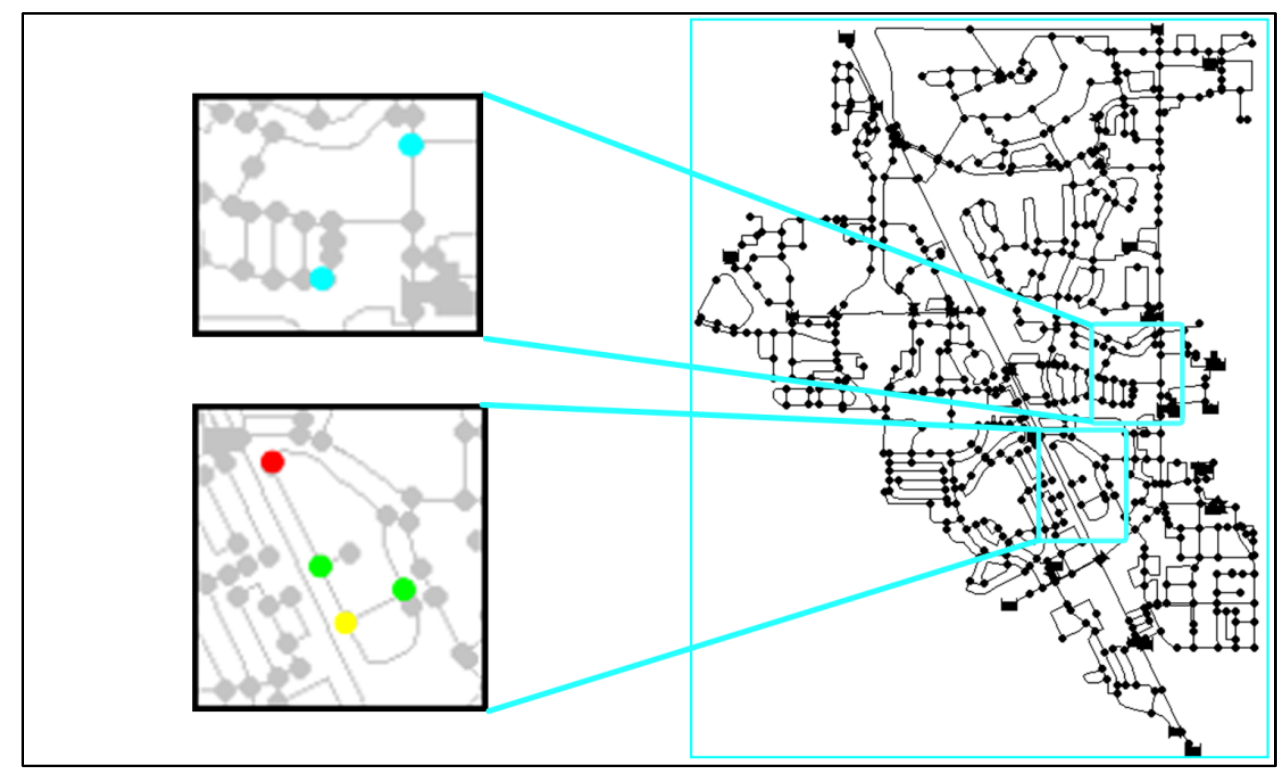

Figure 12: Optimal Sensor Points for Tanks 1 and 3 combined (Half Concentration)

\subsubsection{Tanks 2 and 4}

Tanks 2 and 4 operate on the same schedule and are active on Tuesdays and Saturdays starting at 5:00AM. Figure 13 shows the zones of significance during a full concentration scenario. It is important to note that the effect of tank 4 is not seen in figures 13 and 14, as the spread from tank 4 is well contained in the northeast part of the system and is expelled quickly through user outflows. The concentration change also did not have a substantial effect on the optimal sensor locations, as both figures 13 and 14 demonstrate that roughly the same locations were obtained in both scenarios. 


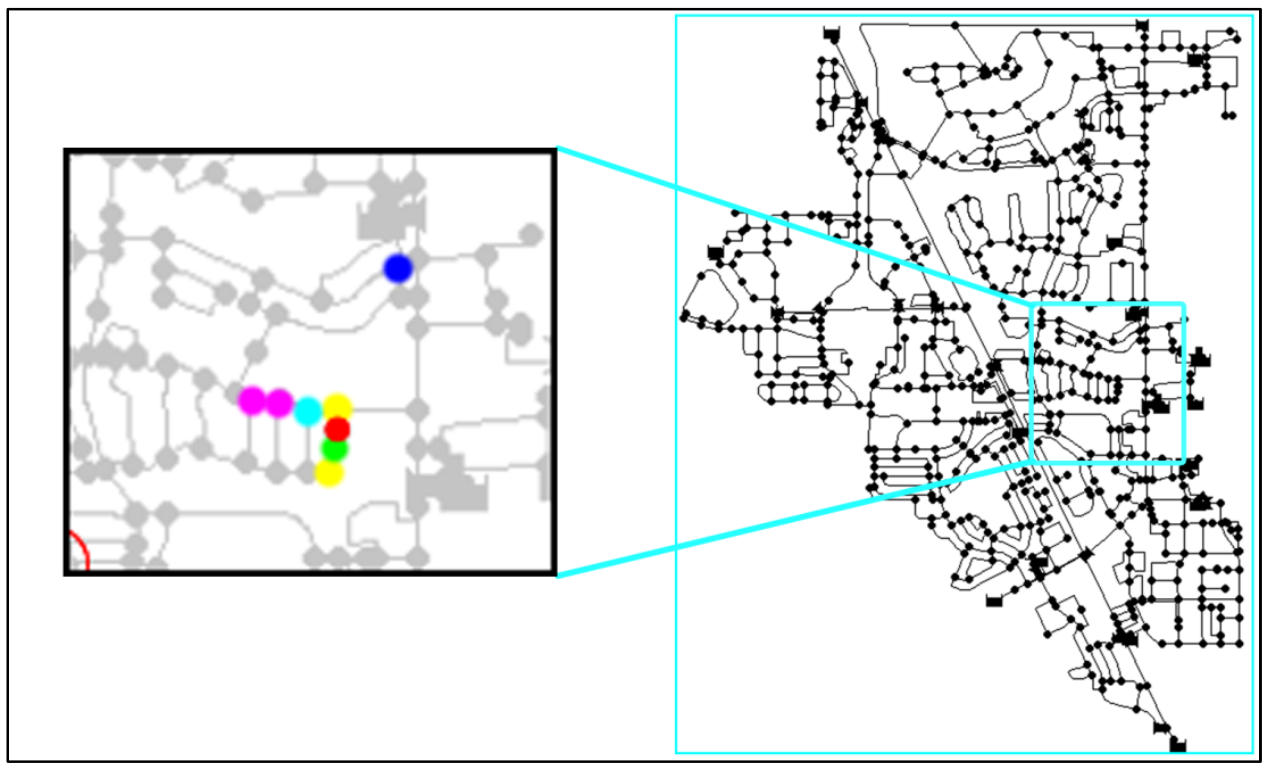

Figure 13: Optimal Sensor Points for Tanks 2 and 4 combined (Full Concentration)

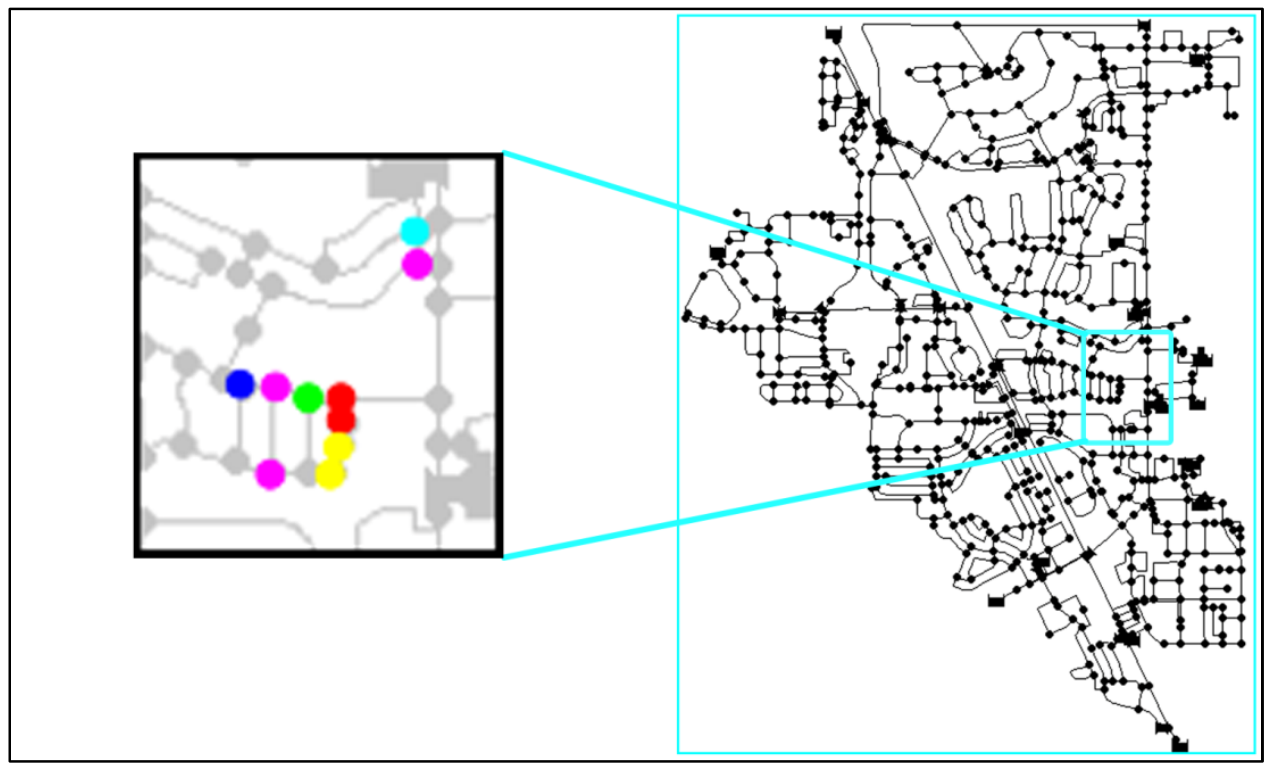

Figure 14: Optimal Sensor Points for Tanks 2 and 4 combined (Half Concentration)

\subsubsection{Tanks 5, 6 and 7}

Tanks 5, 6 and 7 operate on the same schedule and are active on Mondays,

Wednesdays and Fridays. Each tank has an individual start time with Tank 5 starting at 
4:00AM, tank 6 starting at 5:00AM and tank 7 starting at 4:00PM.

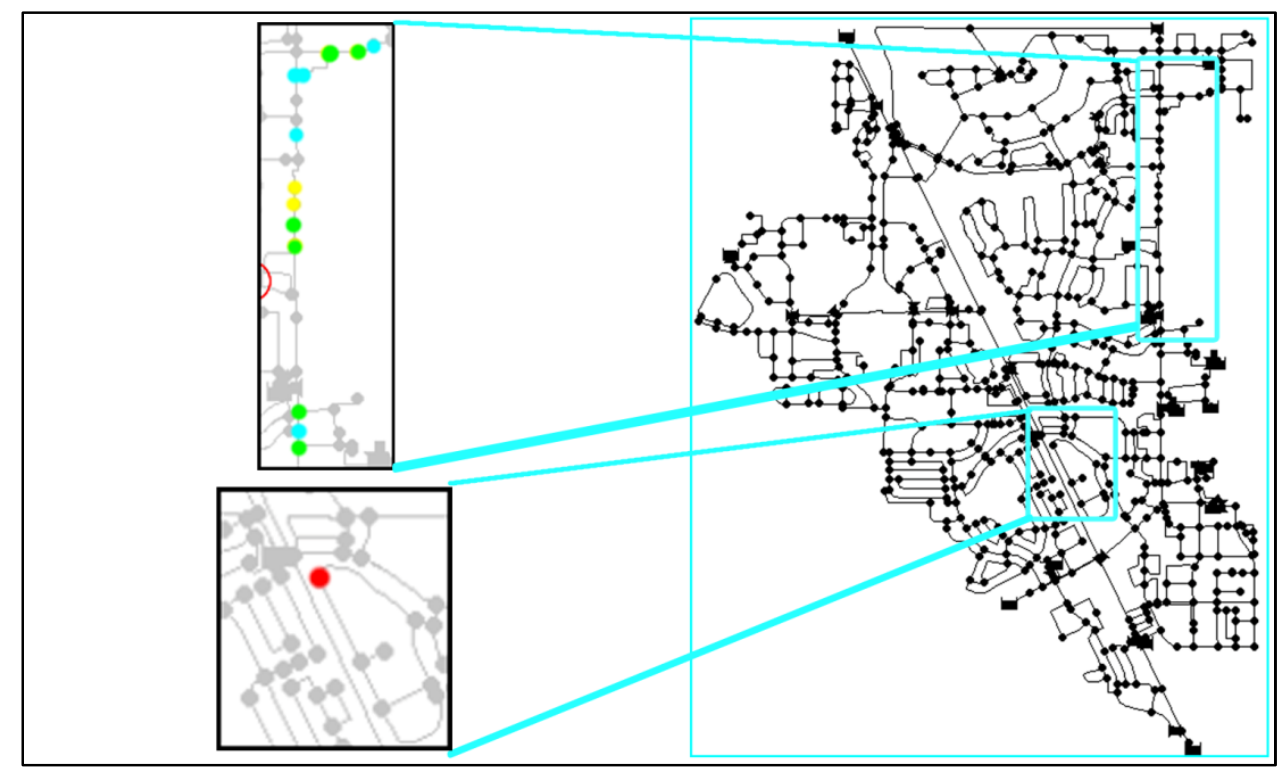

Figure 15: Optimal Sensor Points for Tanks 5, 6 and 7 combined (Full Concentration)

As we can see in figure 15, there were two main zones where the optimal nodes were concentrated. One zone simply contained the node which had the highest number of contamination counts where the other zone contained an abundance of nodes with lesser counts. One of the reasons for this spread of optimal nodes through the two zones is due to the nature of the main line in which a majority of the optimal nodes are located. This is a primary means where water is transported on the east side of the city. Therefore, if the contaminant were to move in that direction, then a majority of those nodes would be expected to have high detection counts.

We can also see that, as with the previous scenarios, the decreased concentration input did not have a significant effect on the placement of the optimal nodes. The 
concentration change did affect was the location of the node with the highest priority in some instances, while the zones of significance remained unchanged.

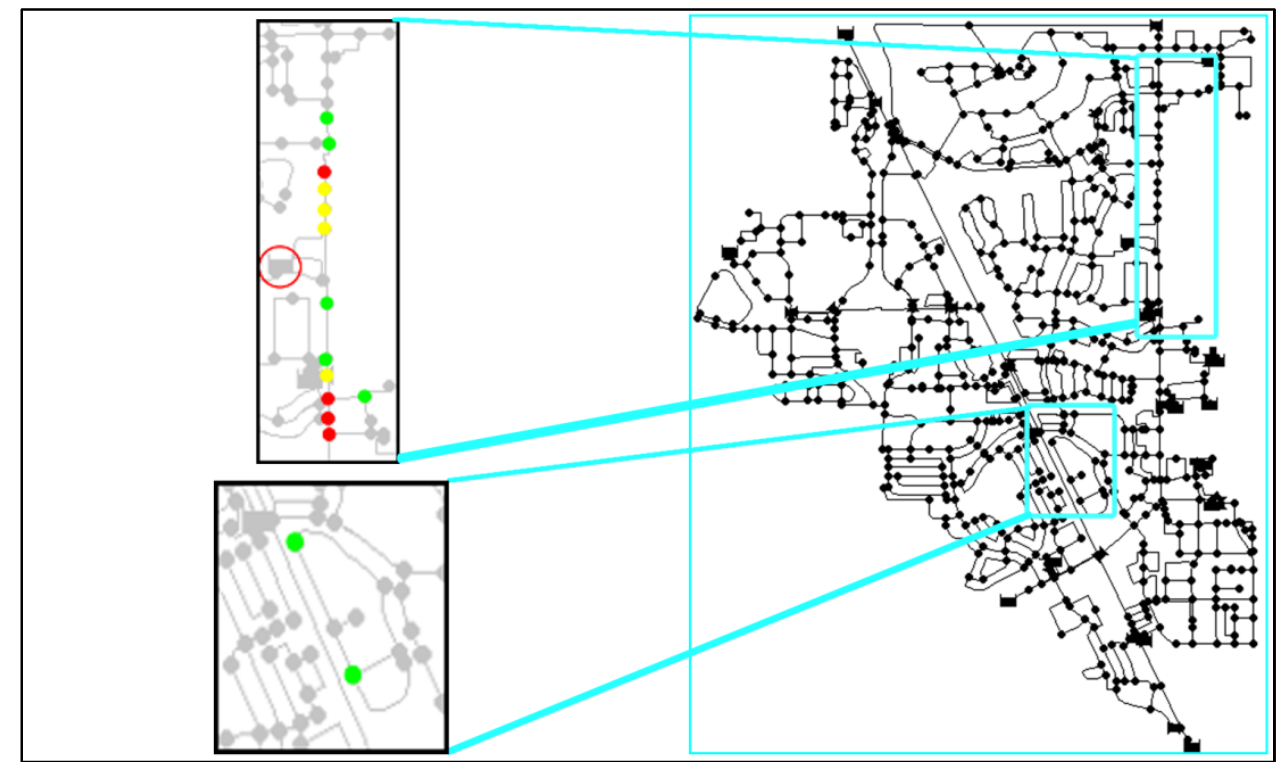

Figure 16: Optimal Sensor Points for Tanks 5, 6 and 7 combined (Half Concentration)

\subsubsection{Individual Tanks (Scenarios 1 and 2)}

Appendix B shows zones of significance for each individual tank scenario. These scenarios by themselves could be indicative of real world expectations if terrorists only contaminate one of the tanks in the system. This will also show which tanks have the most effect on the system.

\subsection{Summary of Results}

As we can see from the results, the change in the injection concentration amount did not have a significant effect on the optimal sensor locations. The effect, if any, was that for a few scenarios the optimal node would change depending on the decrease in injection concentration. The new optimal node would come from the same pool of 
efficient nodes. In other words, the zones where the clusters of nodes were identified did not change in any scenario when the injection concentration was halved. Figure 10 is the most telling of the overall results as it shows the three zones of significance which contained optimal sensor locations in a majority of the contamination scenarios. Of the twenty two scenarios, only four had a majority of their optimal sensor locations outside of the zones of significance shown in Figure 10. These were:

- Tank 4 (Full Concentration)

- Tank 4 (Half Concentration)

- $\quad$ Tank 7 (Full Concentration)

- Tank 7 (Half Concentration)

The potential reasons for these deviations are as follows: For the two Tank 4 scenarios, the reason the optimal sensor points deviate is because the extent of the Tank 4's influence on the system is relatively small. Note from figures 31 and 32 in Appendix A, that the extent of the Tank 4 contamination is isolated in the northeast corner of the distribution system. The reason for this isolation is due to the hydraulics of the system as well as the outflow from users of the system.

Tank 7's range of influence on the system is similar and tends to remain along the western portion of the CITY. Shown in Figures 37 and 38, the spread of the contaminant remains on western and southwestern portions of the distribution system. This is due to the configuration of the distribution system and is highly influenced by the major highway which runs northwest through the center of the system. This effectively isolates the western and eastern portions of the distribution from each other. More importantly, 
the hydraulics of the system also isolates the spread of the contaminant by containing it in the western portion of the system. This phenomenon occurs in all scenarios, but seems more prominent for the Tank 4 and Tank 7 scenarios.

\subsection{Recommendations}

A single optimal point for the system is not feasible to identify because of the vast amount of variables involved. However, the zones of significance which are outlined for each scenario dictate the cluster of optimal nodes which would provide robust coverage of the system in regards to monitoring. Figures 10-16 and 39-52, should therefore be used as guides for the optimal placement of sensors in the WDS. As previously identified, the quantity of sensors will ultimately drive the location of placement. This will depend on the economic feasibility of using multiple monitoring sensors. 


\section{CHAPTER VIII: FUTURE STEPS}

Although the given model was calibrated for the hydraulics of the system by changing the fixed grade elevations of the tanks, a calibration could also be performed for the constituent transport. Chlorine residuals taken at the end points of the water distribution system could be compared to the constituent transport model using chlorine as the "contaminant". This would confirm or dispute the contamination transport model that is being used to predict the optimal sensor point locations for all scenarios. This would involve correctly inputting the properties of the chlorine residual into the constituent properties manager and should include bulk reaction rates, wall reaction rates, as well as the diffusivity coefficient and initial concentration of the residual. Once the scenario is run for the chlorine residual, it could then be compared to actual chlorine residual data gathered from end-point testing.

Other forms of distribution vulnerability should also be explored to fully address the likely consequences of other potential forms of terrorist activity. One such analysis could be a pipe break scenario in order to determine the critical pipes in the distribution system. These types of analyses should explore the other vulnerabilities of the system in order to gleam insight into the possible outcomes if contamination is not the primary intent. This is where the accessibility of the various hydraulic structures will be crucial in identifying the points where physical damage has the highest likelihood of occurring. Treatment plants and major pumping structures are of concern (Deininger et al. (2000). Electrical structures are also of high importance due to the fact that their interruption could cause various failures and disruptions in water delivery of most distribution systems. Reserve generators then become a secondary target of importance for the same 
reasons as the primary electrical structures. These analyses could also be expanded to disruptions and damage caused by natural phenomena such as earthquake, lightening, or flooding.

Other contaminant forms should also be explored in future research.

Cryptosporidium was selected in this study in order to choose a conservative constituent. However, it is evident that there are numerous other contaminants which are much more dangerous than Cryptosporidium. The only caveat is that most of these dangerous contaminants, having low $\mathrm{LD}_{50}$ values, are not resistant to chlorine. Research should be implemented in determining other contaminants which could be weaponized to behave similarly to Cryptosporidium but have a much lower $\mathrm{LD}_{50}$ value, corresponding to a greater risk to the system. This sort of information should have implemented protection from being distributed to the general public as it could be used against the system for which it is researched to protect. This is similar to Botulinus cultures, which when requested by unauthorized individuals, prompt federal authorities to follow up and monitor the use of such cultures.

Another facet of additional contamination research should include identifying properties of various constituents within pressurized water lines. Identifying properties such as diffusivity and improved decay rates would be highly advantages in modeling approaches. A majority of the research into contaminant properties focuses on contaminant movement through groundwater. This would vary dramatically from pressurized pipeline and should be explored to better understand how various constituents behave and react to the turbulent, pressurized nature of distribution lines. 
For the zones of significance identified in this study, further exploration of the node importance should be undertaken to gauge which nodes would serve as the ideal location for sensors. The importance of a node can fluctuate based on the outflow use. Nodes whose outflow use is primarily for irrigation use would be secondary in priority to nodes whose outflow was directly connected to human consumption, especially for important facilities such as hospitals. Studies should be undertaken to categorize the nodes within the zones of significance to better optimize the sensor placements.

As Chastain (2004) describes, the method itself should also be considered and modified for improvement. The primary basis for location in this method is through the time since injection value. However, a more prudent variable to consider would be the volume that a particular node consumes during analysis. This would improve the method to account more directly for adverse health impacts. 


\section{REFERENCES}

Alberti, M. Advances in Urban Ecology: Integrating Humans and Ecological Processes in Urban Ecosystems. 1-26, 2008.

American Society of Civil Engineers. Web. 10 Mar. 2012.

$<$ http://www.asce.org/default.aspx>.

American Society of Civil Engineers. Wastewater. Report Card for America's

Infrastructure. 2009. Web. 10 Mar. 2012.

$<$ http://www.infrastructurereportcard.org/>.

Boccelli, D. L., Tryby, M. E., Uber, J. G., Rossman, L. A., Zierolf, M. L., \& Polycarpou, M. M. Optimal scheduling of booster disinfection in water distribution systems. Journal of Water Resources Planning and Management, 124(2), 99-111, 1998.

Brumbelow, Kelly, Jacob Torres, Seth Guikema, Elizabeth Bristow, and Lufthansa Kanta. Virtual Cities ForWater Distribution and Infrastructure System Research. World Environmental and Water Resources Congress 2007: Restoring Our Natural Habitat (2007). Print.

Burrows, W. D., \& Renner, S. E. (1999). Biological warfare agents as threats to potable water. Environmental Health Perspectives, 107(12), 975-984.

CDC "Parasites-Cryptosporidium". Centers for Disease Control and Prevention, 10 Mar. 2011. Web. 13 June 2012. <http://www.cdc.gov/parasites/crypto/>.

Chastain, James R., A heuristic methodology for locating monitoring stations to detect contamination events in potable water distribution systems. (2004). Theses and Dissertations. Paper 988.

Clark, R.M. and Deininger, R.A. (2000). Protecting the nations critical infrastructure: the vulnerability of U.S. water supply systems. J Contingencies and Crisis Management, 8(2) 
Corso PS, Kramer MH, Blair KA, Addiss DG, Davis JP, Haddix AC. Cost of illness in the 1993 Waterborne Cryptosporidium outbreak, Milwaukee, Wisconsin. Emerg Infect Dis [serial online] 2003 Apr [date cited]. Available from: URL:http://wwwnc.cdc.gov/eid/article/9/4/02-0417.htm

Cullinane, M.J., Jr., Methodologies for the Evaluation of Water Distribution System Reliability/Availability, PhD. Dissertation, University of Texas at Austin, 1989.

Daily Times Herald, "Flesh Chunks Found In Iowa Water Lines." The Associated Press [Carroll] 25 Apr. 2005. Print.

Deininger, Rolf A., Péter Literáthy, and Jamie Bartram. Security of Public Water Supplies. Dordrecht: Kluwer, 2000. Print.

Fox, K.R. and Lytle, D.A. (1996) Milwaukee's crypto outbreak investigation and recommendations, J. Amer. Water Works Assoc. 88, 87-94.

Franke, S. Textbook of Military Chemistry: Volume2, Sabotage and Phytopoisons, Military Publishing House of the German Democratic Republic, Berline, 1977.

Haestaed Methods. (2005). WaterCAD ${ }^{\circledR}$ v8i user's guide. Waterbury, CT: Haestad Methods, Inc.

Haested Methods, Walski, Thomas M., Donald V. Chase, Dragan Savic, Walter Grayman, Stephanus Beckwith, and E. Koelle. Advanced Water Distribution Modeling and Management. Exton, PA: Bentley Institute, 2007. Print.

Haimes, Y. Y., Matalas, N. C., Lambert, J. H., Jackson, B. A., \& Fellows, J. F. (1998). Reducing vulnerability of water supply systems to attack. Journal of Infrastructure Systems, 4(4), 164-177.

Kaminski, J.C. (1994) Cryptosporidium and the Public Water Supply, New England Jour. Medicine 331(22), 1529 
Kessler, A., Ostfeld, A., \& Sinai, G. (1998). Detecting accidental contamination in municipal water networks. Journal of Water Resources Planning and Management, 124(4), 192-198.

Mays, Larry W. Water Resources Engineering. Hoboken, NJ: John Wiley, 2011. Print.

Meadows, D. H. (2008). Thinking in Systems: A Primer. 1-85

Moulton, M. (1995). Wildlife issues in a changing world, 2nd edition. CRC Press.

Pulliam, H. R., \& Johnson, B. (2002). "Ecology's New Paradigm: What Does It Offer Designers and Planners?" Ecology and Design: Frameworks of Learning.

Rossman, L.A. and Grayman, W.M., "Scale-model studies of mixing in drinking water storage tanks," Journal of Environmental Engineering, Vol. 125, No. 8, pp. 755$761,1999$.

Safe Drinking Water Act (1974) Public Law 93-523.

Spirn, A. W. (2002). "The Authority of Nature." Ecology and Design: Frameworks of Learning.

Teunis, P. F. M., Chappell, C. L., \& Okhuysen, P. C. (2002). Cryptosporidium dose response studies: Variation between isolates. Risk Analysis, 22(1), 175-183.

Toze, S., Berkele, E., Declan, P., Sidhu, J., Shackleton, M., Use of Static Quantitative Microbial Risk Assessment to determine pathogen risks in an unconfined carbonate aquifer used for Managed Aquifer Recharge, Water Research, Vol. 44, pp. 1038-1049, 2010.

Tryby, M. E., Boccelli, D. L., Uber, J. G., \& Rossman, L. A., Facility location model for booster disinfection of water supply networks. Journal of Water Resources Planning and Management, 128(5), 322-333., 2002. 
USEPA, Distribution System Water Quality Monitoring: Sensor Technology Evaluation Methodology and Results. EPA/600/R-09/076, Washington, D.C., 2009a.

USEPA, National Primary Drinking Water Standards. EPA/816/F-09/004, Washington, D.C., $2009 b$.

USEPA, Surface Water Treatment Rules: What Do They Mean to You?. EPA/816/R11/009, Washington, D.C., 2011 a.

USEPA. Research and Development.CANARY User's Manual. By D. B. Hart and S. A. Mckenna. Environmental Protection Agency, Sept. 2011b. Web.

Walker, B., \& Salt, D. (2006). Resilience Thinking: Sustaining Ecosystems and People In A Changing World. 1-63. 


\section{APPENDIX A: VISUAL RESULTS FOR EACH SCENARIO}

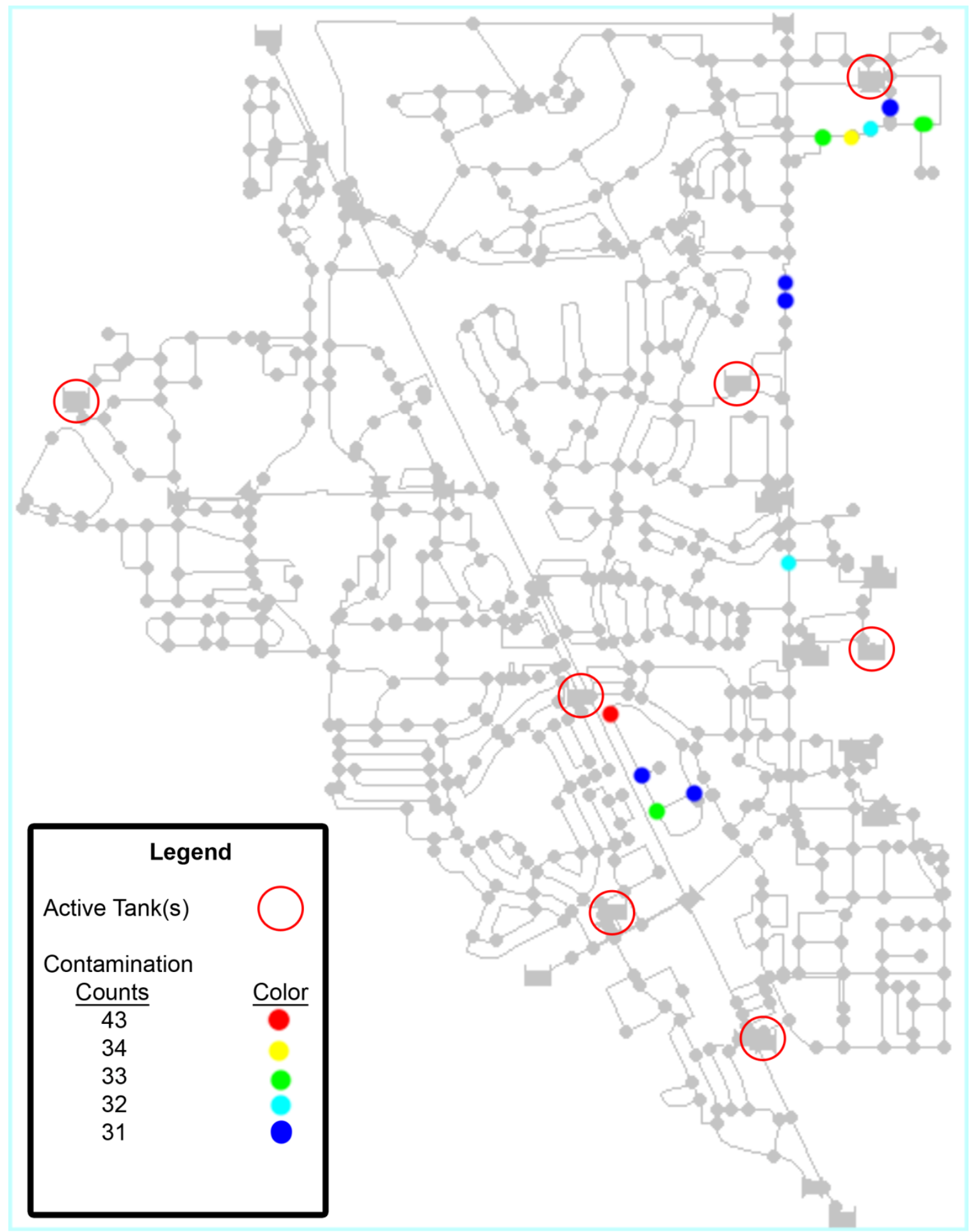

Figure 17: Optimal Sensor Points for All Tanks (Full Concentration) 


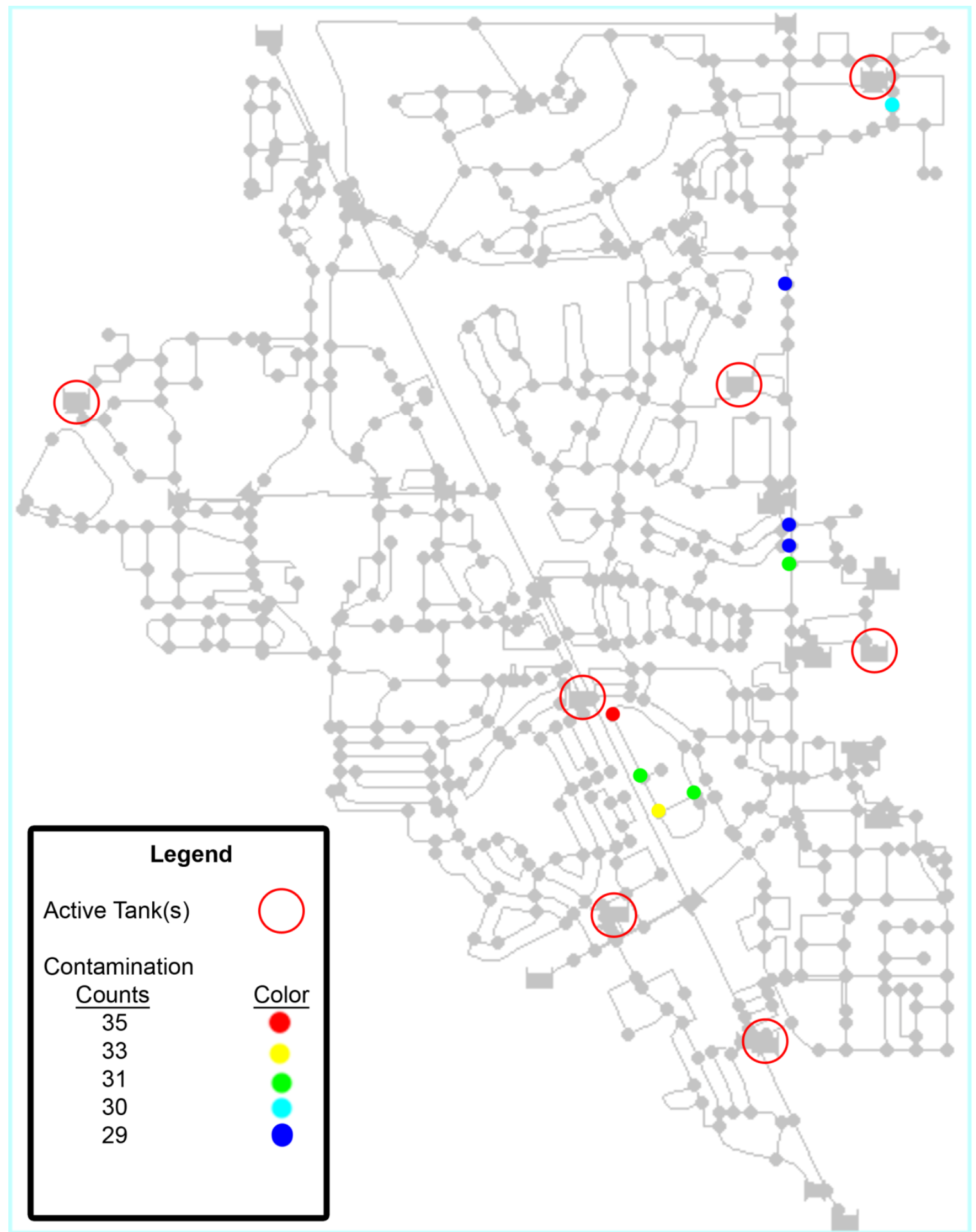

Figure 18: Optimal Sensor Points for All Tanks (Half Concentration) 


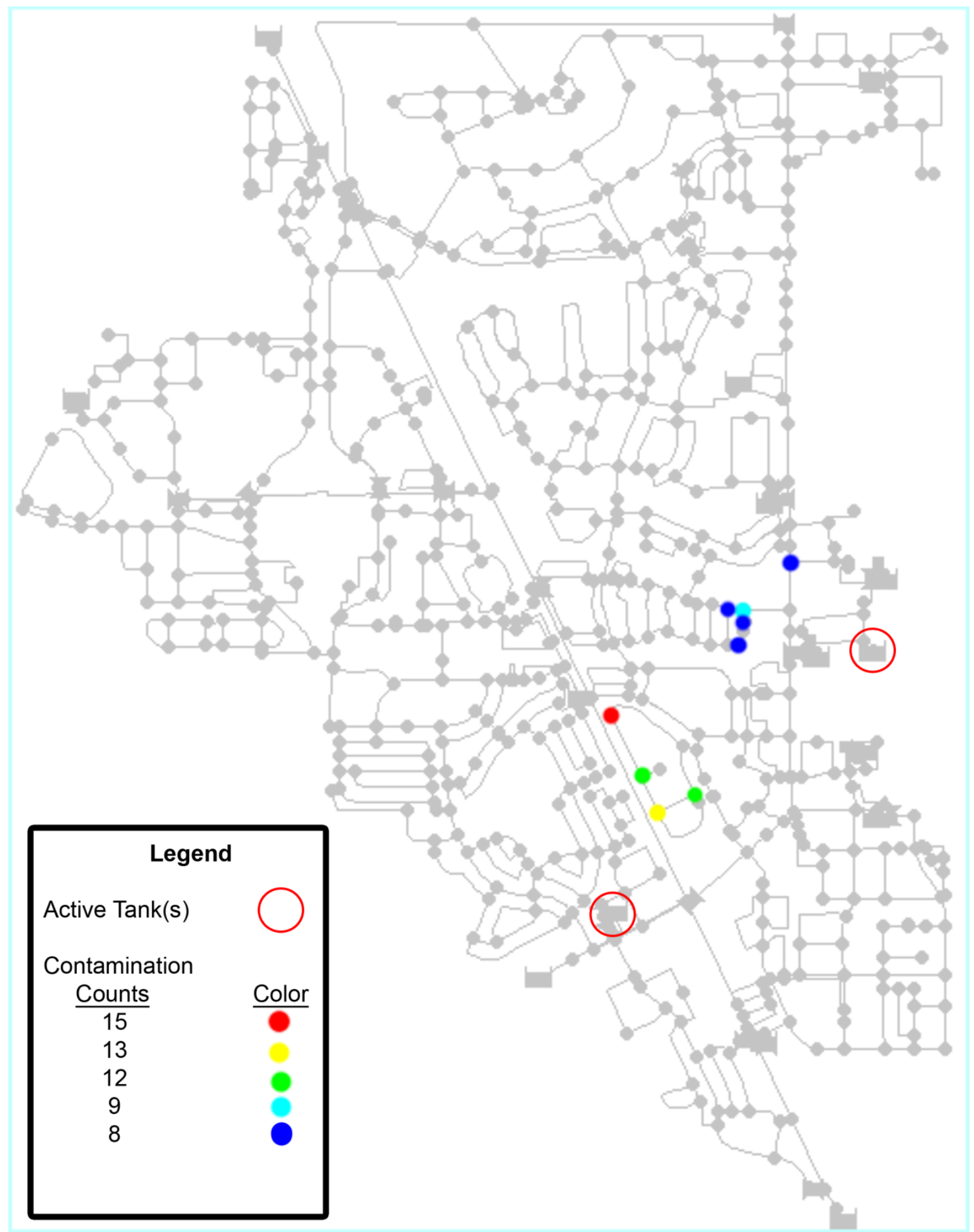

Figure 19: Optimal Sensor Points for Tanks 1 and 3 (Full Concentration) 


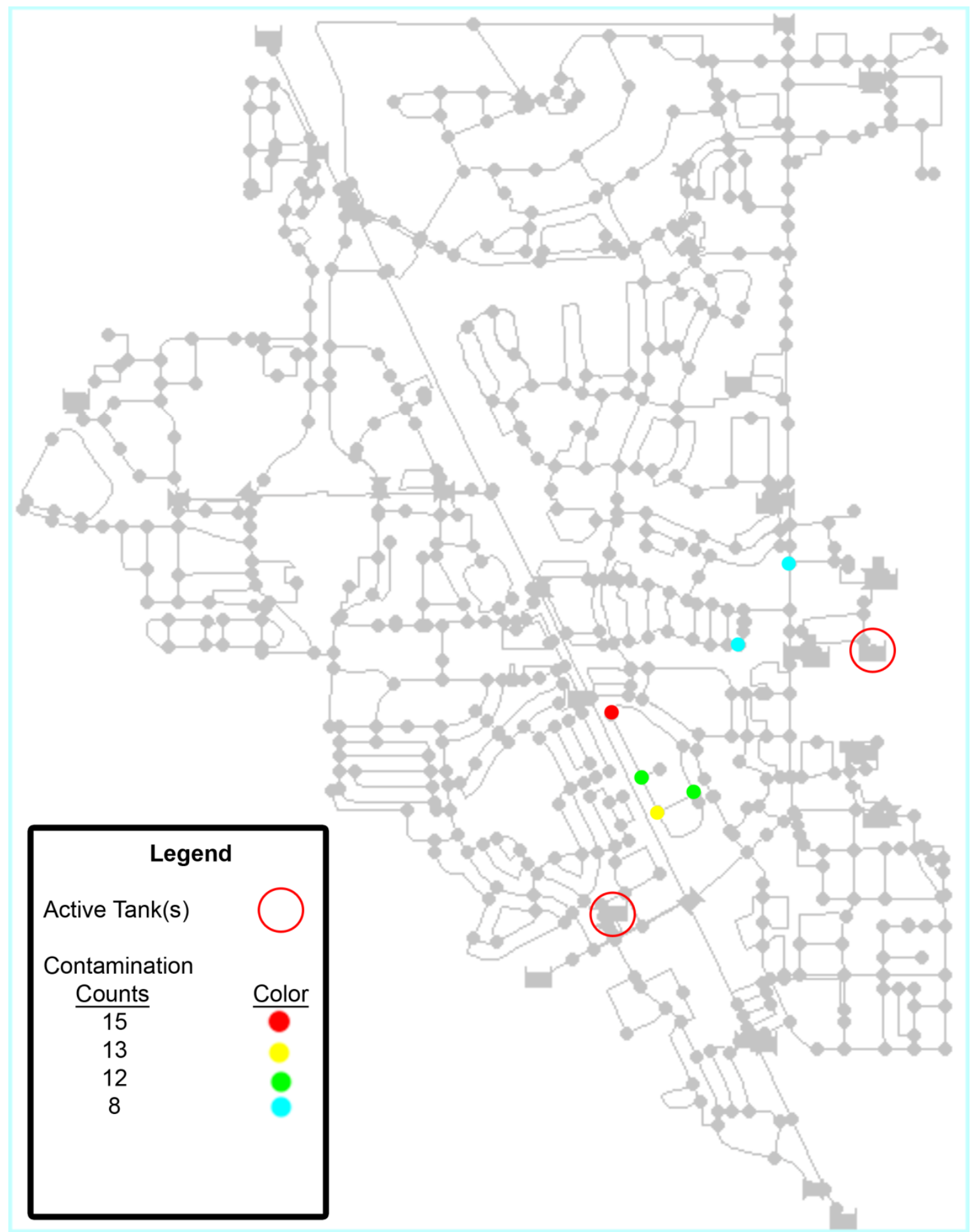

Figure 20: Optimal Sensor Points for Tanks 1 and 3 (Half Concentration) 


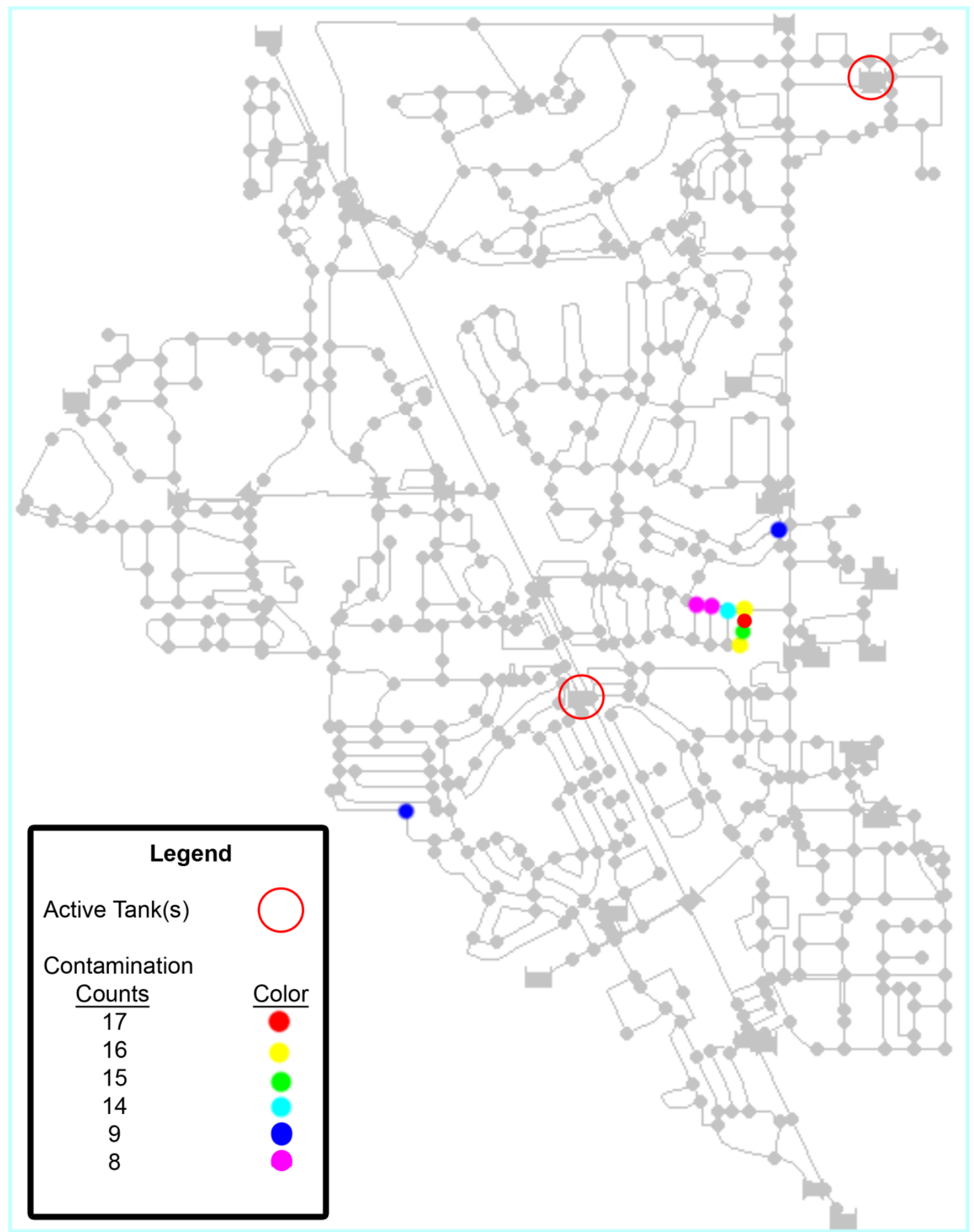

Figure 21: Optimal Sensor Points for Tanks 2 and 4 (Full Concentration) 


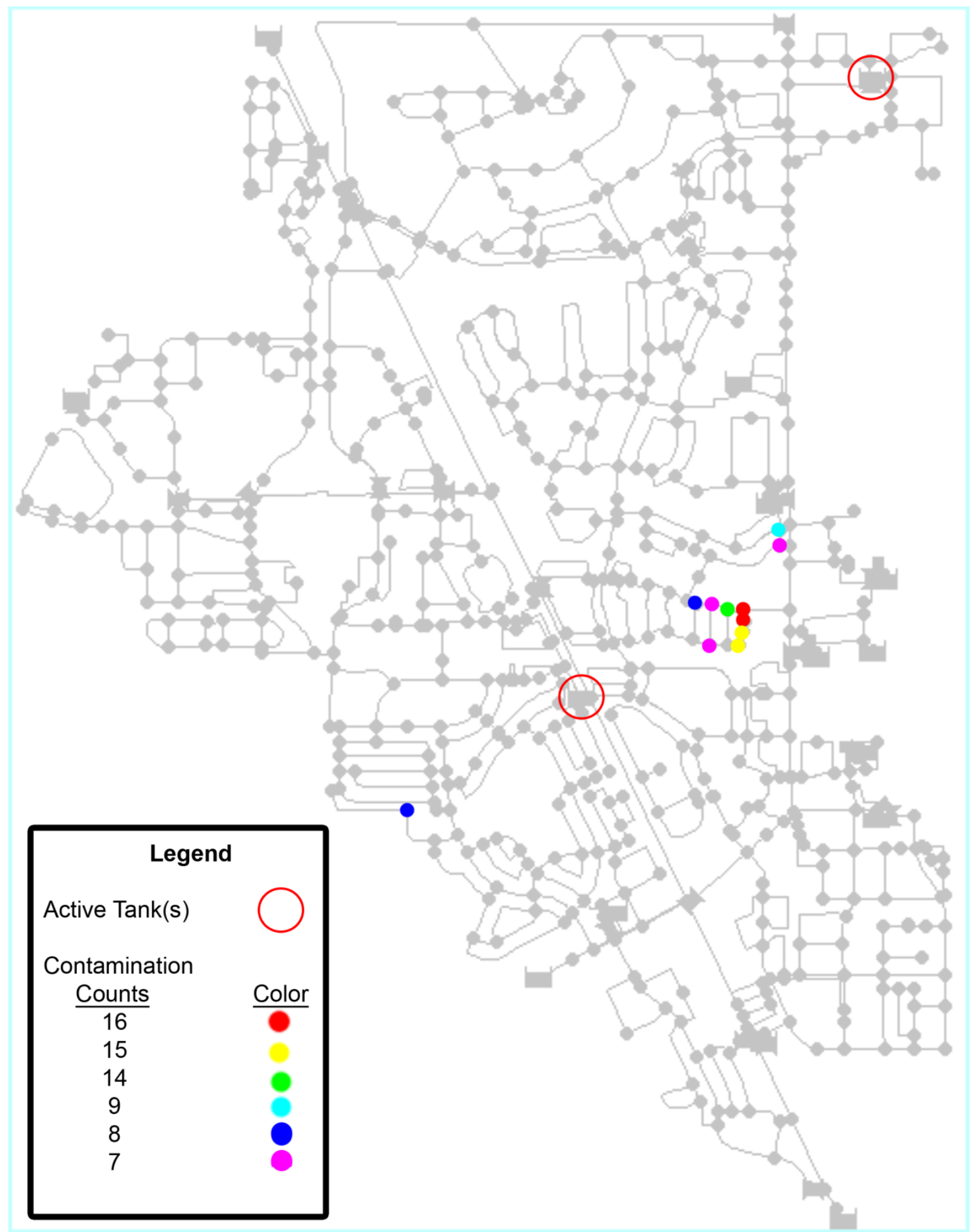

Figure 22: Optimal Sensor Points for Tanks 2 and 4 (Half Concentration) 


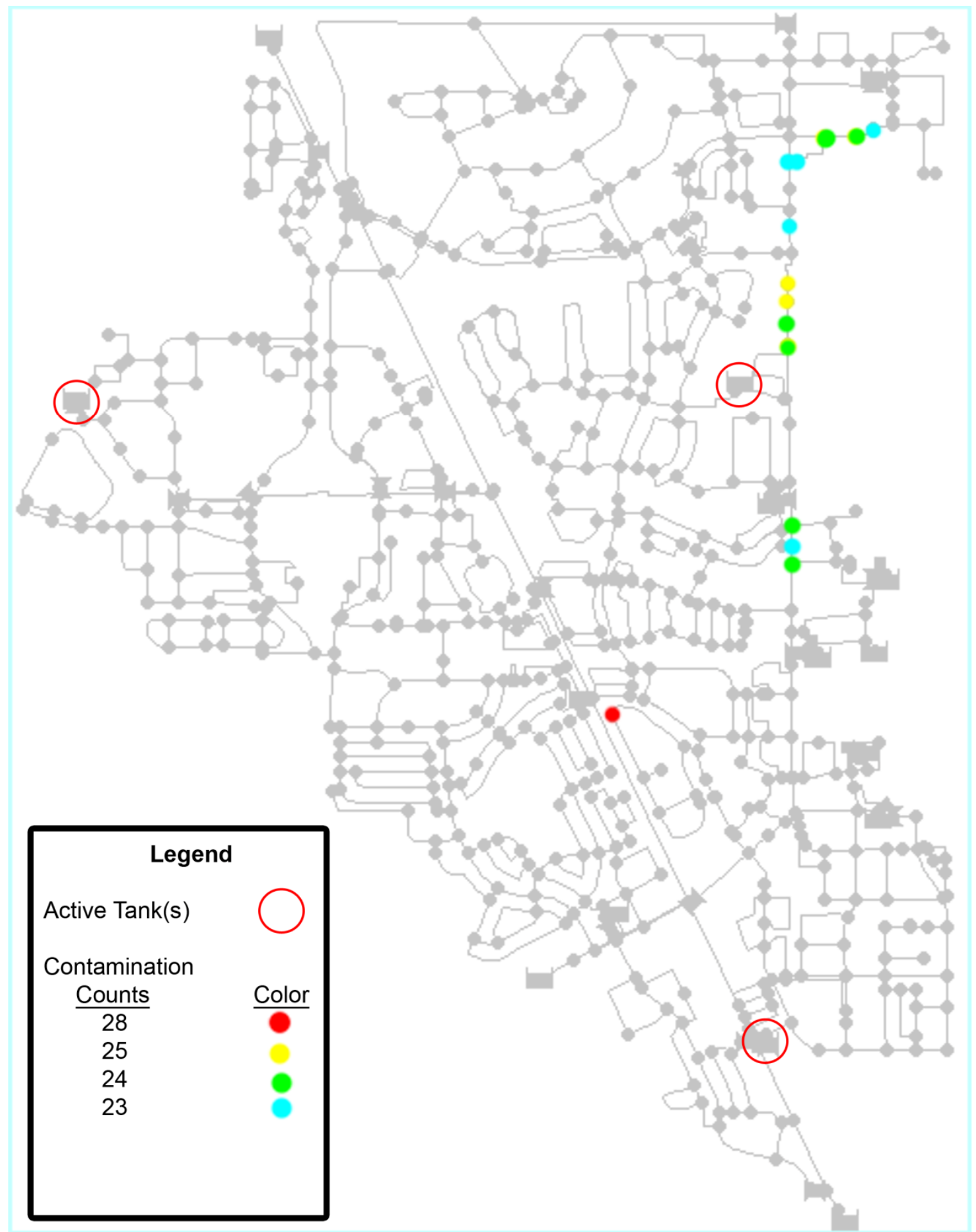

Figure 23: Optimal Sensor Points for Tanks 5, 6, and7 (Full Concentration) 


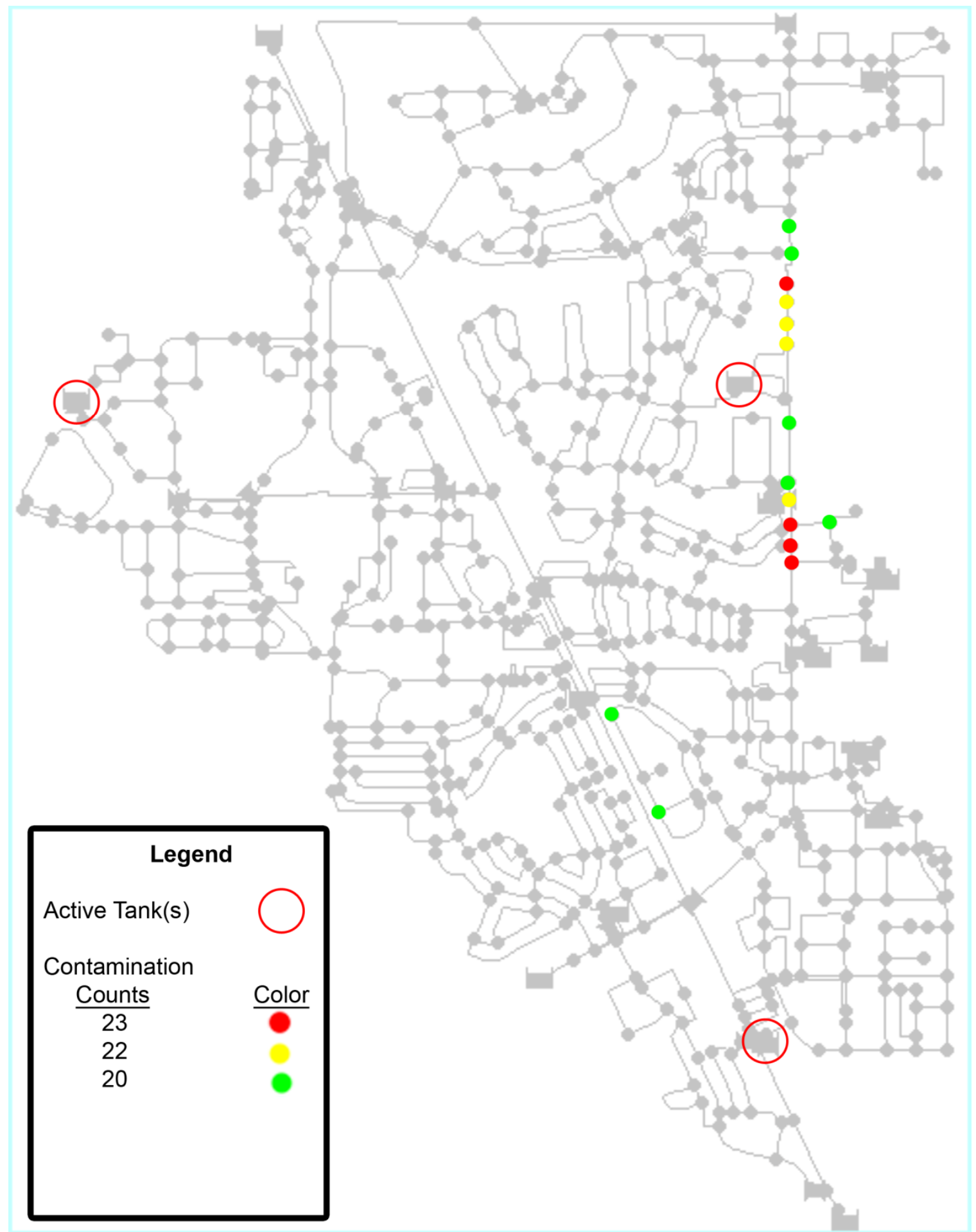

Figure 24: Optimal Sensor Points for Tanks 5, 6, and 7 (Half Concentration) 


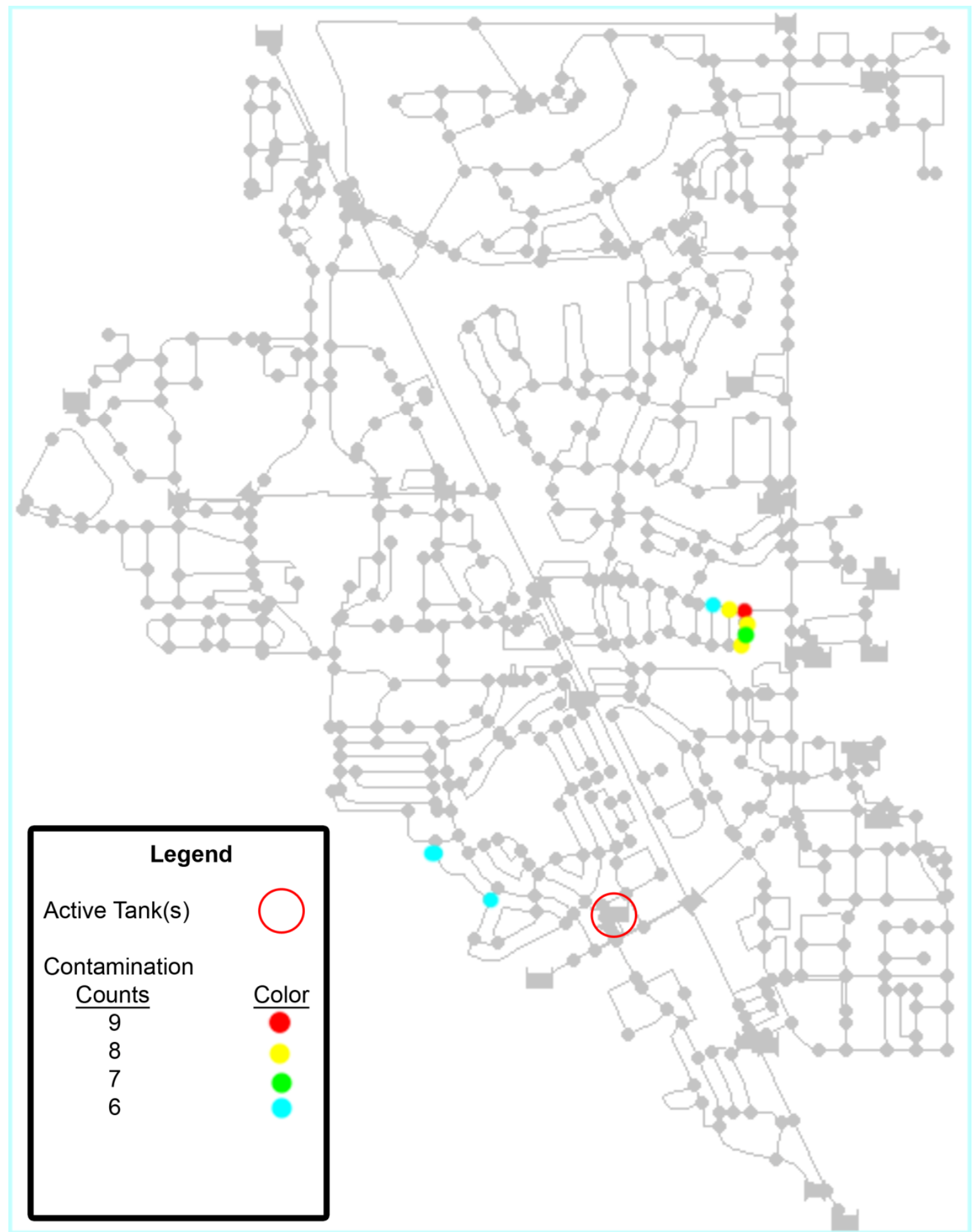

Figure 25: Optimal Sensor Points for Tank 1 (Full Concentration) 


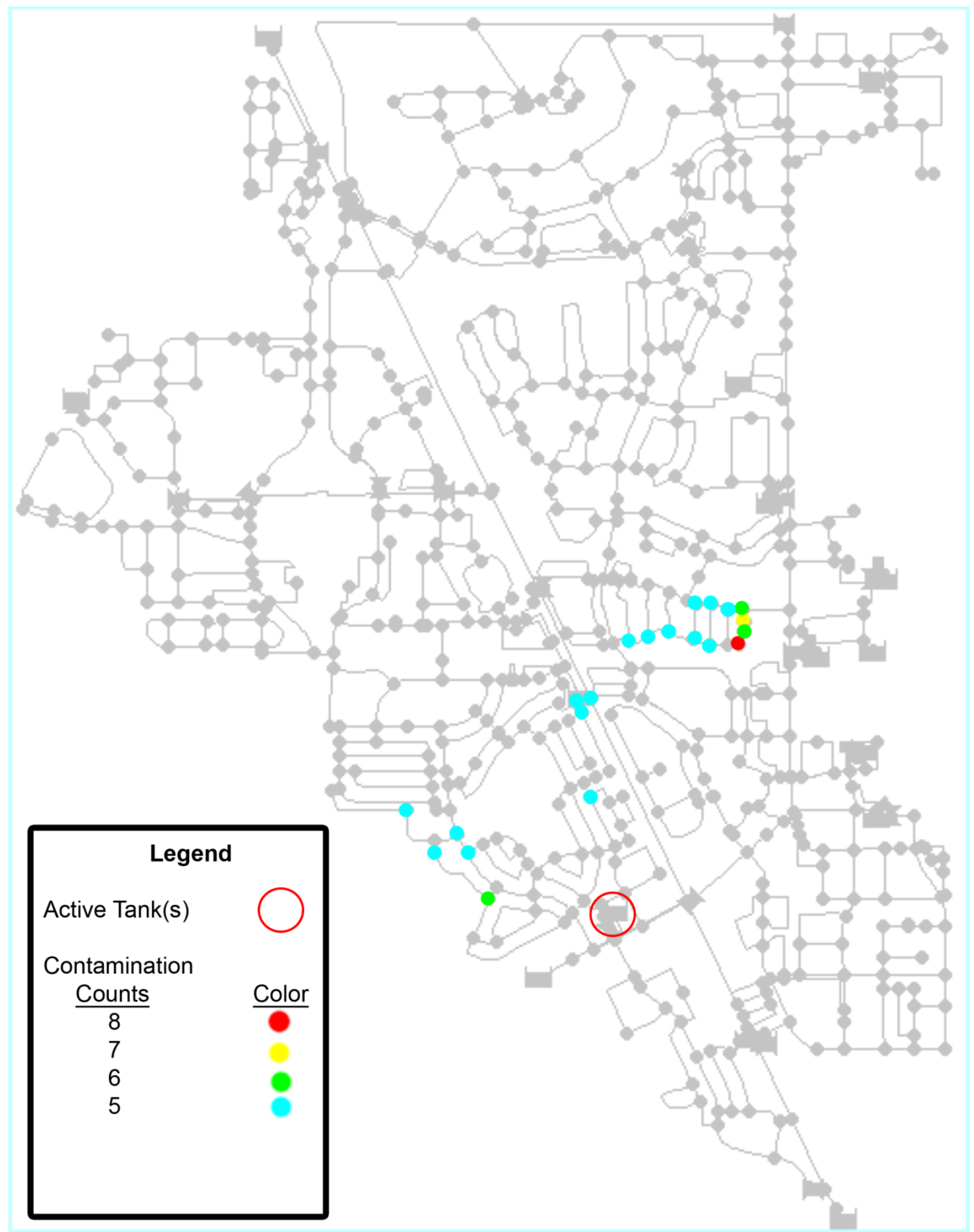

Figure 26: Optimal Sensor Points for Tank 1 (Half Concentration) 


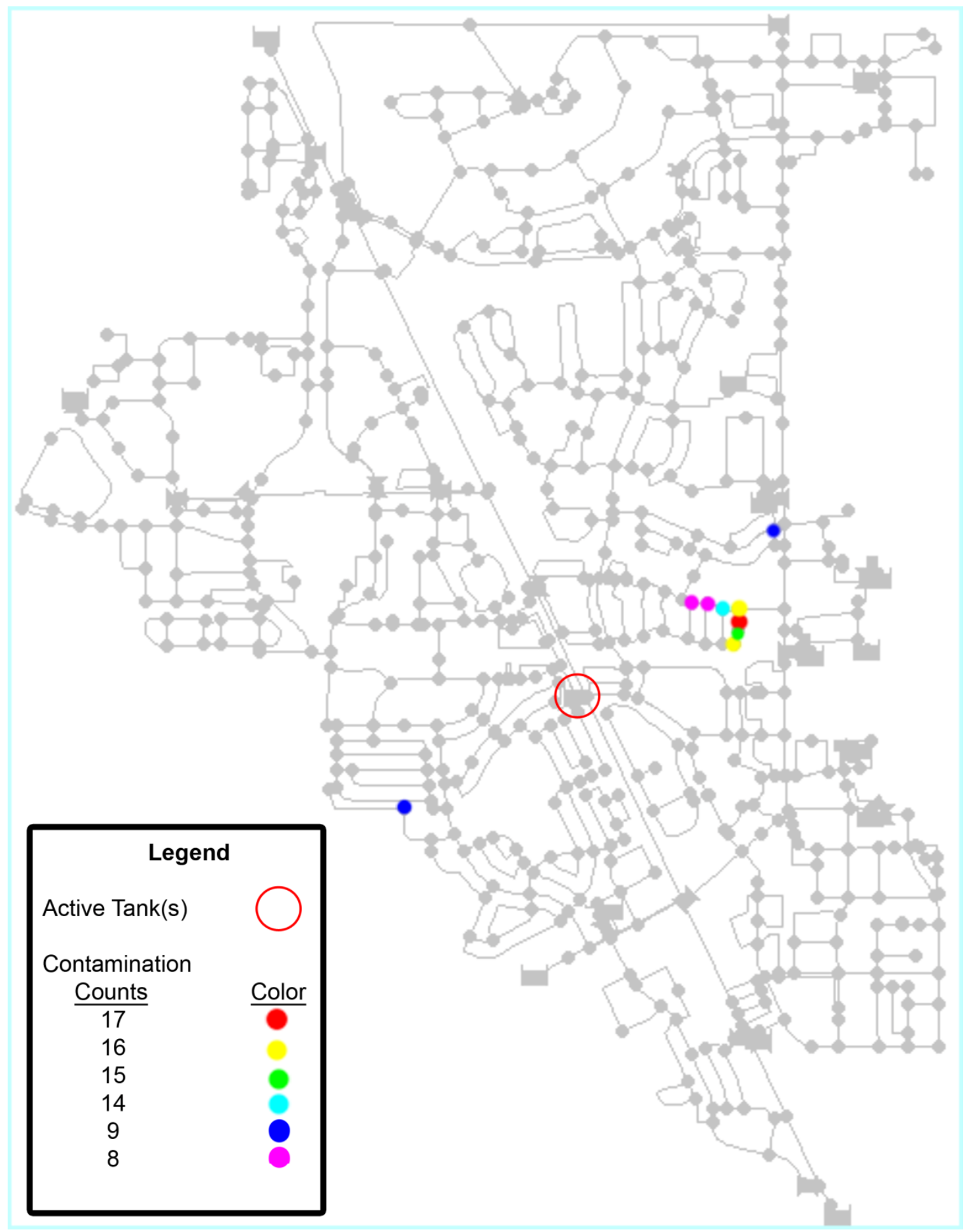

Figure 27: Optimal Sensor Points for Tank 2 (Full Concentration) 


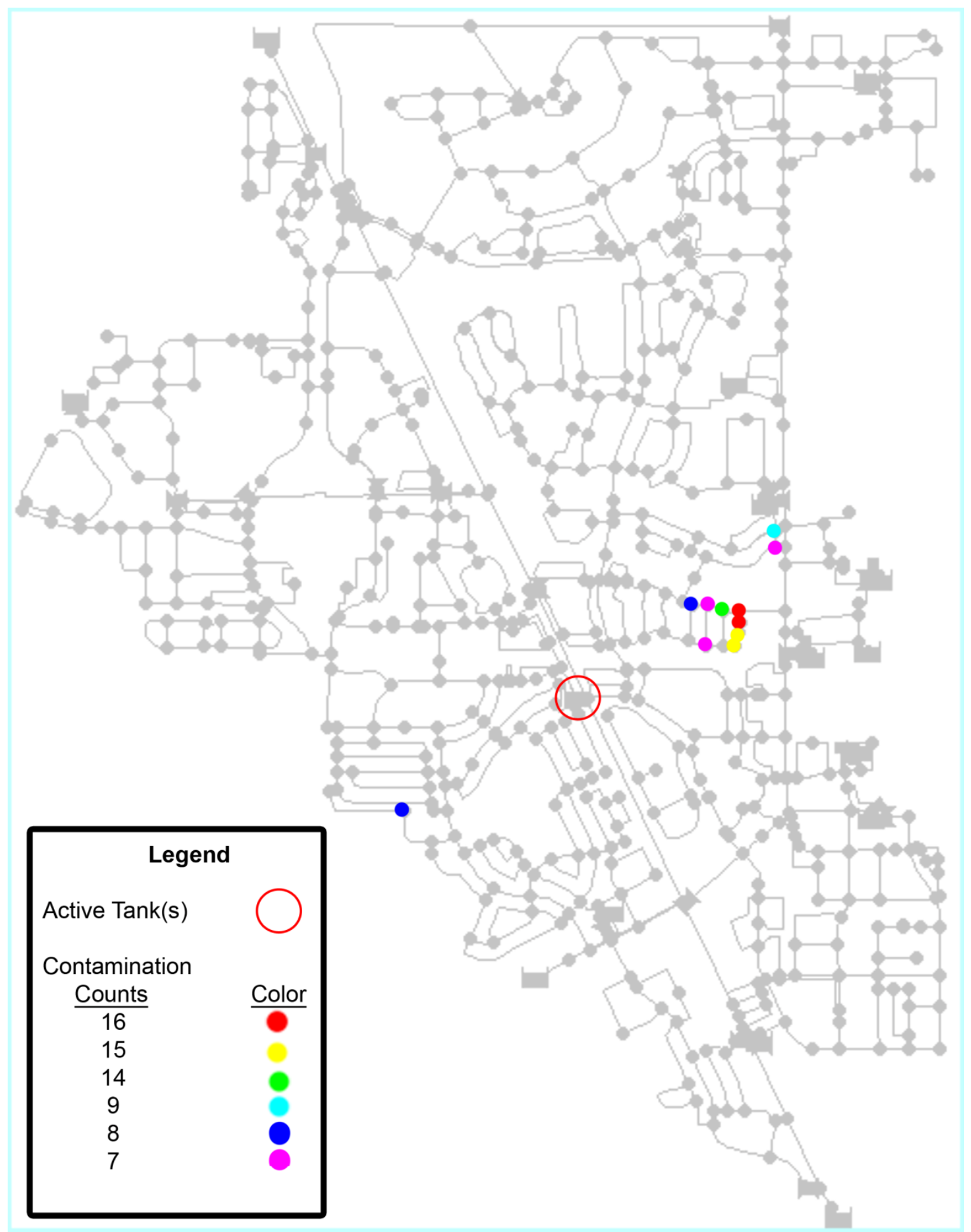

Figure 28: Optimal Sensor Points for Tank 2 (Half Concentration) 


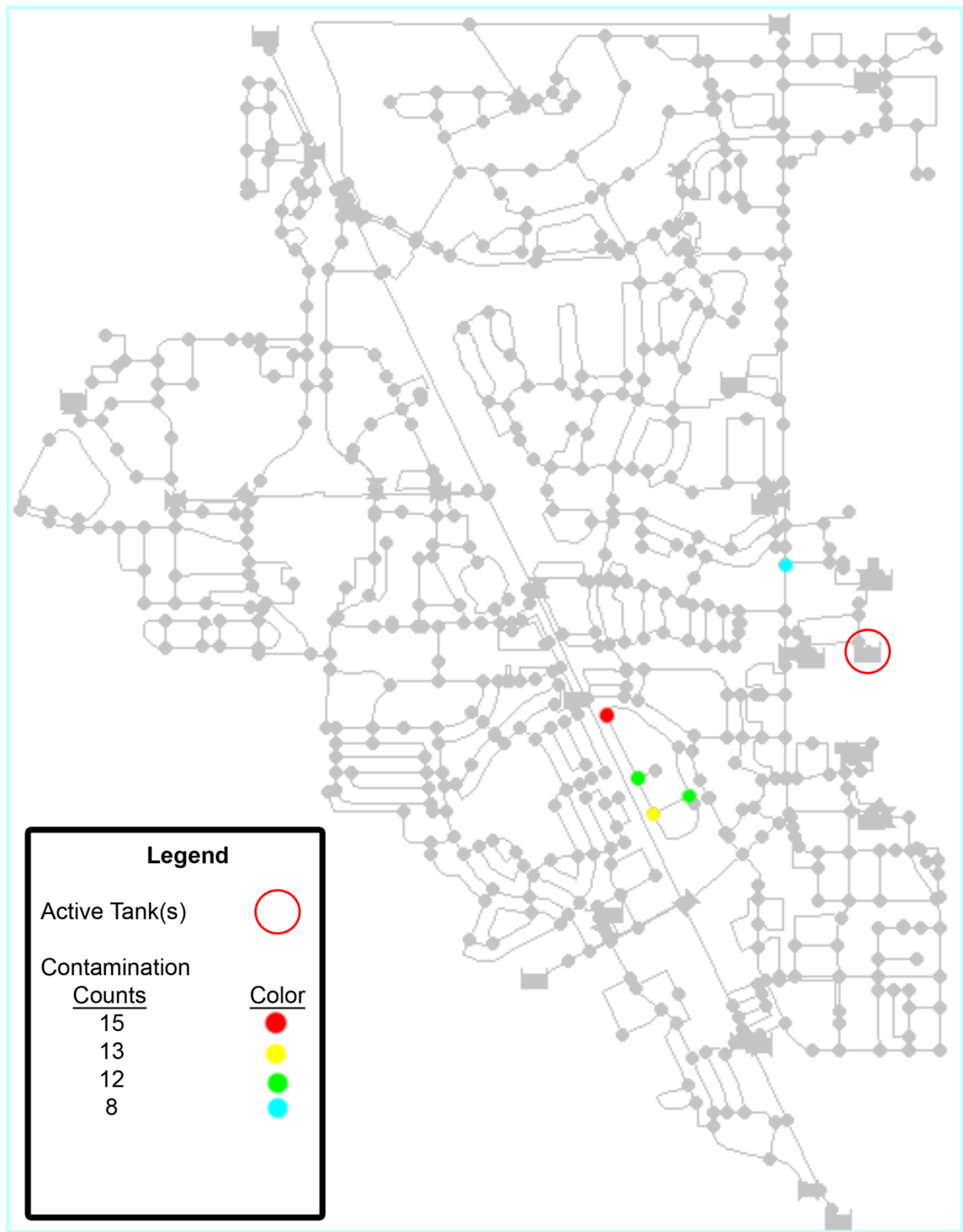

Figure 29: Optimal Sensor Points for Tank 3 (Full Concentration) 


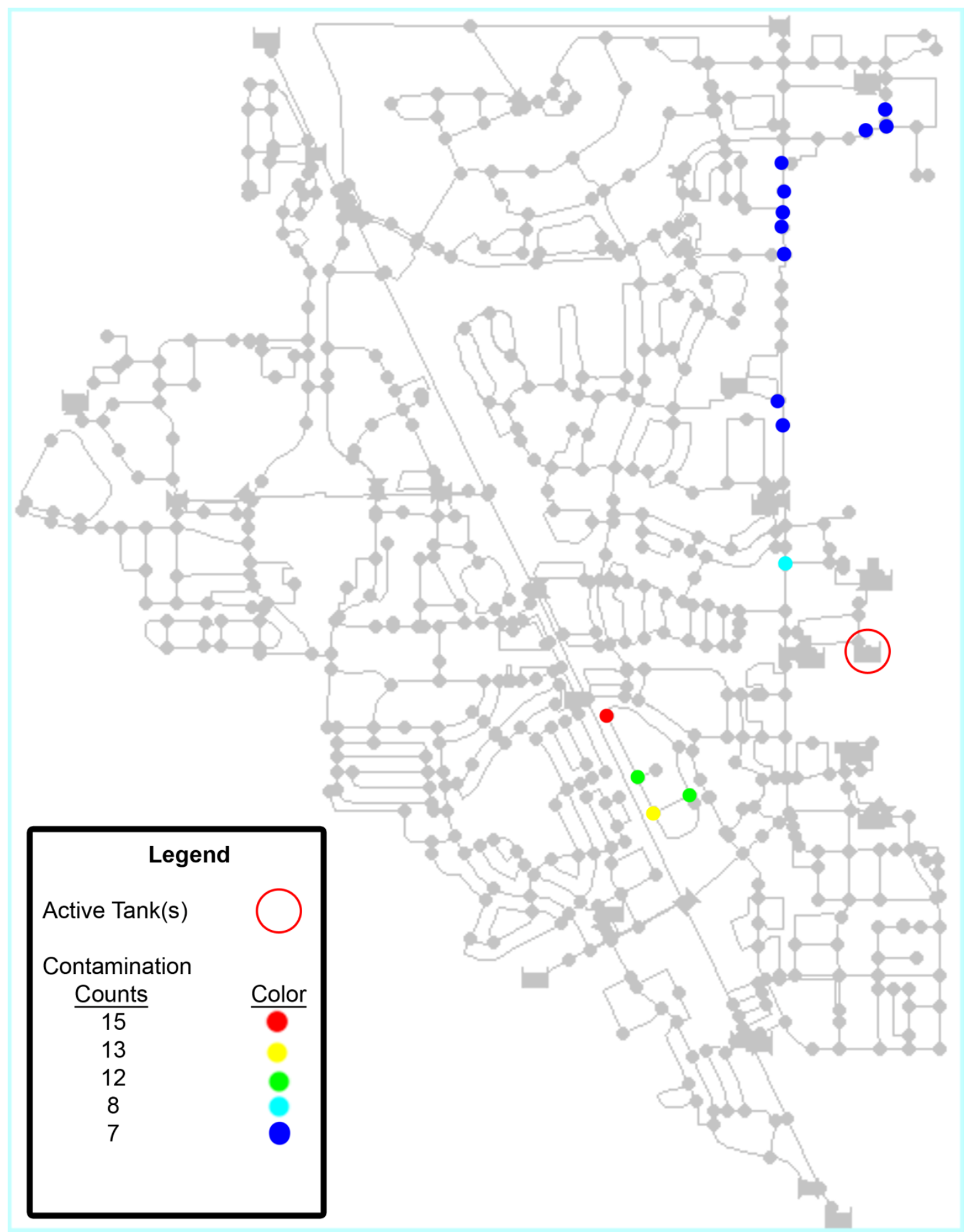

Figure 30: Optimal Sensor Points for Tank 3 (Half Concentration) 


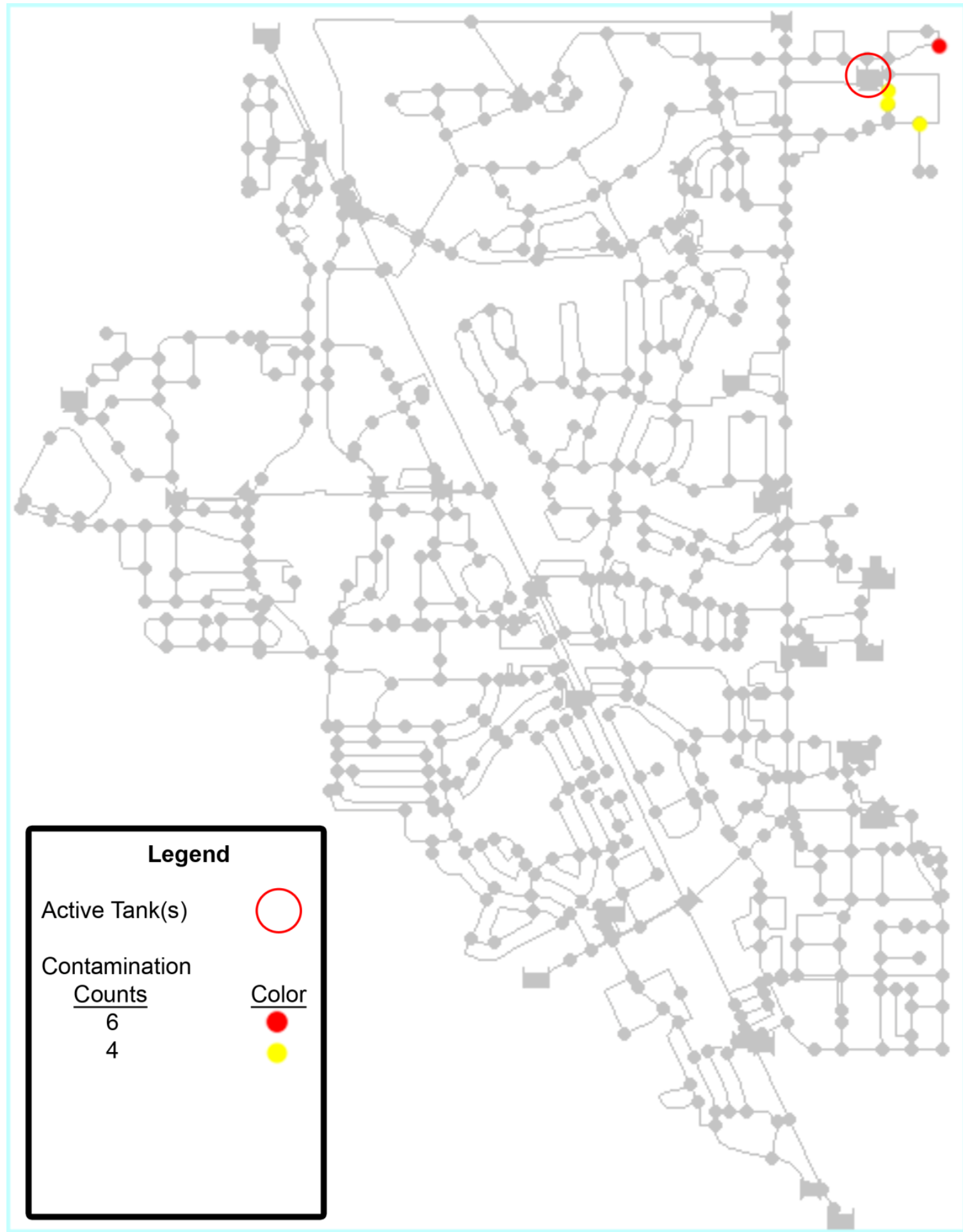

Figure 31: Optimal Sensor Points for Tank 4 (Full Concentration) 


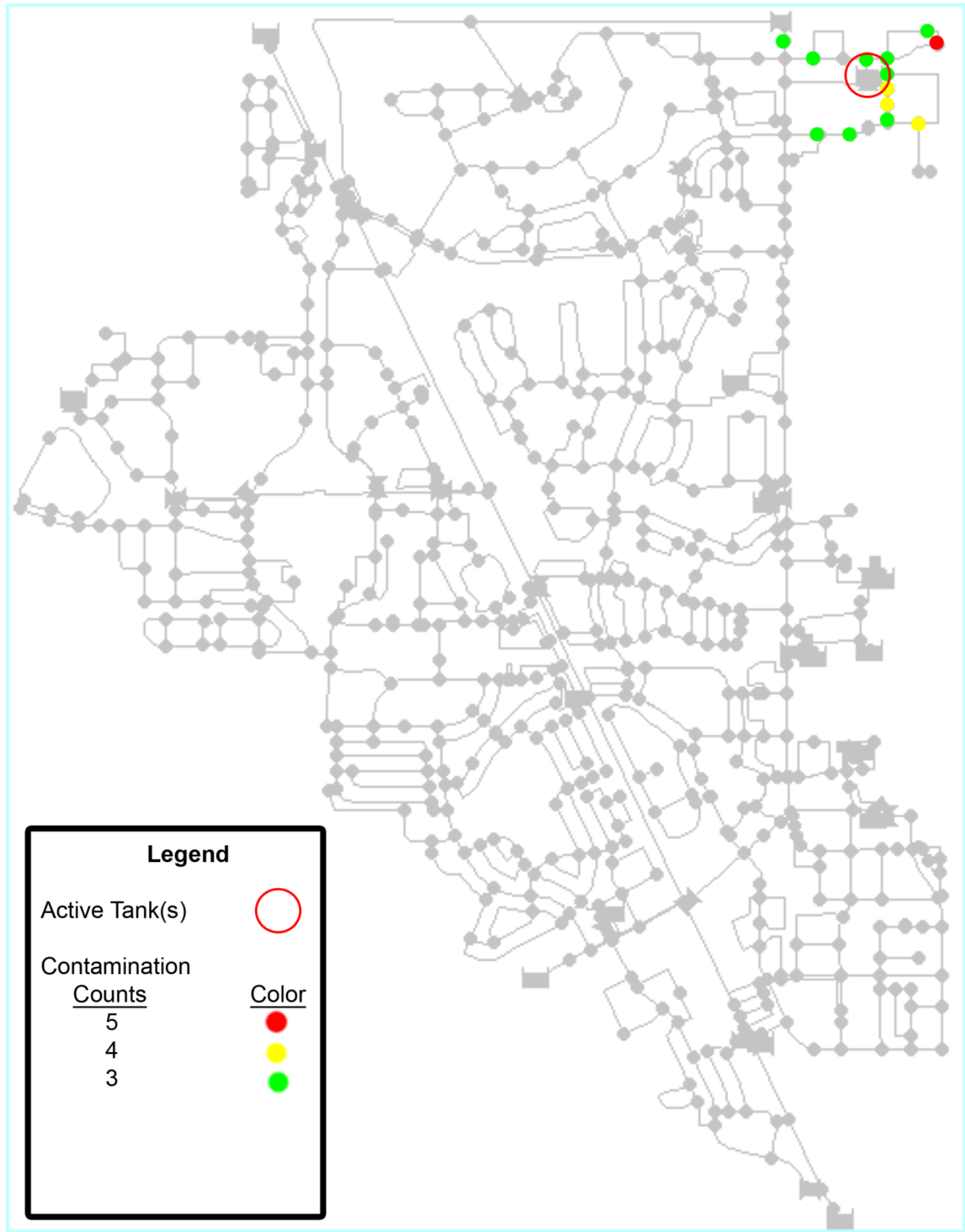

Figure 32: Optimal Sensor Points for Tank 4 (Half Concentration) 


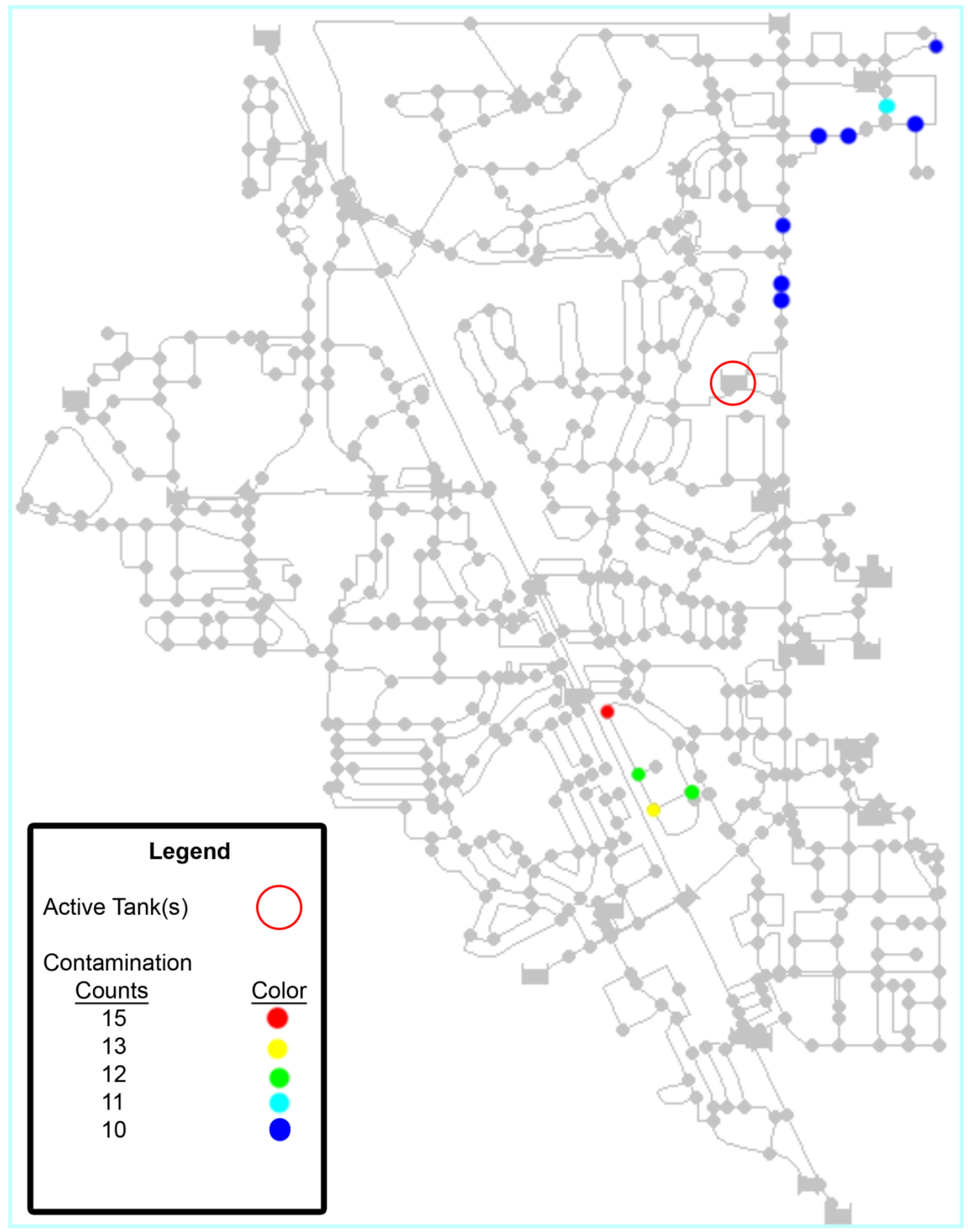

Figure 33: Optimal Sensor Points for Tank 5 (Full Concentration) 


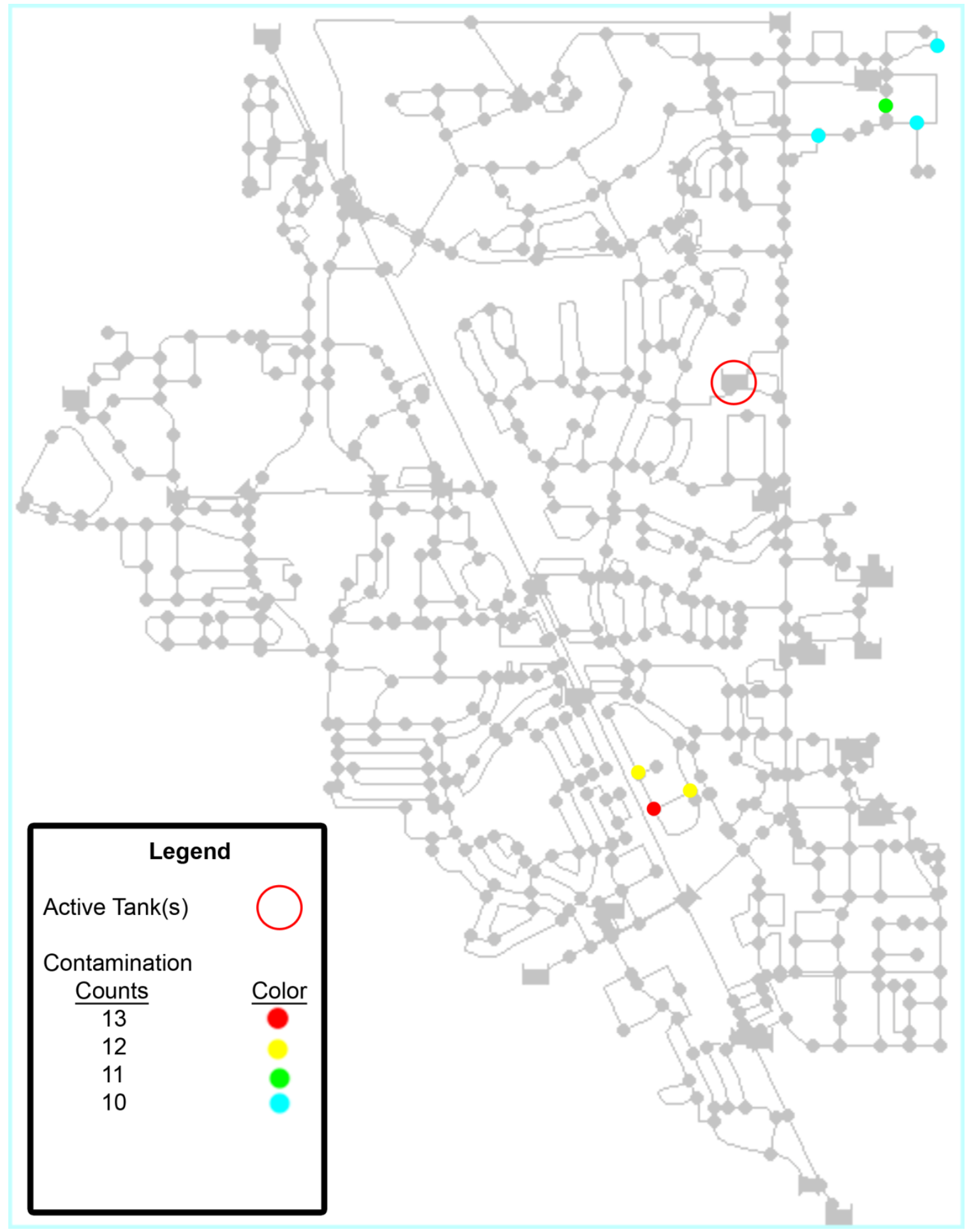

Figure 34: Optimal Sensor Points for Tank 5 (Half Concentration) 


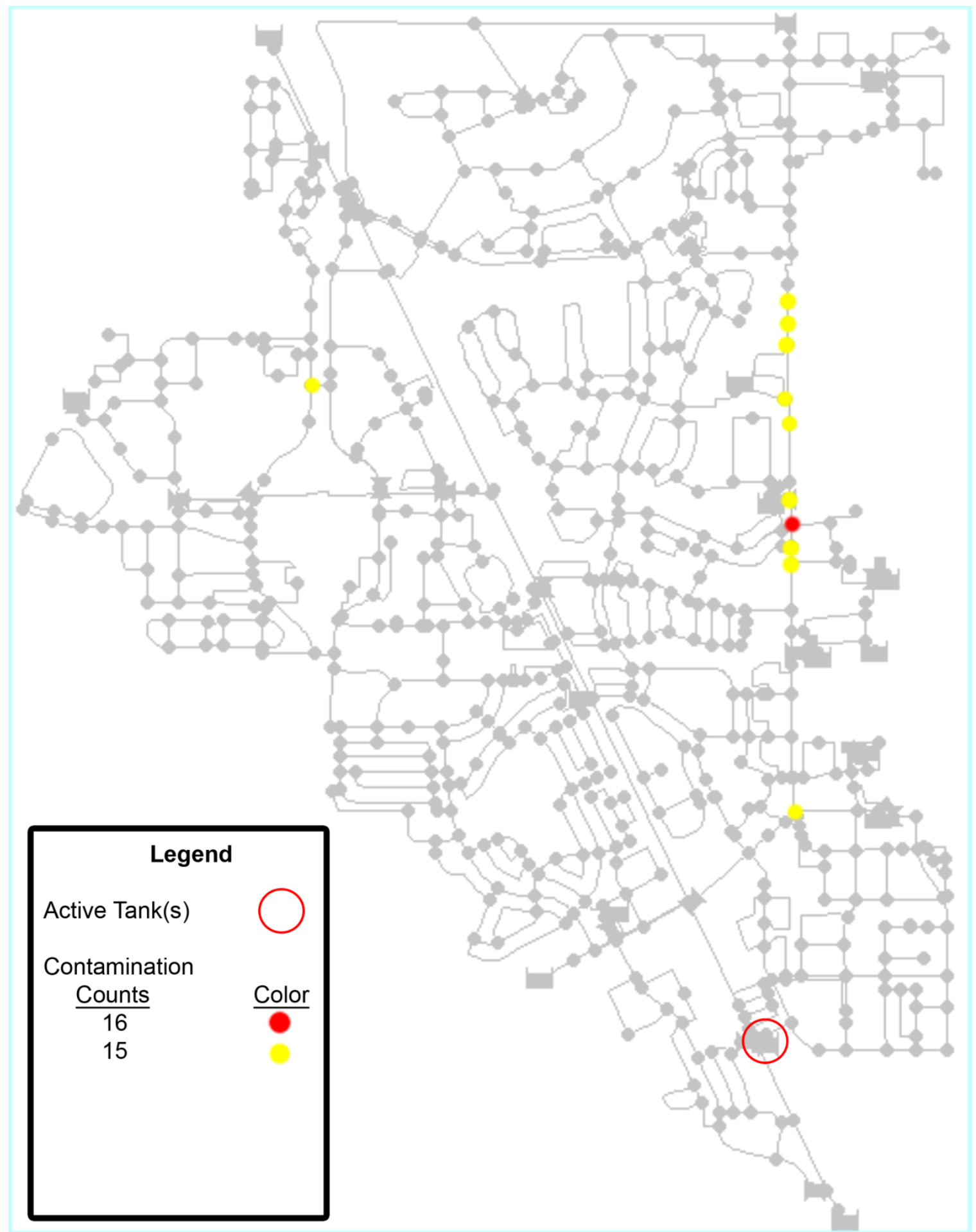

Figure 35: Optimal Sensor Points for Tank 6 (Full Concentration) 


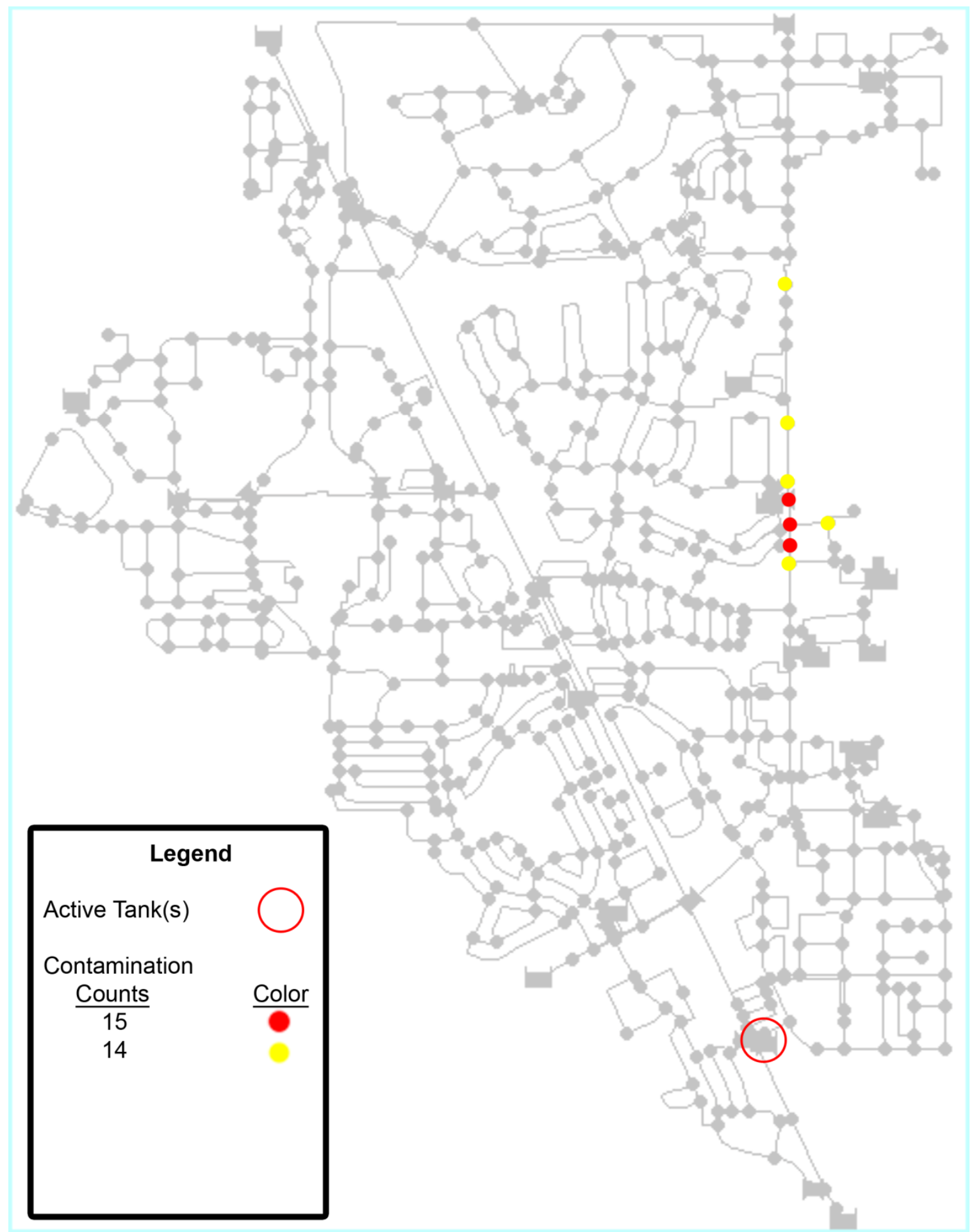

Figure 36: Optimal Sensor Points for Tank 6 (Half Concentration) 


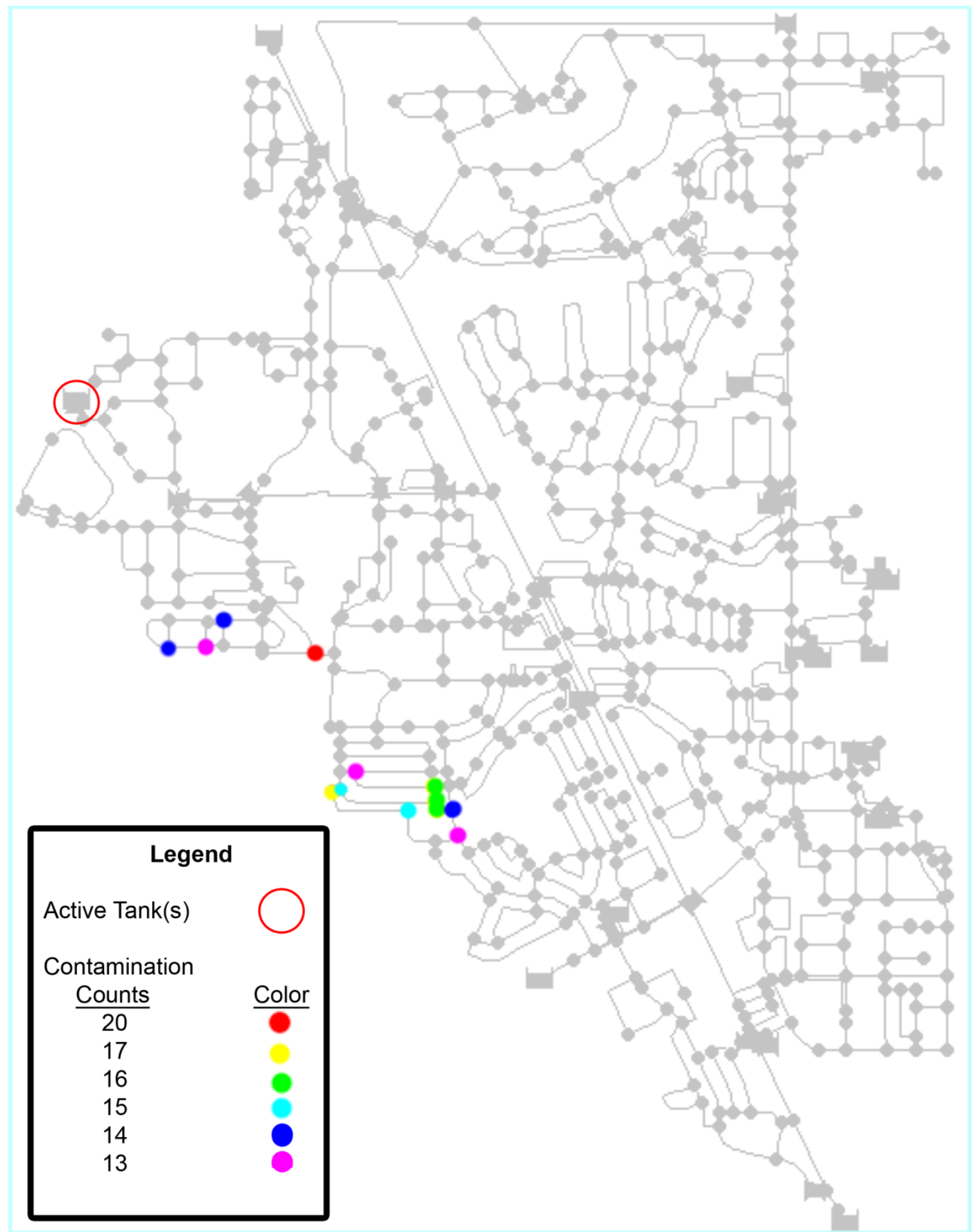

Figure 37: Optimal Sensor Points for Tank 7 (Full Concentration) 


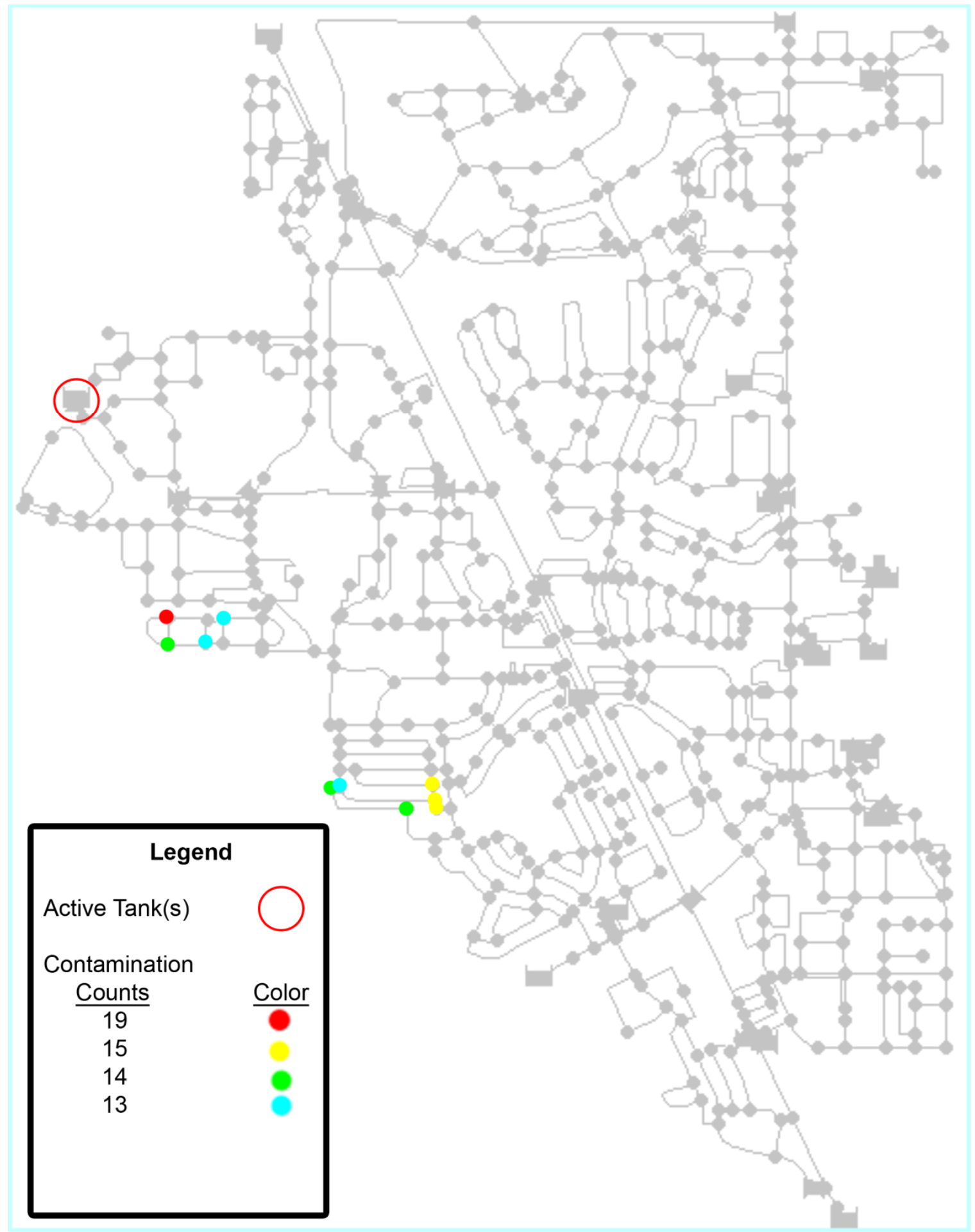

Figure 38: Optimal Sensor Points for Tank 7 (Half Concentration) 
APPENDIX B: ZONES OF SIGNIFICANCE

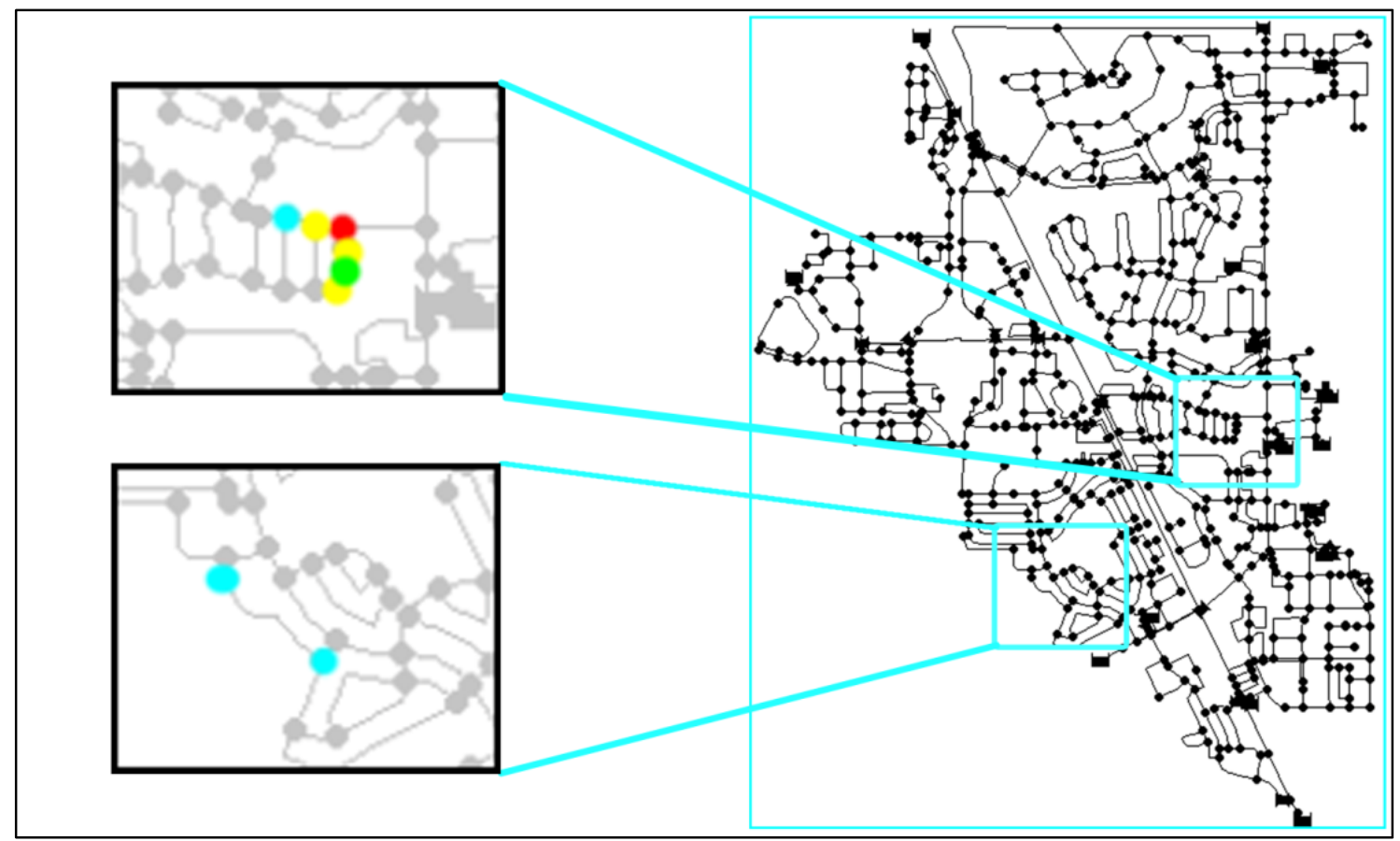

Figure 39: Zones of Significance for Tank 1 (Full Concentration)

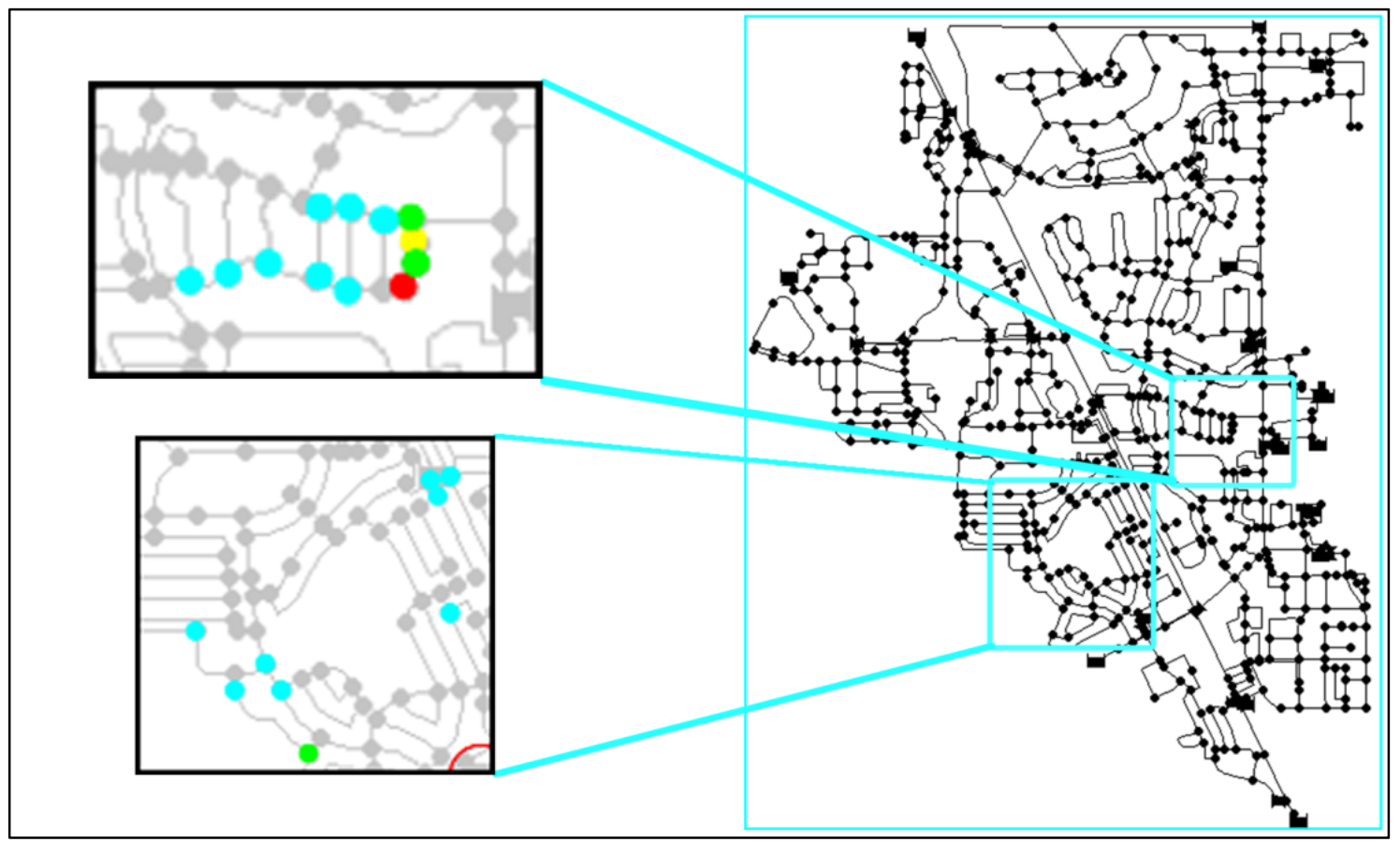

Figure 40: Zones of Significance for Tank 1 (Half Concentration) 


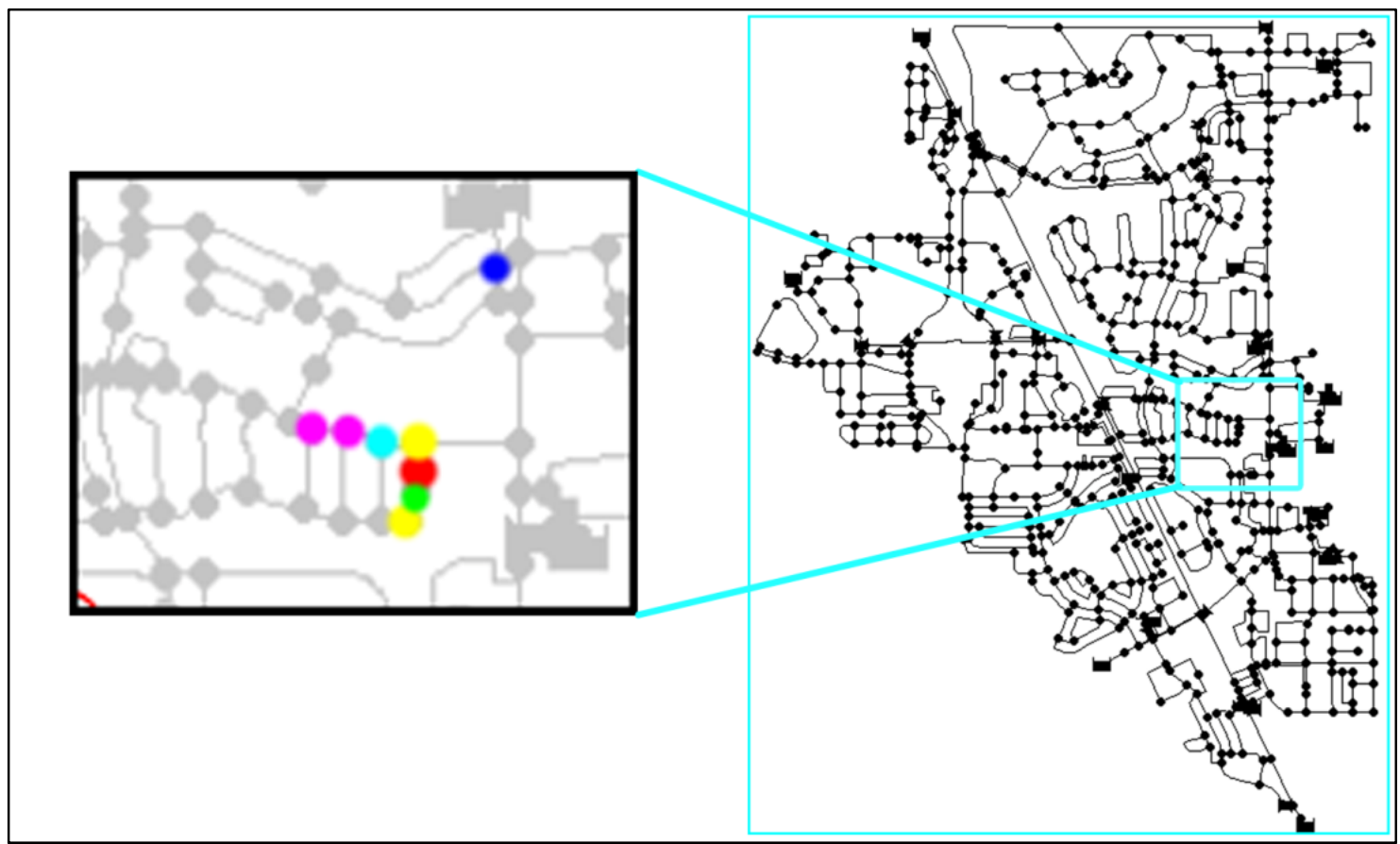

Figure 41: Zones of Significance for Tank 2 (Full Concentration)

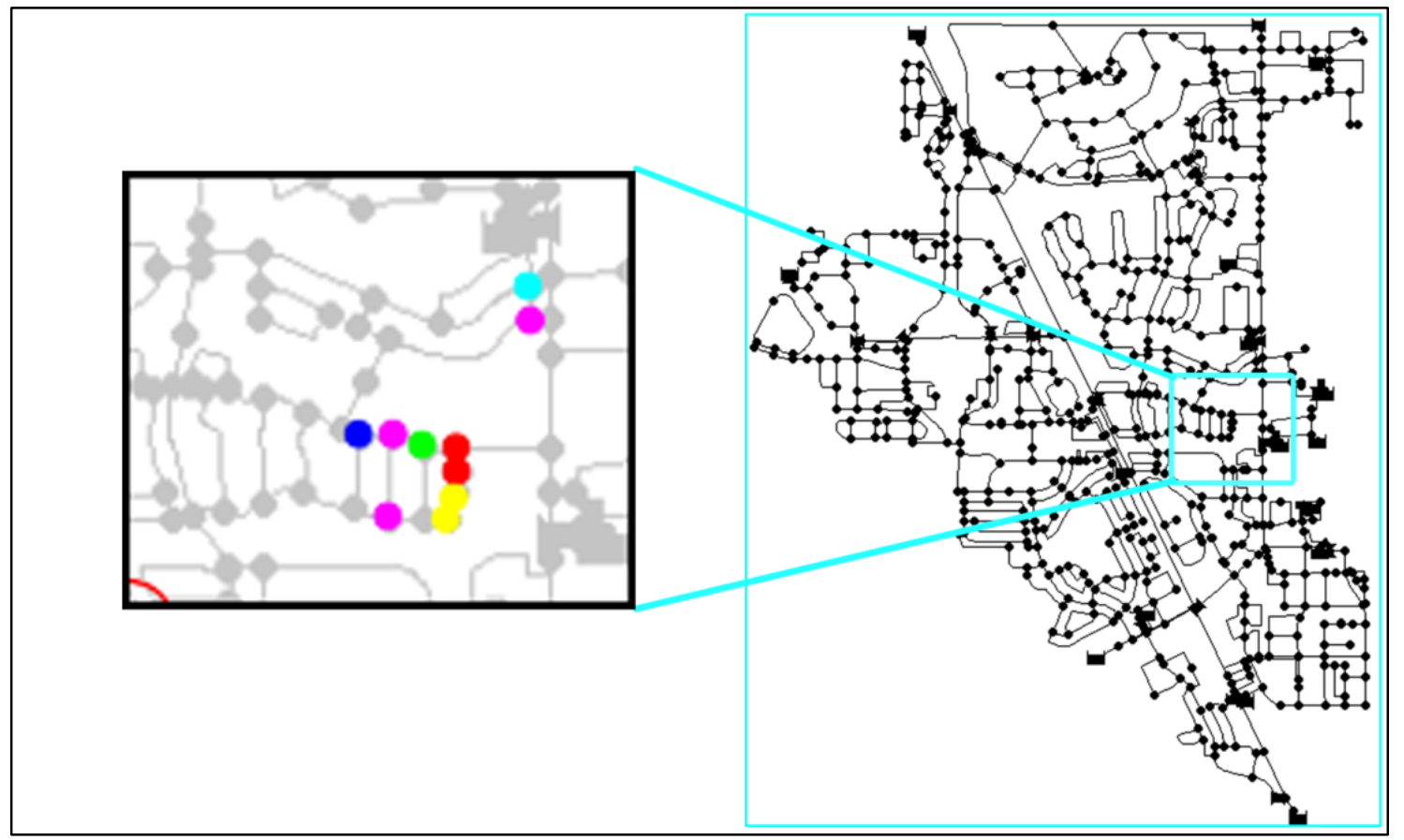

Figure 42: Zones of Significance for Tank 2 (Half Concentration) 


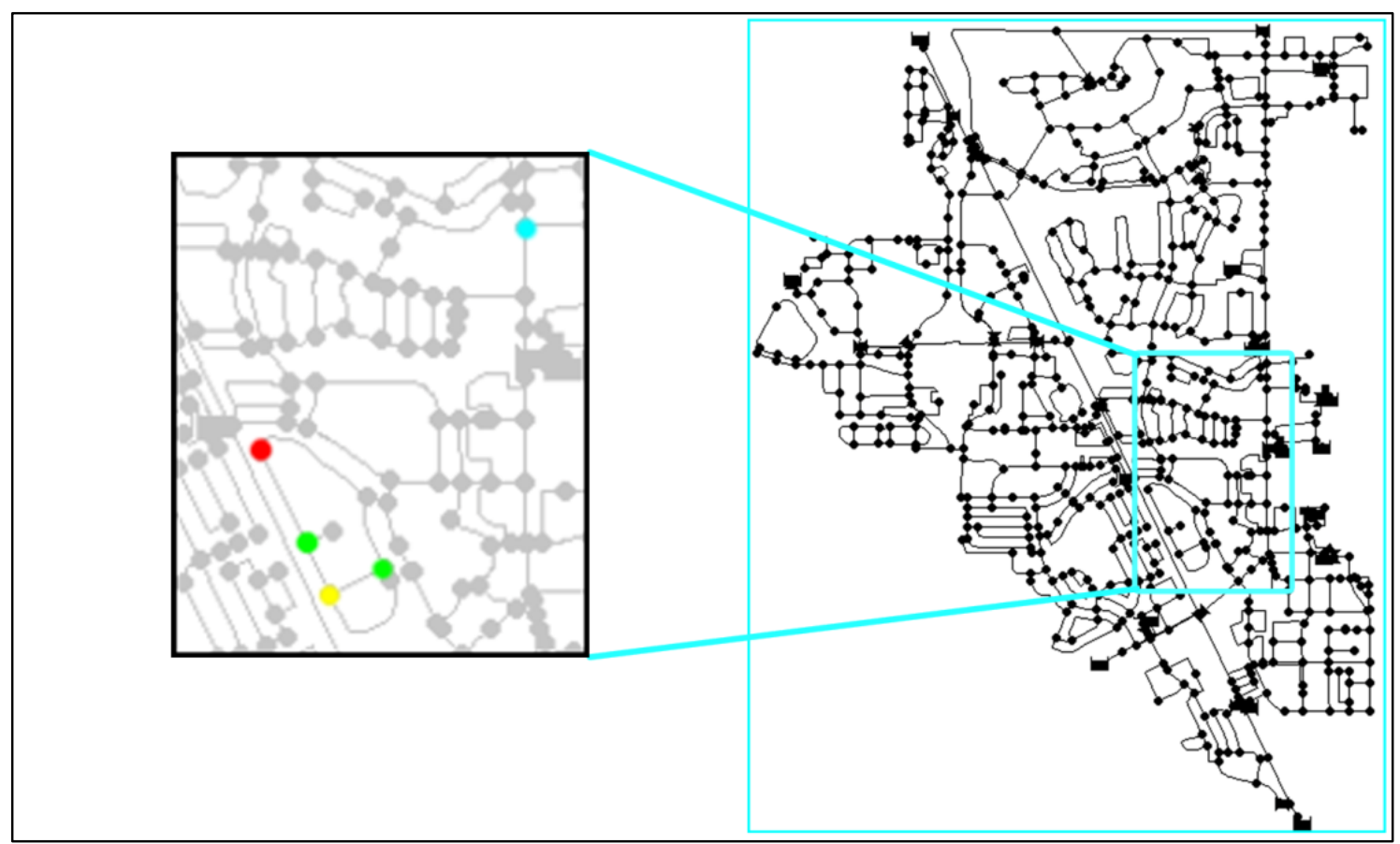

Figure 43: Zones of Significance for Tank 3 (Full Concentration)

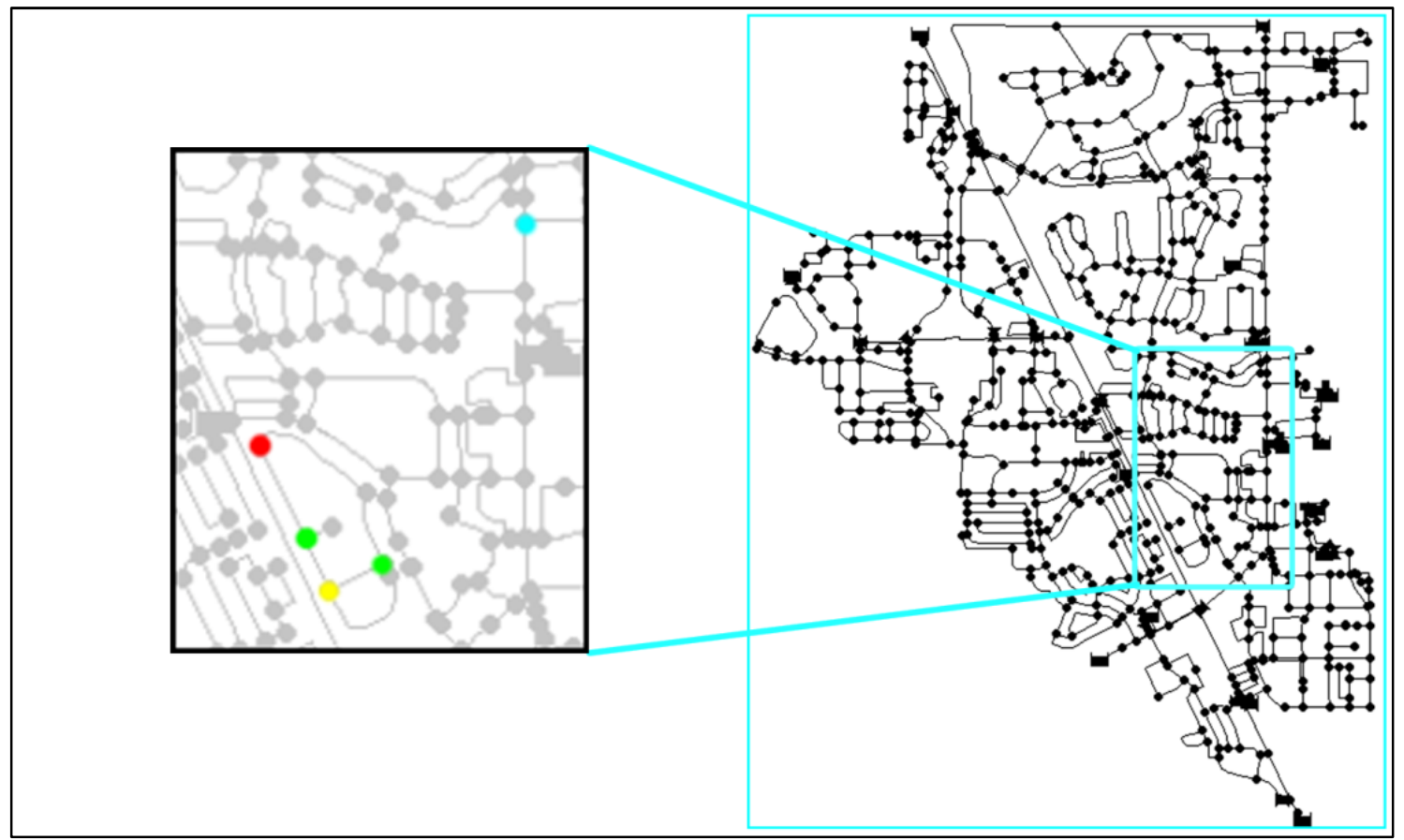

Figure 44: Zones of Significance for Tank 3 (Half Concentration) 


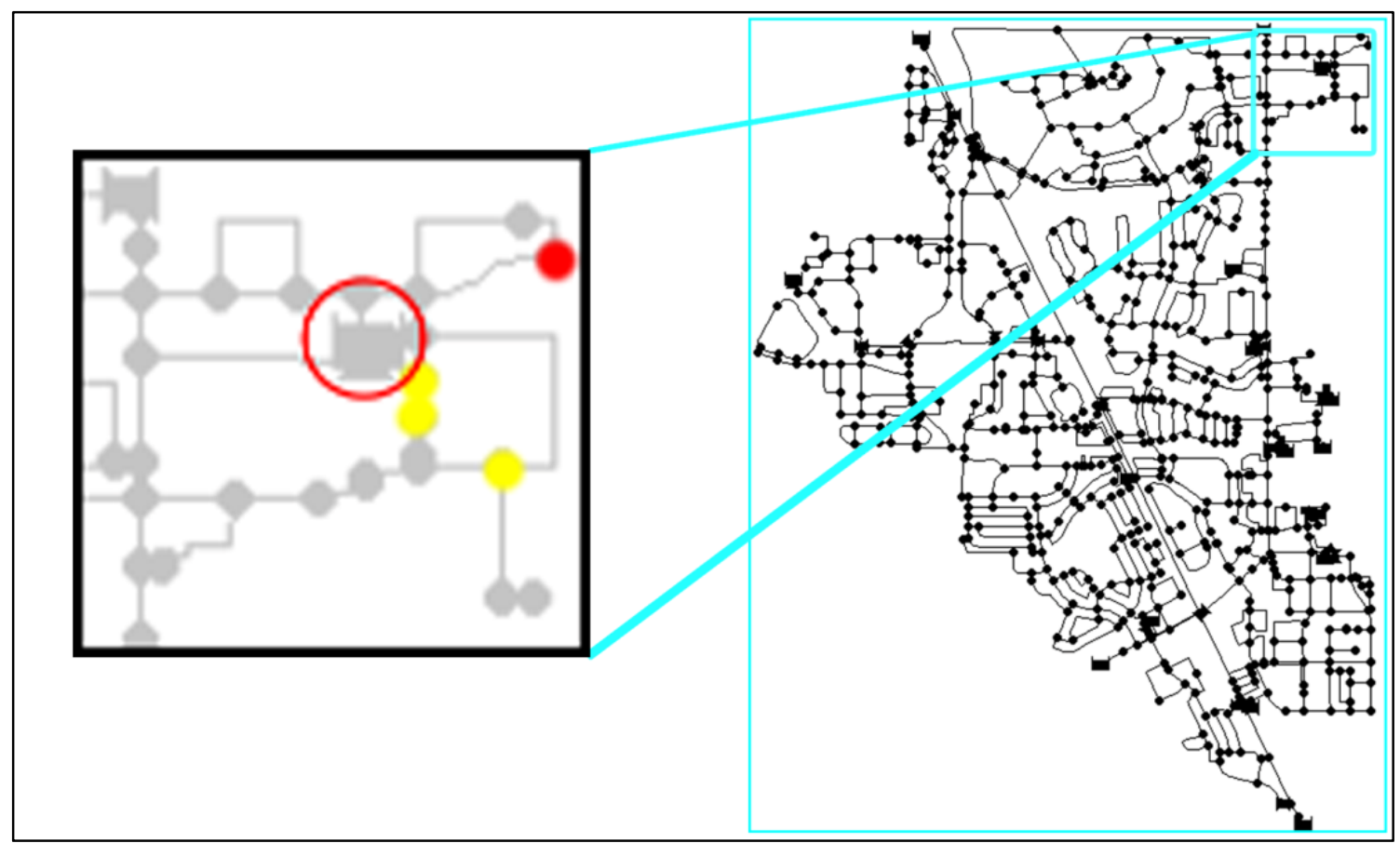

Figure 45: Zones of Significance for Tank 4 (Full Concentration)

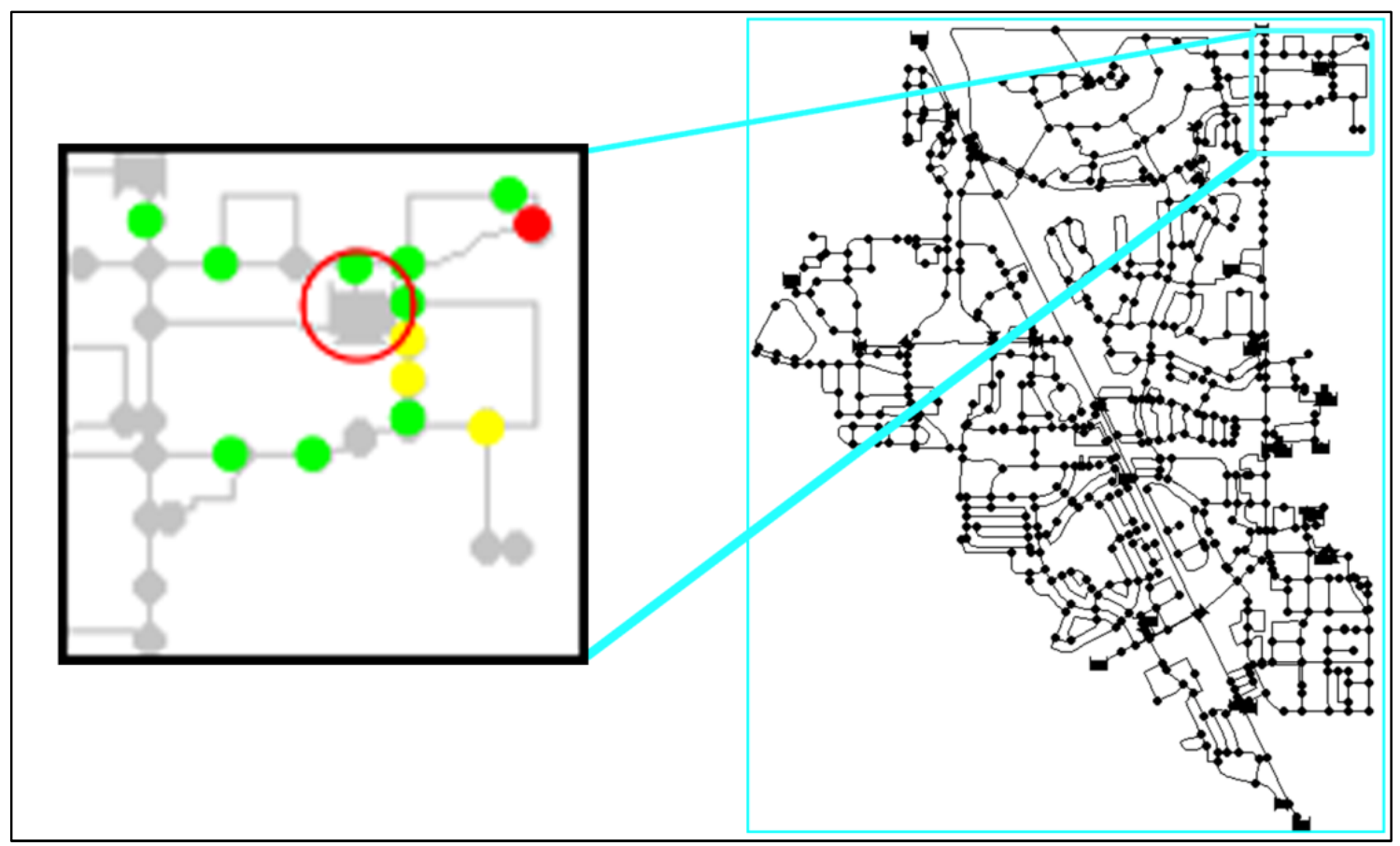

Figure 46: Zones of Significance for Tank 4 (Half Concentration) 


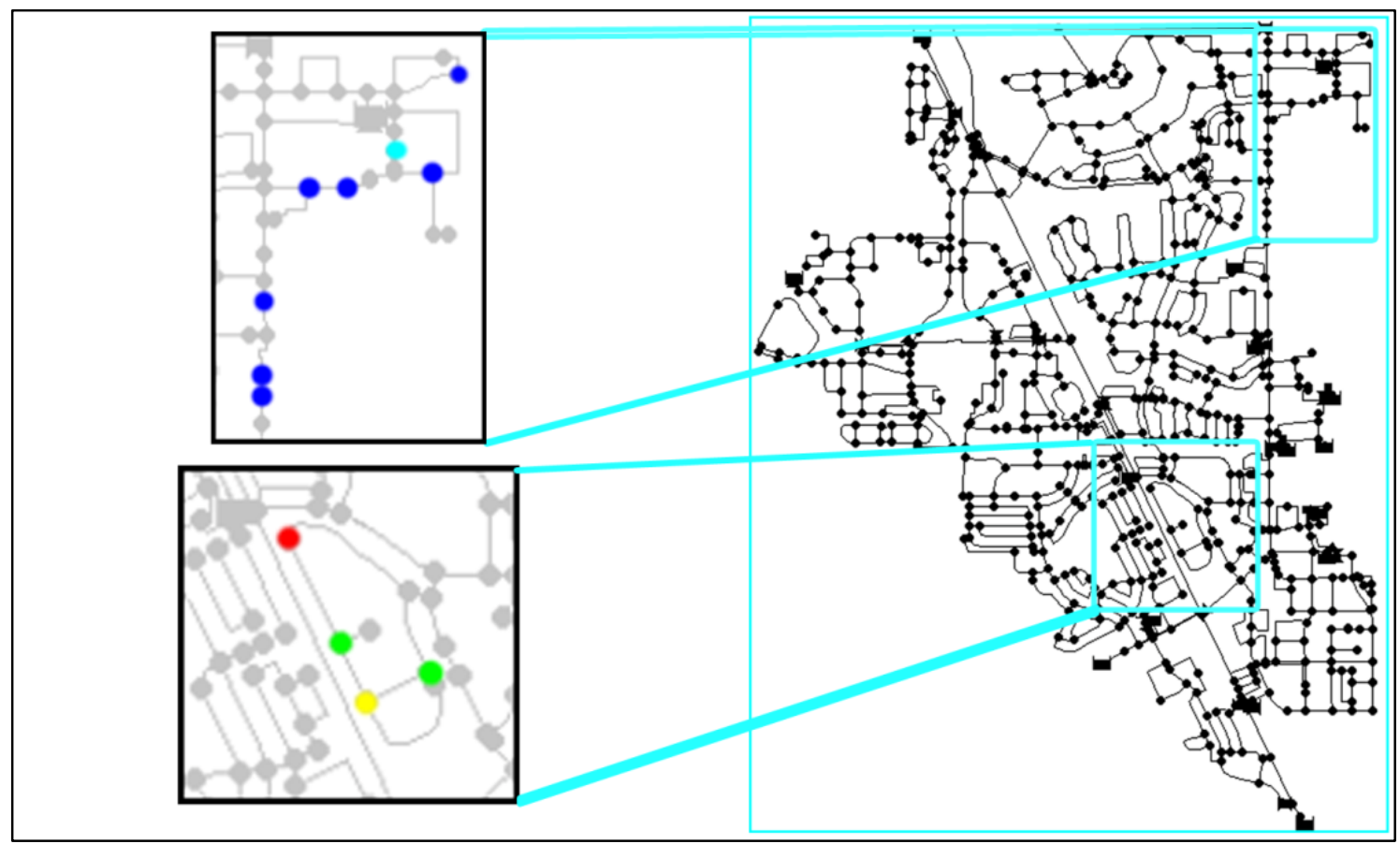

Figure 47: Zones of Significance for Tank 5 (Full Concentration)

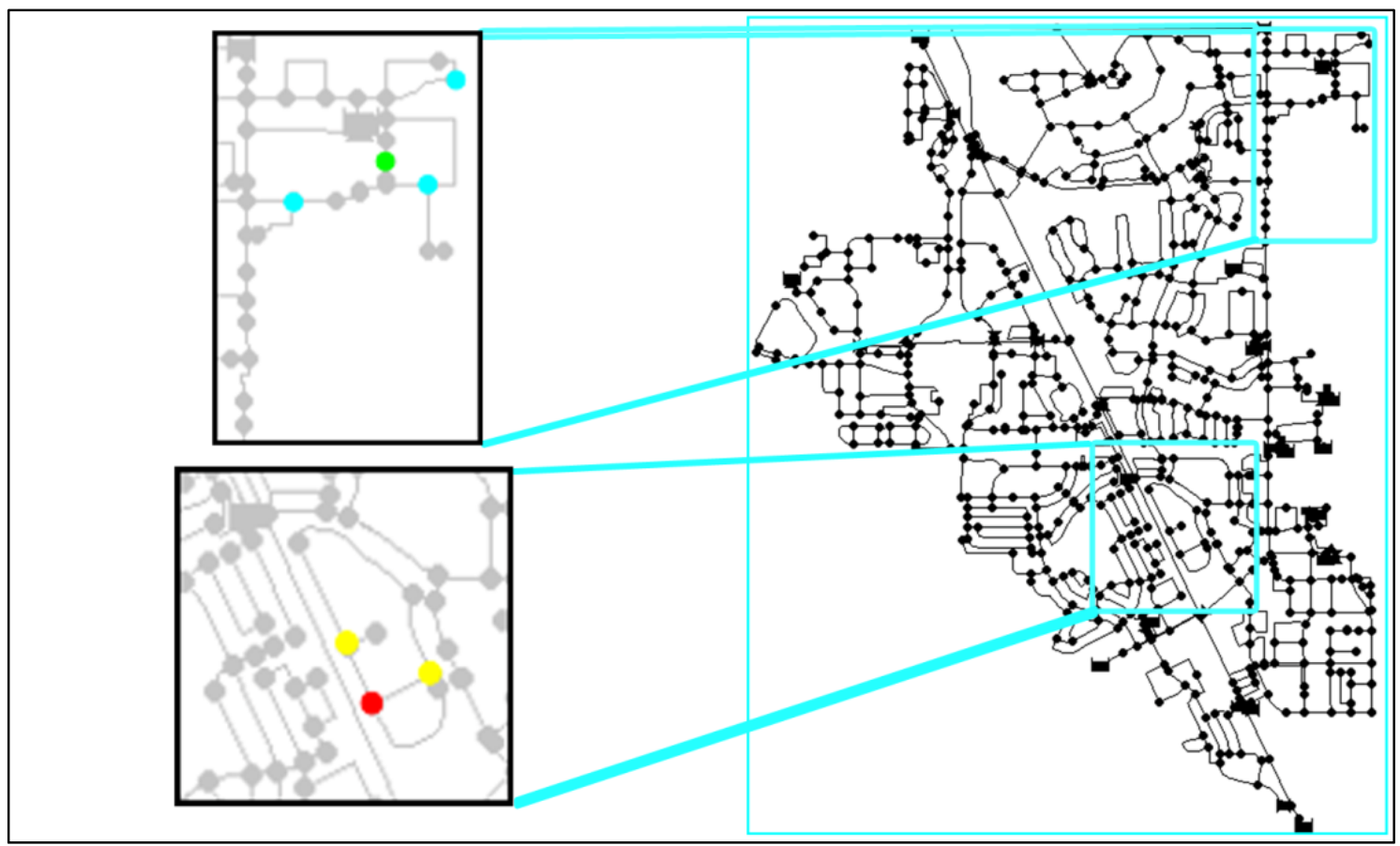

Figure 48: Zones of Significance for Tank 5 (Half Concentration) 


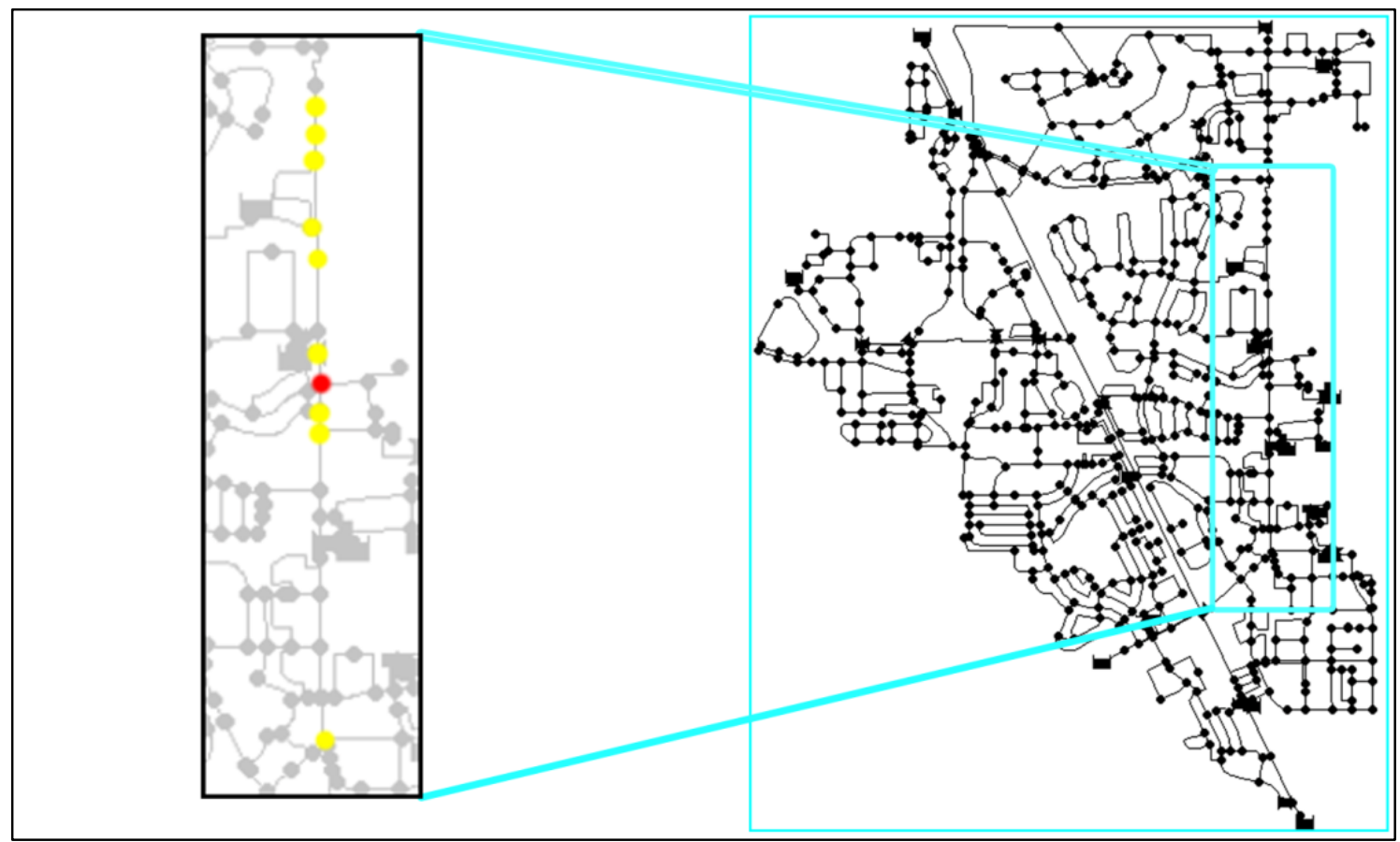

Figure 49: Zones of Significance for Tank 6 (Full Concentration)

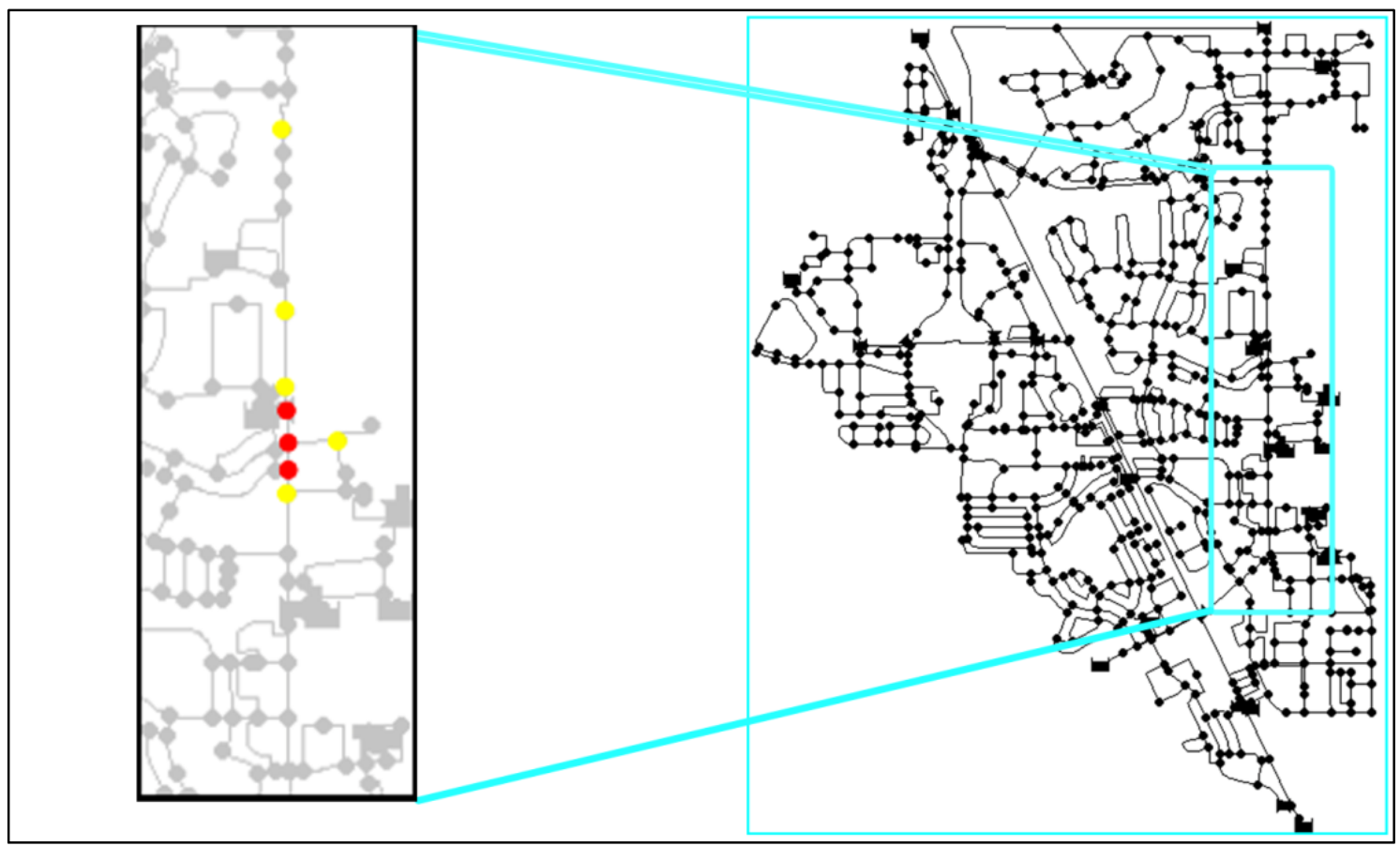

Figure 50: Zones of Significance for Tank 6 (Half Concentration) 


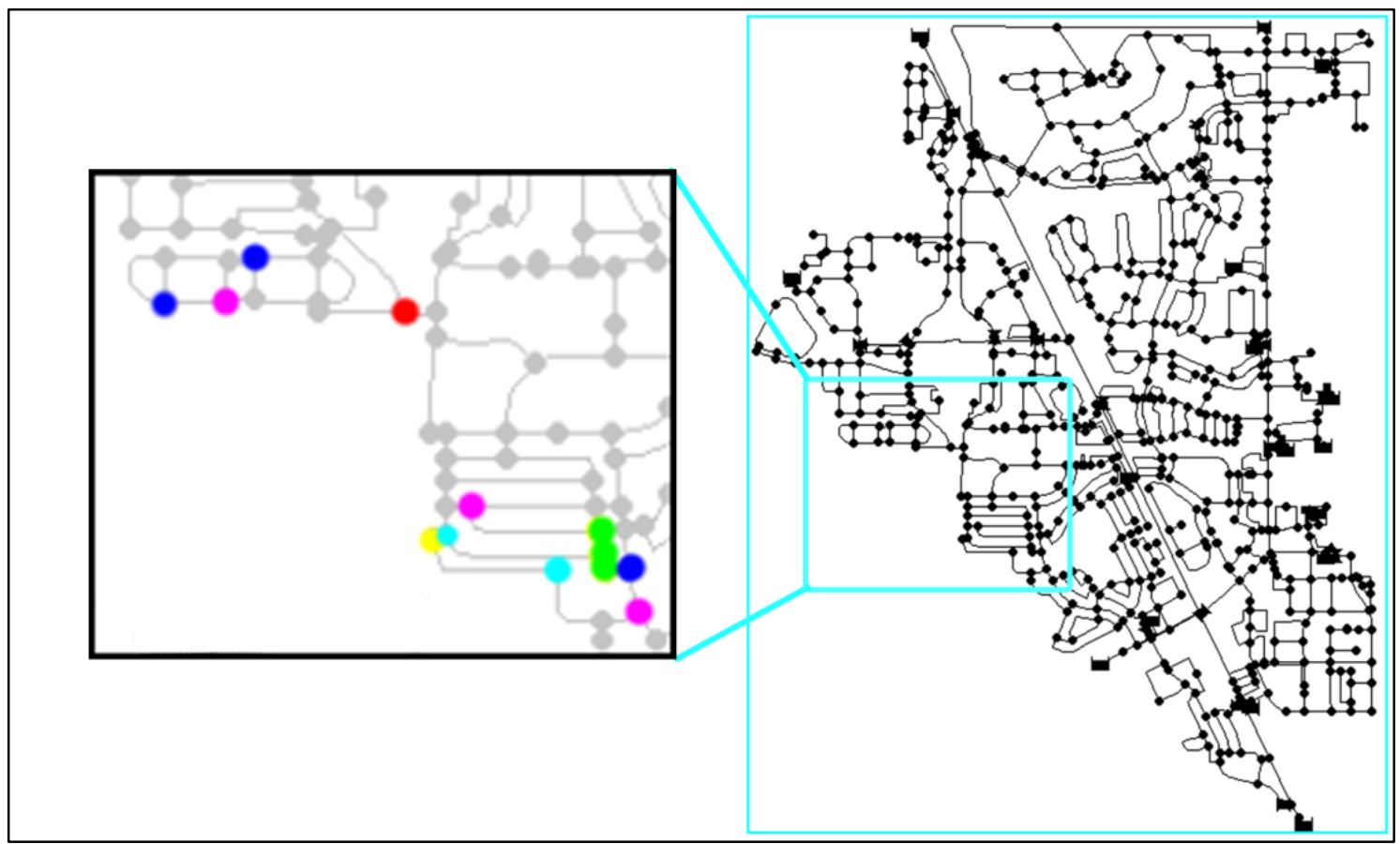

Figure 51: Zones of Significance for Tank 7 (Full Concentration)

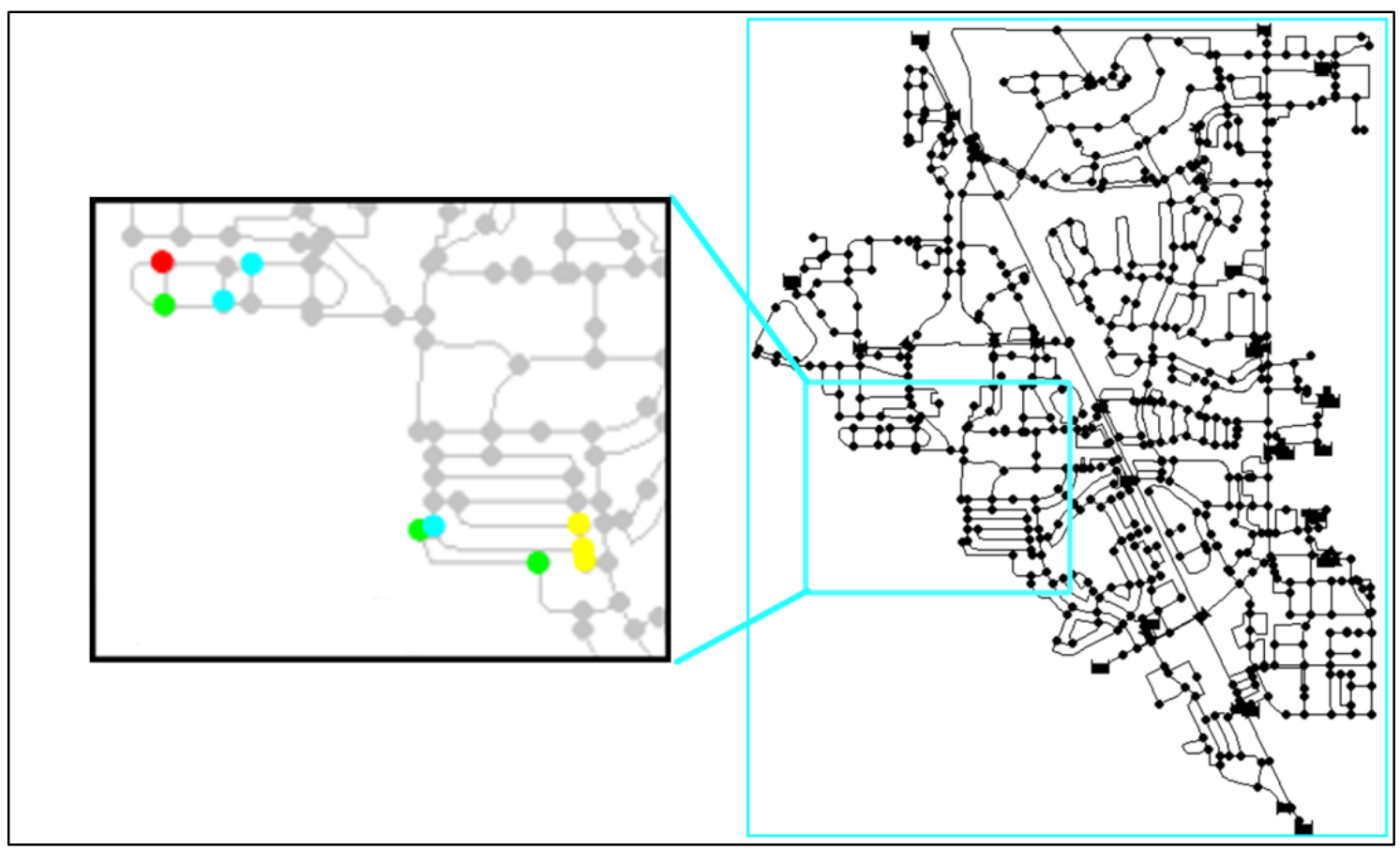

Figure 52: Zones of Significance for Tank 7 (Half Concentration) 